\title{
Expression of Human Tissue Kallikreins (KLKs) in Polymorphous Low Grade Adenocarcinoma (PLGA)
}

Jacqueline M. Cox, The University of Western Ontario

Supervisor: Drs. Mark Darling, The University of Western Ontario

Joint Supervisor: Zia Khan, The University of Western Ontario

Joint Supervisor: Jerrold Armstrong, The University of Western Ontario

A thesis submitted in partial fulfillment of the requirements for the Master of Science degree in Pathology

(C) Jacqueline M. Cox 2017

Follow this and additional works at: https://ir.lib.uwo.ca/etd

Part of the Oral and Maxillofacial Surgery Commons, and the Oral Biology and Oral Pathology Commons

\section{Recommended Citation}

Cox, Jacqueline M., "Expression of Human Tissue Kallikreins (KLKs) in Polymorphous Low Grade Adenocarcinoma (PLGA)" (2017). Electronic Thesis and Dissertation Repository. 4614.

https://ir.lib.uwo.ca/etd/4614

This Dissertation/Thesis is brought to you for free and open access by Scholarship@Western. It has been accepted for inclusion in Electronic Thesis and Dissertation Repository by an authorized administrator of Scholarship@Western. For more information, please contact wlswadmin@uwo.ca. 


\begin{abstract}
Polymorphous low grade adenocarcinoma (PLGA) is the second most common malignant salivary gland tumour of the minor salivary glands. Human tissue kallikreins (KLKs) are a family of highly conserved serine proteases expressed by various tissues throughout the body. KLKs have become powerful tumour markers for the diagnosis of the cancer patient (e.g. PSA (KLK3)). The literature demonstrates a link between KLKs and salivary gland neoplasms. The purpose of this study is to determine levels of KLK mRNA in tissue samples of formalin fixed paraffin embedded polymorphous low grade adenocarcinoma (PLGA). Secondly, we wish to determine if KLK expression is limited to tumour cells alone.

Nineteen cases of PLGA were reviewed (1987-2013). A diagnosis of PLGA was confirmed, demographic data was collected, and formalin fixed paraffin-embedded PLGA and normal salivary gland tissue samples were obtained. RNA isolation was achieved, followed by conversion to complementary DNA via reverse transcription. Synthesized DNA primers were added to target kallikrein DNA and through PCR, the quantitative level of expression of KLKs 1-15 was recorded. Samples exhibiting high and low KLK expression were selected for immunohistochemistry staining, using a standard protocol.

Results from PCR data reveals statistically significant increase in the mean KLK mRNA expression for KLK1, KLK4, KLK10, KLK12 and KLK15 in PLGA tissue samples, as compared with normal salivary gland tissue (Mann Whitney $U$ test, $\mathrm{p}<0.05$ ). Immunohistochemistry results demonstrate tumour specific staining. Notably, all samples demonstrating relatively higher KLK mRNA expression showed equivalent or increased staining grade scores relative to the low KLK mRNA expression samples, with respect to a specific KLK.

In tissue samples of polymorphous low grade adenocarcinoma there is an increase of KLK1, KLK4, KLK10, KLK12 and KLK15 mRNA relative to normal salivary gland tissue. Furthermore, the tumour cells stain positively and specifically for kallikreins.
\end{abstract}

Keywords: Salivary gland neoplasm, polymorphous low-grade adenocarcinoma, human tissue kallikreins, RT-PCR, immunohistochemistry, biomarkers 


\section{Dedication}

This thesis is dedicated to Rosetta Jean and Harper Elizabeth. 


\section{Acknowledgements}

I must graciously thank the many individuals that were instrumental in the completion of this thesis. To my project supervisors, Drs Mark Darling, Zia Khan, and Jerrold Armstrong, thank you for your unyielding support and hard work. Dr. Darling, your kind and understanding qualities are unmatched; I truly appreciate your genuine nature and willingness to accommodate my, often rigid, schedule. Dr. Khan, I am thankful for the patience you have shown me since the outset of this project. You have selflessly supported and helped me at a moment's notice, countless times. Your dedication to education is impressive and I am grateful to have been part of the Khan Lab. Dr. Armstrong, your guidance throughout the journey of residency has been very much appreciated, and I thank you for taking the time and effort in playing the clinical supervisor role on this project. I must also acknowledge Dr. Tom Daley, who has been an academic mentor throughout my time at Western and has always been so supportive of OMFS resident research. I thank you for your offered suggestions, thoughts and encouraging words over the years. This thesis would not have been possible without the tireless efforts of Linda Jackson-Boeters, who's laboratory skills and technical assistance were paramount to the success of this project. Linda, I appreciate your willingness to guide me through experiments, your accommodating helpfulness and cheerful lightheartedness while we completed our tasks.

Last, but not least, I must thank my family for their unwavering support throughout my academic career. I am tremendously grateful and am indebted to my parents for teaching me the value in good work ethic, and instilling in me the confidence to reach my goals. Thank you for providing me the opportunities in life that have afforded me both happiness and pride. To my sister and brother-in-law, thank you for encouraging me to be my very best, to keep my chin up, and most of all, thank you for making me the aunt of two special girls. My accomplishments would not mean anything without all of you. 


\section{Table of Contents}

Abstract.................................................................................ii

Dedication..........................................................................iii

Acknowledgements......................................................................iv

Table of Contents.....................................................................v

List of Tables...........................................................................viii

List of Figures......................................................................ix

List of Abbreviations..............................................................xi

Chapter 1.............................................................................1

1.0 Introduction....................................................................1

1.1 Salivary Gland Neoplasms..................................................1

1.1.1 Polymorphous Low-Grade Adenocarcinoma .................................1

1.1.1.1 Epidemiology, demographics.........................................2

1.1.1.2 Clinical Features......................................................2

1.1.1.3 Imaging Features......................................................3

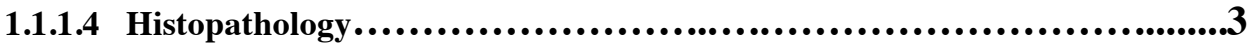

1.1.1.5 Diagnosis.............................................................5

1.1.1.6 Treatment and Prognosis...................................................5

1.1.1.7 PLGA variant, Cribriform adenocarcinoma of the tongue and minor salivary glands........................................................................7

1.1.1.8 Biomarkers associated with PLGA.......................................8

1.1.1.8.1 Ki-67....................................................8

1.1.1.8.2 C-kit (CD117)..............................................8

1.1.1.8.3 p63+/p40-................................................9

1.1.1.8.4 p53.....................................................9

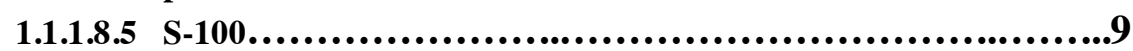

1.1.1.8.5.1 Mammaglobin and S-100 co-expression...................9

1.1.1.8.6 CD43.........................................................10

1.1.1.8.7 Osteopontin (OPN), CD44, integrin avb3......................10

1.1.1.8.8 Cytokeratins, Vimentin.....................................10

1.1.1.8.9 Carcinoembryonic antigen (CEA) ............................10

1.1.1.8.10 Smooth muscle actin (SMA), muscle specific actin (MSA), galactin-3, cyclin D1, glial fibrillary acid protein (GFAP), epithelial

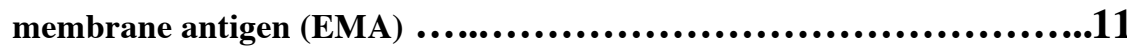

1.1.1.8.11 Maspin and Mini-chromosome maintenance protein (MCM2)........11

1.1.1.9 Genetic studies in PLGA........................................14

1.1.1.9.1 Translocation, $t(11 ; 19)$...................................14

1.1.1.9.2 Gene fusions...................................................14

1.1.1.9.2.1 MYB-NFIB.......................................14

1.1.1.9.2.2 ARID1A-PRKD1 and DDX3X-PRKD1..............14

1.1.1.9.3 PRDK1 hotspot mutation...................................14 
1.2 Kallikreins (KLKs) ....................................................16

1.2.1 Plasma Kallikrein...................................................16

1.2.2 Tissue Kallikrein.....................................................16

1.2.2.1 General Overview..........................................16

1.2.2.2 Historical Development........................................18

1.2.2.3 Kallikreins as proteases at the genomic, mRNA, and protein level..18

1.2.2.4 Activation of tissue kallikreins..................................20

1.2.2.5 Regulation of kallikreins...................................20

1.2.2.6 Physiologic function of kallikreins..............................23

1.2.2.7 Kallikreins in pathologic states................................28

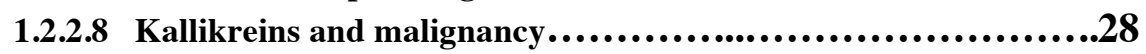

1.2.2.9 Kallikreins and salivary gland neoplasia.........................30

1.2.2.10 Kallikreins as biomarkers.......................................31

1.3 Hypothesis, Rationale and Aims.............................................................35

1.3.1 Hypothesis.....................................................................................................................35

1.3.2 Rationale...........................................................................................................................35

1.3.3 Aims..........................................................................................................................................35

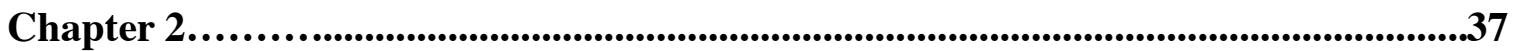

2.0 Experimental Materials and Methods............................................................................37

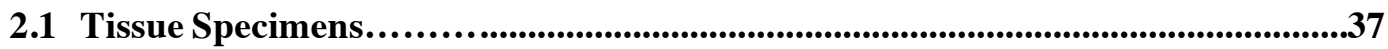

2.1.1 Tumour criteria............................................................................37

2.1.2 Patient data collection from PLGA samples............................................37

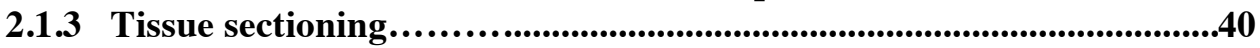

2.1.4 Normal Tissues................................................................................40

2.2 RNA isolation from formalin-fixed, paraffin-embedded tissue............................40

2.2.1 Deparaffinization...........................................................................................40

2.2.2 RNA isolation protocol...............................................................................40

2.2.3 RNA quantification and cDNA synthesis....................................................41

2.3 SYBR Green Real Time Polymerase Chain Reaction (PCR) ..................................41

2.4 Data analysis for PCR...........................................................................................43

2.5 Statistical Analysis................................................................................................................43

2.6 Assay Methods...................................................................................................................43

2.6.1 Immmunohistochemistry sample selection..............................................43

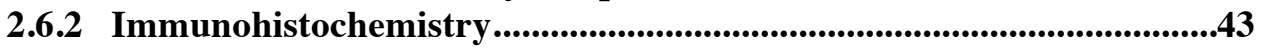

2.6.3 Antibody selection.........................................................................................43

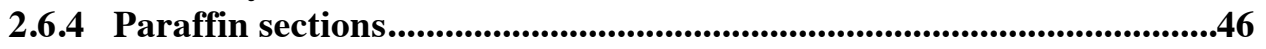

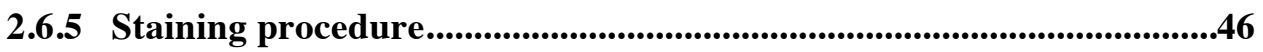

2.7 Data collection and statistical analysis for immunohistochemistry.........................46

2.7.1 Scoring criteria.................................................................................46

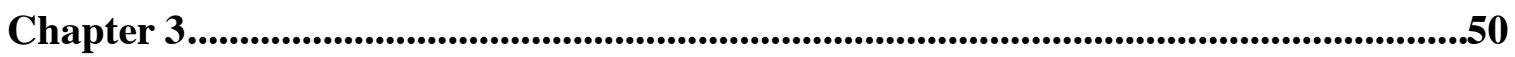

3.0 Results..................................................................................................................................

3.1 RNA isolation .....................................................................................................................50 


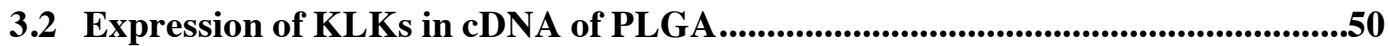

3.3 Expression of KLKs in PLGA compared to normal salivary gland tissue (NSGT)........50

3.4 Immunohistochemical staining results......................................62

3.5 PCR and IHC correlation...................................................................72

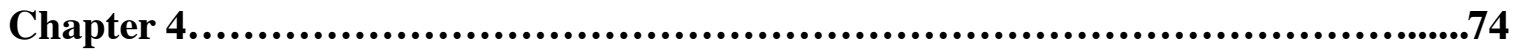

4.0 Discussion ......................................................................................................................74

4.1 Increased mRNA levels of KLKs in PLGA.....................................................74

4.2 IHC demonstrates PLGA tumour cell-specific staining pattern..........................74

4.3 KLK mRNA profile of PLGA vs ACC...................................................................74

4.4 Analysis of IHC staining of KLKs in PLGA..................................................75

4.5 IHC staining of KLKs in salivary gland neoplasia................................................76

4.6 Study limitations................................................................................................77

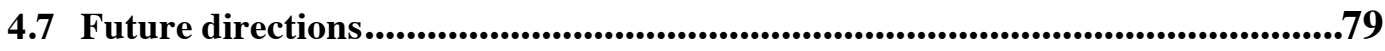

4.7.1 PLGA and activation of a kallikrein protein cascade...........................79

4.7.2 KLK upregulation and PRDK1 hotspot mutation in PLGA.................80

4.7.3 PLGA cell lines, KLK overexpression and knockout............................80

4.7.4 Gender role in PLGA......................................................................81

4.7.5 KLK as biomarkers in PLGA..................................................82

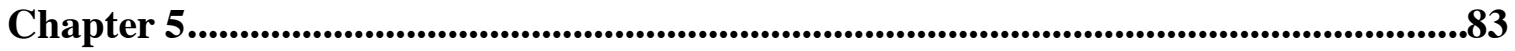

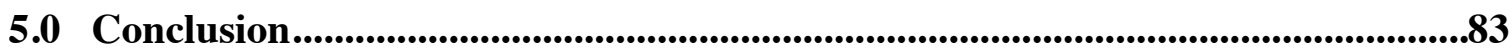

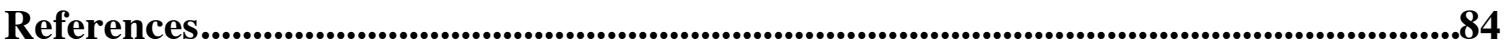




\section{List of Tables}

Table 1.1.1.8.1. Biomarkers studied in PLGA.............................................................12

Table 2.1.1: Patient Demographics for PLGA Samples.....................................................38

Table 2.1.2: Patient Demographics for NSGT Samples.....................................................39

Table 2.3.1: Qiagen Catalogue numbers.....................................................................42

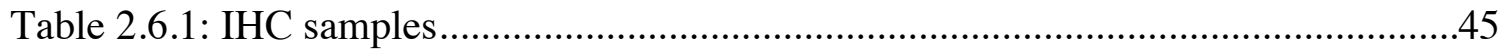

Table 2.6.2.1: Positive Controls for Selected KLK Antibodies.........................................45

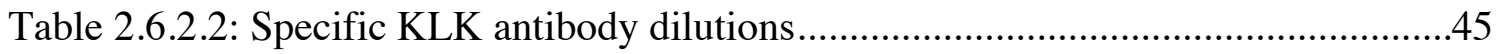

Table 2.7.1.1: Proportion score for estimated fraction of immunoreactive tumour cells.......48

Table 2.7.1.2: Intensity score for tumour cells.............................................................48

Table 3.1.1 RNA quantification by Qubit Fluorometer for each PLGA tissue sample.....51

Table 3.2.1 Percentages of PLGA cases with detectable KLK mRNA..............................52

Table 3.3.1 Calculated p-values, as determined by Mann Whitney U Test, for the comparison of expression of KLK1-15 in PLGA tissues and NSGT...................61

Table 3.4.1 Immunohistochemistry stain results..................................71

Table 3.5.1 Summary of PCR and IHC results.....................................72 


\section{List of Figures}

Figure 1.1.2.1: The human tissue kallikrein gene cluster............................17

Figure 1.1.2.2: KLK Activome and regulatory KLK cascades in normal physiology and disease. .21

Figure 1.1.2.3: KLK expression in human tissues...................................27

Figure 2.7.1.1: Diagrammatic Representation of Interpretation of Allred Scores...............49

Figure 3.3.1: Mean value of KLK1 mRNA expression in PLGA vs NSGT..................... 53

Figure 3.3.2: Mean value of KLK2 mRNA expression in PLGA vs NSGT.......................53

Figure 3.3.3: Mean value of KLK3 mRNA expression in PLGA vs NSGT......................54

Figure 3.3.4: Mean value of KLK4 mRNA expression in PLGA vs NSGT......................54

Figure 3.3.5: Mean value of KLK5 mRNA expression in PLGA vs NSGT.......................55

Figure 3.3.6: Mean value of KLK6 mRNA expression in PLGA vs NSGT......................55

Figure 3.3.7: Mean value of KLK7 mRNA expression in PLGA vs NSGT......................56

Figure 3.3.8: Mean value of KLK8 mRNA expression in PLGA vs NSGT......................56

Figure 3.3.9: Mean value of KLK9 mRNA expression in PLGA vs NSGT......................57

Figure 3.3.10: Mean value of KLK10 mRNA expression in PLGA vs NSGT ...................57

Figure 3.3.11: Mean value of KLK11 mRNA expression in PLGA vs NSGT..................58

Figure 3.3.12: Mean value of KLK12 mRNA expression in PLGA vs NSGT ..................58

Figure 3.3.13: Mean value of KLK13 mRNA expression in PLGA vs NSGT ..................59

Figure 3.3.14: Mean value of KLK14 mRNA expression in PLGA vs NSGT ..................59

Figure 3.3.15: Mean value of KLK15 mRNA expression in PLGA vs NSGT ...................60

Figure 3.3.16: Relative fold increase of mRNA levels of KLK1-15 in PLGA tissue as compared with normal salivary gland tissues..................................................................60

Figure 3.4.1 Immunohistochemical localization of KLK7 in PLGA....................63

Figure 3.4.2 Immunohistochemical localization of KLK8 in PLGA. ..........................64 
Figure 3.4.3 Immunohistochemical localization of KLK10 in PLGA.......................65

Figure 3.4.4 Immunohistochemical localization of KLK11 in PLGA. ....................66

Figure 3.4.5 Immunohistochemical localization of KLK14 in PLGA. ....................67

Figure 3.4.6 Immunohistochemical negative controls staining of PLGA tissue samples. .68

Figure 3.4.7 Immunohistochemical localization of KLK in controls.....................69 


\section{List of Abbreviations}

ACC: $\quad$ Adenoid cystic carcinoma

ACI: $\quad$ Acinic cell carcinoma

ACPT: $\quad$ Testicular acid phosphatase gene

ACS: $\quad$ American Cancer Society

AJCC: $\quad$ American Joint Committee on Cancer

ALL: $\quad$ Acute lymphoblastic leukemia

ANOS: $\quad$ Adenocarcinoma not otherwise specified

AUA: $\quad$ American Urological Association

BOT: $\quad$ Base of tongue

BPH: $\quad$ Benign prostatic hypertrophy

CAG: $\quad$ Cancer associated gene

CATMSG: Cribriform adenocarcinoma of the tongue and minor salivary glands

cDNA: $\quad$ Complimentary deoxyribonucleic acid

CEA: $\quad$ Carcinoembryonic antigen

CNS: $\quad$ Central nervous system

CSF: $\quad$ Cerebrospinal fluid

CT: $\quad$ Computed tomography

DNA: Deoxyribonucleic acid

DSG1: Desmoglein1

DSS: $\quad$ Disease specific survival

ECM: $\quad$ Extracellular matrix

EMA: $\quad$ Epithelial membrane antigen

FFPE: $\quad$ Formalin-fixed paraffin embedded 
FNAB: $\quad$ Fine-needle aspiration biopsy

GFAP: Glial fibrillary acid protein

HRE: $\quad$ Hormone response elements

H\&E: $\quad$ Hematoxylin \& eosin stain

IHC: Immunohistochemistry

KLK: Kallikrein-related peptidase protein

KLK: $\quad$ Kallikrein-related peptidase gene

KKS: $\quad$ Kallikrein-kinin system

MCM: $\quad$ Mini-chromosome maintenance protein

MEC: $\quad$ Mucoepidermoid carcinoma

miRNA: $\quad$ Micro ribonucleic acid

MRI: $\quad$ Magnetic resonance imaging

mRNA: Messenger ribonucleic acid

MSA: $\quad$ Muscle specific actin

NSGT: Normal salivary gland tissue

NOS: $\quad$ Not otherwise specific

OPN: $\quad$ Osteopontin

OSS: $\quad$ Overall staining score

PA: Pleomorphic adenoma

PCR: $\quad$ Polymerase chain reaction

PLCO: $\quad$ Prostate, Lung, Colorectal, and Ovarian Cancer Screening Trial

PLGA: Polymorphous low-grade adenocarcinoma

PSA: $\quad$ Prostate specific antigen

RISC: $\quad$ RNA-induced silencing complex

RNA: $\quad$ Ribonucleic acid 
$\mathrm{RT}^{2}$-qPCR: Real-time quantitative polymerase chain reaction

SEM: $\quad$ Standard error of mean

SMA: $\quad$ Smooth muscle actin

TNM: $\quad$ Tumour, Node, Metastasis

WHO: World Health Organization 


\section{Chapter 1}

\subsection{Introduction}

\subsection{Salivary Gland Neoplasms}

Salivary gland tumours comprise $2-6.5 \%$ of all head and neck malignancies and have a global incidence of approximately 1-6.5 cases per 100,000 persons annually[1,2]. These tumours are most commonly found in the parotid gland, but may also occur in the other major salivary gland tissue, the submandibular and sublingual glands, as well as the minor salivary glands[2,3]. The minor salivary glands are widely distributed along the upper aerodigestive tract, including the lips, gingiva, buccal mucosa, palate, tongue, oropharynx, paranasal sinuses, and the parapharyngeal space[4].

Although the parotid comprises $64-80 \%$ of all salivary gland neoplasia cases, only about $15-32 \%$ of these tumours are malignant $[2,5]$. The most common benign salivary gland tumour of the parotid gland is pleomorphic adenoma (PA), whereas the most common malignancy is mucoepidermoid carcinoma (MEC)[1, 2, 5]. Submandibular glands account for about 8-11\% of salivary gland tumours; however, the rate of malignancy is substantially higher, ranging from 37$45 \%$ [2]. Still, PA remains the most common benign entity, and adenoid cystic carcinoma (ACC) is the most common malignancy, found in the submandibular glands[2]. Tumours in the sublingual gland are rare, occurring $<1 \%$, but the gross majority are malignancies[2]. Minor salivary glands comprise $9-23 \%$ of salivary gland tumours[2]. They are more common to be malignant, with MEC being the most common malignant tumour of the minor salivary glands[2, 5].

\subsubsection{Polymorphous Low-Grade Adenocarcinoma}

Polymorphous low-grade adenocarcinoma (PLGA) was first described in 1983 by Freedman and Lumerman, and Batsakis et al. as "lobular carcinoma" and "terminal duct carcinoma" for its similarities to lobular carcinoma of the breast[6-9]. In 1984, the term "polymorphous low-grade adenocarcinoma" was suggested by Evans and Batsakis, and, subsequently, it was recognized as its own entity by the World Health Organization (WHO) in 1990[9-12]. Previous to this, it was considered under the umbrella of pleomorphic adenoma, adenocarcinoma NOS, or ACC $[2,13]$. By definition, PLGA is a "malignant epithelial tumour 
characterized by cellular uniformity, morphologic diversity, an infiltrative growth pattern, and low metastatic potential'"[3]. PLGA is a diagnostic challenge for pathologist, overlapping in histologic characteristics with other salivary gland neoplasms[14].

\subsubsection{Epidemiology, demographics}

PLGA is the second most common malignant salivary gland tumour of the minor glands and the third most common salivary gland tumour found in the oral cavity[14, 15]. It comprises 7 $11 \%$ of all tumours in the minor salivary glands, and $19-26 \%$ of all malignancies of the minor salivary glands[9]. PLGA is not limited to minor salivary glands, but may occur in major salivary glands or from an existing pleomorphic adenoma; however, in both instances this is rare[8, 9, 11]. In a 2015 retrospective study, the incidence of PLGA was noted to be 0.051 per 100000 persons annually[11]. In their 2013 epidemiologic study, de Araujo et al. noted a significant increase in the fraction of PLGA cases reported in the literature since 2007, but did suggest this was secondary to improved diagnostic accuracy by pathologists[16]. PLGA is most commonly found in the Caucasian population; however, some publications have reported higher incidences amongst Asian and African populations $[11,16,17]$. Two retrospective studies out of Northeast and Eastern China documented a lower incidence of PLGA in these regions, than that noted globally[4, 18]. PLGA has a female predilection, with a female-to-male ration of 2.15:1[11, 19]. PLGA is most frequent in the $6^{\text {th }}$ and $7^{\text {th }}$ decades; the age of presentation peaks during the $6^{\text {th }}$ decade[16,20]. Cases in the literature vary from the $2^{\text {nd }}$ to $10^{\text {th }}$ decades of life, with the mean age at time of diagnosis being 61.3 years of age[ $[4,11]$.

\subsubsection{Clinical Features}

The clinical presentation of PLGA is non-specific and patients may or may not have symptoms[10, 13, 21]. Most commonly, this tumour presents as a firm, non-tender swelling of the palate, buccal or lip mucosa[21]. The lesion may exhibit pain, and infrequently, paresthesia[13, 20]. Patients, on average, have symptoms for 27 months prior to diagnosis. Usually the mass lies within the submucosal plane, with intact and normal surface epithelium[20]. However, bleeding, ulcerations and telangectasias have been reported[21]. Furthermore, Chi and Neville recently described a rough stippled overlying mucosa feature, which was significantly found more often in PLGA tumours versus non-PLGA tumours[21]. 
The most common location to develop PLGA is on the palate, particularly at the junction of the hard and soft palate, where many minor salivary glands reside[11, 13, 16]. PLGA is also regularly found on the lips, as well as the buccal mucosa. Other intra-oral sites include: retromolar trigone, tongue, mandible, floor of mouth, and gingiva[10, 22]. Although rare, PLGA may occur in the major salivary glands; Sun et al.'s review of sublingual gland pathology in 2010 noted PLGA comprised $4.76 \%$ of tumours of the sublingual gland [23]. Even more rarely, PLGA may be found in extra-oral sites, including: the maxillary sinus, paranasal sinuses, lacrimal glands, orbit, ear, oropharynx/base of tongue, nasopharynx, larynx, uvula, breast and mammary gland, vulva, vagina, and skin[17, 24, 25]. Lesions have been found in the lungs as metastases, but also as primary lesions[15].

PLGA is usually a slow growing tumour, but tumour size can vary from smaller to larger diameters, depending on location. The average tumour size at the time of presentation is $2.1 \mathrm{~cm}$ +/- $1.3 \mathrm{~cm}[11,14,16]$. PLGA may be locally invasive, for example, palatal lesions will eventually invade the adjacent maxillary bone and sinuses[19]. Regional lymph node metastasis has been reported as high as $29 \%$, but there is rarely hematogenous spread[26-28]. However, distant metastasis have reportedly been found in the lung and abdomen[29]. In their retrospective epidemiologic study, Patel et al. found a distant metastasis rate of 4.3\%[11].

\subsubsection{Imaging Features}

PLGA exhibits variable radiographic characteristics; features are generally consistent with a slow growing, but aggressive tumour[8]. In a radiology journal, Potluri et al. presented a PLGA case with significant imaging findings; plain film investigations noted loss of maxillary bone and lack of sinus floor visualization, whereas computed tomography showed irregular cortical density, thinning of cortical plates, and mass effect with maxillary bowing and bony perforations[8]. Soft tissue findings on imaging noted hypervascularity and irregular contrast enhancement[8].

\subsubsection{Histopathology}

PLGA is defined histologically as a well-circumscribed, non-encapsulated lesion with infiltrative borders $[6,11,29,30]$. As the name "polymorphous" would suggest, this tumour demonstrates substantial histologic heterogeneity. Multiple growth patterns have been seen, including: solid, cribriform, trabecular, ductotubular, fascicular, papillary, glandular, cord-like, 
and lobular[10, 14, 16, 20]. Importantly, more than one pattern may be visualized in the same tumour[9]. Furthermore, certain growth patterns, such as papillary, have been associated with more aggressive clinical behaviour, and higher rates of metastasis[26, 31].

Concentric growth patterns are often exhibited, with streaming columns of single-filed tumour cells, forming "whorls", which appear targetoid in nature[12, 13]. The surface epithelium is usually not violated by tumour cells, and infiltrating nests or islands are less common, rather the tumour cells exhibit a "pushing" type of invasion[6,13]. The tumour cells have been shown to invade salivary glands, muscle, connective tissue and bone; however, true skeletal muscle invasion is rare[6,9].

While, histomorphologically heterogeneous, PLGA displays nuclear homogeneity[11]. Nuclei are round, open-faced with dense and scattered nucleoli[13]. They demonstrate a classic "salt and pepper" nuclear form, with optically clear chromatin[8, 10, 14]. PLGA tumour cells contain scant to moderate cytoplasm, which may be eosinophilic, amphophilic, and infrequently contain oncocytes and mucin cells[6,9, 16]. Langerhans cells have been seen in greater density with PLGA than other salivary gland malignancies, but not to a statistically significant level[32].

Again, as its title would suggest, PLGA demonstrates "low-grade" pathologic features. Cell necrosis and hemorrhage are infrequently encountered and mitosis are scant, if present $[6,10,30$, 31]. Peri-neural and intra-neural invasion is seen; however, it does not correlate with more aggressive clinical behaviour[9, 16, 33]. Moreover, these tumours may display prominent vascularity, with perivascular invasion occasionally evident[16]. According to Ki-67 staining for proliferation indices of tumours, PLGA exhibits a relatively lower mean proliferation index $(<6.4 \%)$, signifying a more indolent behaviour[25].

In their epidemiologic study, Patel et al. revealed 37.2\% of PLGA tumours were welldifferentiated/Grade I, and the remaining $62.8 \%$ of cases were moderately differentiated/Grade II[11]. Rare cases of histologic transformation from low-grade to high-grade have been reported[15, 26, 29]. This de-differentiation has correlated to more aggressive clinical behaviour[26].

The diagnostic challenge PLGA poses is its morphologic resemblance and overlap with PA and ACC under the microscope[14, 34]. Specifically, all three of these neoplasms exhibit cribriform and tubular growth patterns[26]. Given the therapeutic and prognostic differences between these entities, it can be a significant pitfall to misdiagnose[9]. PA is composed of 
proliferating epithelial, stromal, and myoepithelial cells which do not demonstrate the infiltrative pattern seen with PLGA; however, this is not always apparent, particularly in smaller biopsy specimens[22]. Myxochondroid and chondroid regions are seen commonly in PA, which can aid in differentiating from PLGA[22]. ACC is more common in major salivary glands, where PLGA is uncharacteristically found, so this is often useful in distinguishing between the two tumours[9]. Overlapping microscopic features seen with ACC and PLGA include: diffusely invasive borders, solid and cribriform growth patterns, and perineural invasion[35]. ACC characteristics that set it apart from PLGA are smaller cell size with less cytoplasm, hyperchromatic nuclei, coarser nuclear chromatin, and a higher nuclear-to-cytoplasmic ratio[6].

\subsubsection{Diagnosis}

The diagnostic work up for PLGA consists of a thorough history and physical examination, followed by appropriate diagnostic imaging. Many diagnostic modalities, such as sialography, radionucleotide scanning, and ultrasonography primarily have a role in pathology of the major glands[5]. Computed tomography (CT) and magnetic resonance imaging (MRI) are the favoured

imaging modalities when investigating minor salivary glands[5]. Despite information gained from imaging studies, neoplastic growths of the salivary glands require histological tissue diagnosis. Fine-needle aspiration biopsy (FNAB) has a role in the diagnosis of major salivary gland pathologies; however, in minor salivary gland pathology it has little to no value[5]. The hallmark of diagnosis for PLGA remains adequate open tissue biopsy.

\subsubsection{Treatment and Prognosis}

The treatment of choice for PLGA is surgery, with or without adjuvant radiotherapy[5, 11]. Surgery usually consists of wide local excision, with $1 \mathrm{~cm}$ margins, or resection to the closest anatomic barrier[5]. In most cases, this will achieve local control of disease[15]. Depending on tumour size, reconstruction may be necessitated[30]. Neck dissection is generally not warranted in NO disease; however, some advocate that if the primary site of PLGA is the base of tongue (BOT), it should be more seriously considered[17]. Others suggest therapeutic neck dissections should be limited to patients with clinical and radiographic evidence of positive cervical lymphadenopathy[19]. Furthermore, Pogodziski et al. and Gonzalez-Garcia et al. have 
recommended no neck dissection unless a major resection and reconstruction has been planned[11].

The role of radiotherapy for the treatment of PLGA remains uncertain[1, 5, 11, 30]. Adjuvant radiotherapy is considered in the setting of positive surgical margins; typical dosages are 66Gy in 33 fractions for residual microscopic disease or 70Gy in 35 fractions for gross residual disease[30]. Furthermore, radiation may be considered as a primary treatment when patients are not suitable for surgery, when complete resection is not possible, or if the tumour is in close proximity to vital structures (e.g. parotid gland PLGA about the facial nerve)[17]. A cohort study by Castle et al. and a case series by Kimple et al. both demonstrated that post-operative radiotherapy had no significant change in patient outcomes[6, 10]. In the context of negative surgical margins, peri-neural involvement seen in PLGA does not warrant adjuvant radiotherapy, as it does not affect prognosis, and may be monitored[30]. Patel et al. reported that in all cases treated from 2001-2011, 77.9\% had surgery alone, $2.6 \%$ had radiation alone, and $19.5 \%$ were treated with both[11]. Adjuvant chemotherapy has seldom been given, and requires further investigation as to its usefulness in the treatment of PLGA.

Staging of PLGA utilizes the American Joint Committee on Cancer (AJCC), Tumor, Nodes, Metastases (TNM) system. Patel et al. were able to obtain staging for 319/460 PLGA cases reviewed in their study; the tumours comprised the following stages: Stage I: $46.7 \%$, Stage II: 17.6\%, Stage III: 5.6\%, and Stage IV: 11.9\%[11]. Further classification using TNM was also reported. Tumour status, T1: 48\%, T2: 20.1\%, T3: 4.4\%, T4: 10.0\% and Tx: $17.6 \%$, node status, N0:88.4\%, N1:3.4\%, N2: 1.6\%, and Nx:6.6\%, and metastases status, M0: 93.1\%, M1: 1.6\%, and $\mathrm{Mx}: 5.3 \%[11]$.

Recurrence rates for PLGA vary in the literature, but have been reportedly as high as $33 \%[11,36]$. Other documented ranges for local recurrence have suggested 9-17\%[2, 3, 21]. Recurrences of PLGA have been found in the context of negative surgical margins[20, 24]. It has also been reported that females are more likely to experience recurrent disease[6]. Late recurrences are not uncommon, with reports of recurrent PLGA arising anywhere between 1 and 24 years[10, $30]$. The average time to present with recurrence of disease is 7.2 years[6, 17]. In their case series, Kimple et al. stated $50 \%$ of recurrences happened by 35 months, and they also went on to note of the recurrent PLGA cases studied, 54\% demonstrated local recurrences, 32\% were nodal, and $8 \%$ were distant[10]. Rates of recurrence with surgical resection alone, compared to surgical resection 
with adjuvant radiotherapy have not demonstrated any significant difference[6, 10]. Histologically, recurrent disease appears more aggressive, with evidence of papillary histomorphology, increased mitotic figures, and overall "intermediate-grade adenocarcinoma"[11, 17]. Interestingly, peri-neural invasion has not been linked to increase rates of recurrence in PLGA[11]. The potential for delayed recurrence, and recurrent nodal disease, warrants prolonged clinical follow up; recommendations for at least 15 years of follow up have been suggested[20, 31].

Overall, the prognosis for PLGA is excellent $[13,21]$. The 5 and 10-year disease specific survival (DSS) has been reported as 98.6\% and 96.4\%[11]. Based on treatment modality, 10-year DSS survival notes $98 \%$ for surgery alone, $90.9 \%$ for surgery, with adjuvant radiotherapy, and $75 \%$ for radiotherapy alone[11].

\subsubsection{PLGA variant, Cribriform adenocarcinoma of the tongue and minor salivary glands}

Recently, a variant of PLGA has been noted in the literature, thought to differ in clinical location, behaviour and histopathology[12]. Termed "Cribriform Adenocarcinoma of the Tongue and Minor Salivary Glands" (CATMSG), it is currently regarded as a "provisional entity" by the WHO[33]. Originally, Michal et al. described this tumour as Cribriform Adenocarcinoma of the Tongue in 1999; however, with more cases reported, the term has now expanded to include the minor salivary glands[26]. Presently, there are 41 well-documented CATMSG cases in the literature, but it remains controversial whether CATMSG and PLGA remain separated entities or whether they are variants of one tumour spectrum[26, 37].

CATMSG occurs primarily in adults, with one adolescent case report by Takhar et al[12, 37]. Unlike PLGA, CATMSG shows no gender predilection[37]. Furthermore, CATMSG demonstrates a more aggressive clinical behaviour, having higher rates of local metastatic spread $(61.2 \%)[12,33]$. Michal et al. postulate that if CATMSG was considered a separate entity, the rate of PLGA metastasis to regional lymph nodes would be significantly lower[33]. Distant metastases have not been reported to date[38]. Although more patient lymph node metastases at the time of presentation, the tumour remains indolent overall, with a favourable prognosis[33].

Histologically, CATMSG shares characteristics of cribriform, microcribriform, and solid patterns with PLGA; however, it can exhibit clefts and tumour nests resulting in a glomeruloid appearance[33, 38]. Moreover, the nuclei overlap, are pale, optically clear, with a ground glass 
appearance, making this tumour variant quite histologically similar to papillary thyroid carcinoma[38]. Rarely, psamomma bodies may be seen[33]. Importantly, these tumours stain negatively for thyroglobin and TTF-1[33,38]. The immunohistochemical profile of CATMSG has otherwise been variable; positive staining has been noted in cytokeratin markers (AE1-3, CAM5.2, CK7, CK8, CK18), S-100, SMA, calponin, and vimentin. C-kit, p16, cyclin D1, p53, and CK19 have been inconsistent. Lastly, the Ki-67 index has usually been low[33].

\subsubsection{Biomarkers associated with PLGA}

In an effort to improve diagnostic accuracy in salivary gland pathology, many groups have examined the immunohistochemical profile of PLGA. The summary of biomarkers studied to date are presented in Table 1.1.1.8.1.

\subsection{Ki-67}

$\mathrm{Ki}-67$ is a cell cycle-associated antigen which is useful as a biomarker for cell proliferation, and is therefore, thought to have use as a prognostic indicator in salivary gland malignancies[35, 39]. Ki-67 is only expressed by proliferating cells, and has its peak expression in $M$ phase of the cell cycle[39]. The Ki-67 index for PLGA is usually $<6.4 \%$, with mean values $1.6 \%-2.4 \%[3,37]$. In comparison to other malignant salivary gland tumours, Skalova et al. and Vargas et al. reported PLGA had a significantly lower Ki-67 index than ACC $[14,30]$. Beltran et al. also demonstrated a lower Ki-67 index in PLGA versus ACC; however, this was only "suggestive statistical significance"[35]. Other groups have noted no significant difference in Ki-67 index between ACC and PLGA and/or an increased index in PLGA[7, 29, 35]. Higher Ki-67 indices have been seen with de-differentiated PLGA tumours, and therefore, a ki-67expression analysis may be a useful tool in identifying this high-grade variant of PLGA[29]. In their 2011 study, Falchete do Prado et al. examined Ki-67 and fatty acid synthase expression in salivary gland tumours, noting greatest fatty acid synthase expression in PA and higher Ki-67 index in salivary gland malignancies[39]. MEC showed the highest Ki-67 index, followed by ACC and PLGA; there was no correlation between fatty acid synthase expression and Ki-67 index[39].

\subsection{C-kit (CD117)}

C-kit is a proto-oncogene that encodes a transmembrane receptor tyrosine kinase and is shown to be overexpressed in $\mathrm{ACC}[3,35]$. In their clinicopathologic study, Schwarz et al. cited their most remarkable finding was that c-kit expression is primarily absent in PLGA, when 
compared to ACC[7]. Beltran et al. found PLGA had significantly weaker staining for c-kit in PLGA versus ACC [35]. Moreover, Rooper et al. presented studies demonstrating diffuse positive c-kit staining in ACC and c-kit negative staining in PLGA; however, they cited other studies noting no significant difference between the two malignancies[14].

\subsubsection{3 p63+/p40-}

Recently, a p63+/p40- immunohistochemical staining panel has been argued as a valuable tool for diagnosing PLGA. The immunohistochemical marker p63 is normally expressed in the basal layer of stratified epithelium, myoepithelial cells, and the malignancies that proliferate from these cells[14]. It's isotype, p40 is a more specific marker of basal stratified epithelial and myoepithelial differentiation[14]. To date, p63 has not shown diagnostic use for PLGA, as despite lack of myoepithelial proliferation in this tumour, it stains diffusely positive for p63; however, Rooper et al. demonstrated that PLGA stained negatively for the more specific p40 isotype[14]. They concluded that the p63+/p40- phenotype was 100\% sensitive and 93\% specific for PLGA, showing diagnostic promise[14].

\subsubsection{4 p53}

p53 is a tumour suppressor protein encoding for a nuclear phosphoprotein, controlling cell proliferation[40]. PLGA has shown variable p53 staining in the literature as well[9]. Some studies demonstrate little p53 staining in PLGA, whereas other groups report PLGA shows the highest expression of p53 out of all salivary gland neoplasms[34].

\subsection{S-100}

The S-100 protein family is a group of low molecular weight proteins, with calcium binding sites and are expressed by a number of cell types[41]. Furthermore, these proteins have been implicated in inflammatory process regulation, as well as the development of metastasis in several cancers[41]. S-100 protein stains have been well-examined in salivary gland neoplasia[9]. The majority of PLGA are S-100 positive, demonstrating diffuse staining[6, 42]. In contrast, ACC and adenocarcinoma NOS both show weaker S-100 protein staining; however, ACC staining may be variable[9, 42].

\subsection{Mammaglobin and S-100 co-expression}

To improve the diagnostic value of S-100 in salivary gland neoplasms, Patel et al. studied its co-expression with mammaglobin, a glycoprotein and biomarker used in breast cancer[43]. They concluded that $100 \%$ of PLGA cases stained positive for mammaglobin, and $93 \%$ of PLGA 
cases stained positive for S-100[42]. Ultimately, 60\% of PLGA cases met the staining criteria for co-expression of S-100 and mammaglobin, whereas only $13.3 \%$ cases of ACC met such criteria[42].

\subsection{CD43}

CD43 is a transmembrane surface protein, normally expressed in T lymphocytes, natural killer cells, and myeloid cells[44]. Weak expression of CD43 has been found in epithelial cells, synovial cells, fibroblasts and chondrocytes[44]. CD43 has been found to be expressed more strongly in ACC when compared to PLGA[13, 21].

\subsection{Osteopontin (OPN), CD44, integrin avb3}

OPN is an acidic phosphoglycoprotein, which interacts with two ligands, cell receptors CD44 and integrin avb3, and is expressed in various tumours[45]. Increased expression of OPN is thought to be involved with malignant tumour invasion and metastasis[45]. Fok et al. studied the expression of osteopontin, as well as it's ligands in salivary gland tumours, concluding that PLGA and ACC demonstrate increased OPN expression compared to benign salivary gland tumours and normal salivary gland tissue (NSGT)[45]. Furthermore, CD44 expression was reduced in PLGA, which they postulated could suggest a less aggressive tumour behaviour, as CD44 interacts with OPN to promote metastasis[45]. Integrin avb3 showed scattered staining in PLGA[45].

\subsection{Cytokeratins, Vimentin}

Cytokeratins are keratin-containing intermediate filaments, which are expressed in epithelial tissue and may be divided into low and high molecular weight keratins[46]. Cytokeratins have shown positive staining in PLGA, specifically de Araujo et al. noted CK8 and CK18 to have increase expression in PLGA[47].

Vimentin is an intermediate filament protein that is expressed by mesenchymal cells[47]. PLGA has demonstrated positive vimentin staining in various studies, and in contrast, ACC shows weaker staining[30]. Darling et al. reviewed the literature for the immunohistochemistry staining profile of PLGA, and concluded that vimentin was the only immunohistochemical marker to reliably differentiate PLGA from ACC[9].

\subsection{Carcinoembryonic antigen (CEA)}

CEA is a glycoprotein which functions in cell adhesion. CEA has demonstrated expression in ACC; however, the CEA expression profile has varied with PLGA[9, 30]. Several groups have shown PLGA stains negatively for CEA, whereas other groups have reported some staining 
variability, thus CEA is not uniformly negative in PLGA and has decreased diagnostic value[9, 29].

\subsection{Smooth muscle actin (SMA), muscle specific actin (MSA), galactin-3, cyclin D1, glial fibrillary acid protein (GFAP), epithelial membrane antigen (EMA)}

Other biomarkers have been less reliable in differentiating between salivary gland tumours. Multiple studies have shown that ACC demonstrate increase expression of smooth muscle actin (SMA), and increased nuclear expression of galectin-3 and cyclin D1, as compared to PLGA[10, $21,30]$. GFAP staining has been reported as both negative and positive in PLGA; its expression is relatively higher in PA, whereas ACC's expression of GFAP is unknown[9, 14]. EMA stains positive in both ACC and PLGA[9]. MSA stains moderately positive in ACC; however, in PLGA the stain is negative to weak[9].

\subsection{Maspin and Mini-chromosome maintenance protein (MCM2)}

Maspin is a mammary serine protease inhibitor, that functions to prevent apoptosis and decrease cell invasion, and may have a role in preventing angiogenesis[48]. MCM2's are mini chromosome maintenance proteins, which are paramount for DNA replication and therefore, have use as markers for cell proliferation[48]. In 2011, Ghazy et al. studied the expression of maspin and MCM2 in salivary gland tumours, and specifically wanted to determine if their expression correlated to lymph node metastasis[48]. Salivary gland tumours, including PLGA and ACC, stained positively for both maspin and MCM2 to a variably degree, but ACC showed a higher proliferation profile versus PLGA. There was no significant correlation between maspin and MCM2 expression and regional metastatic disease[48]. 
Table 1.1.1.8.1. Biomarkers studied in PLGA

\begin{tabular}{|c|c|c|c|c|c|}
\hline Biomarker & Definition & Indicates & $\begin{array}{c}\text { PLGA } \\
\text { value }\end{array}$ & Significance & Clinical use \\
\hline Ki-67 & $\begin{array}{c}\text { Cell } \\
\text { cycle- } \\
\text { associated } \\
\text { antigen }\end{array}$ & $\begin{array}{c}\text { Cell } \\
\text { proliferation }\end{array}$ & $<6.4 \%$ & $\begin{array}{c}\text { Index } \\
\text { PLGA }<\text { ACC }<\mathrm{M} \\
\text { EC }\end{array}$ & $\begin{array}{c}\text { "only } \\
\text { suggestive } \\
\text { statistical } \\
\text { significance" }\end{array}$ \\
\hline $\begin{array}{c}\text { C-kit } \\
\text { (CD117) }\end{array}$ & $\begin{array}{c}\text { Proto- } \\
\text { oncogene }\end{array}$ & $\begin{array}{c}\text { Increase in } \\
\text { transmembrane } \\
\text { receptor } \\
\text { tyrosine kinase }\end{array}$ & Absent & $\begin{array}{c}\text { Overexpressed in } \\
\text { ACC }\end{array}$ & $\begin{array}{c}\text { Differences } \\
\text { may or may } \\
\text { not be } \\
\text { significant }\end{array}$ \\
\hline p63+/p40- & $\begin{array}{c}\text { IHC } \\
\text { markers } \\
\text { for tumour } \\
\text { proteins }\end{array}$ & $\begin{array}{c}\text { Staining } \\
\text { p63: } \\
\text { basal layer } \\
\text { p40: } \\
\text { myoepithelial } \\
\text { differentiation }\end{array}$ & $\begin{array}{l}\text { PLGA } \\
\text { stains }+ \\
\text { for p63 } \\
\text { and }- \text { for } \\
\text { p40 }\end{array}$ & $\begin{array}{c}\mathrm{p} 63+/ \mathrm{p} 40- \\
\text { phenotype } 100 \% \\
\text { sensitive and } 93 \% \\
\text { specific for } \\
\text { PLGA }\end{array}$ & $\begin{array}{l}\text { Diagnostic } \\
\text { promise in } \\
\text { PLGA }\end{array}$ \\
\hline p53 & $\begin{array}{l}\text { Tumour } \\
\text { suppressor } \\
\text { protein }\end{array}$ & $\begin{array}{l}\text { Controls cell } \\
\text { proliferation }\end{array}$ & Variable & $\begin{array}{c}\text { p53 } \\
\text { overexpression } \\
\text { seen in 38\% of } \\
\text { PLGA } \\
\end{array}$ & Limited \\
\hline S-100 & $\begin{array}{c}\text { Low } \\
\text { molecular } \\
\text { weight } \\
\text { protein }\end{array}$ & $\begin{array}{l}\text { Present in neural } \\
\text { crest cells, } \\
\text { chondrocytes, } \\
\text { adipocytes, } \\
\text { myoepithelial cells, } \\
\text { macrophages, } \\
\text { Langerhans cells, } \\
\text { dendritic cells, } \\
\text { keratinocytes }\end{array}$ & $\begin{array}{l}\text { Majority } \\
\text { positive }\end{array}$ & $\begin{array}{c}\text { PLGA stains } \\
\text { positive and } \\
\text { diffusely vs ACC } \\
\text { (may be variable) }\end{array}$ & Limited \\
\hline $\begin{array}{l}\text { Mammagl- } \\
\text { obin \& } \\
\text { S-100 }\end{array}$ & $\begin{array}{l}\text { Mammaglobin } \\
\text { : glycoprotein }\end{array}$ & $\begin{array}{c}\text { Present in } \\
\text { variable cells }\end{array}$ & $\begin{array}{l}\text { Majority } \\
\text { positive } \\
\text { for both }\end{array}$ & $\begin{array}{l}\text { PLGA: } 60 \% \text { co- } \\
\text { expression } \\
\text { ACC: } 13 \% \text { co- } \\
\text { expression }\end{array}$ & Limited \\
\hline CD43 & $\begin{array}{c}\text { Trans- } \\
\text { membrane } \\
\text { surface protein }\end{array}$ & $\begin{array}{l}\text { Present in } \mathrm{T} \\
\text { lymphocytes, } \\
\text { natural killer } \\
\text { cells, myeloid } \\
\text { cells }\end{array}$ & Variable & $\begin{array}{c}\text { Expressed more } \\
\text { strongly in ACC } \\
\text { vs PLGA }\end{array}$ & Limited \\
\hline $\begin{array}{l}\text { Osteopontin, } \\
\text { CD44, } \\
\text { integrin } \\
\text { avb3 }\end{array}$ & $\begin{array}{c}\text { OPN: } \\
\text { phosphoglyco } \\
\text { protein } \\
\text { CD44 and } \\
\text { integrin } \\
\text { avb3: } \\
\text { ligands for } \\
\text { OPN }\end{array}$ & $\begin{array}{c}\text { OPN involved } \\
\text { in malignant } \\
\text { tumour } \\
\text { invasion }\end{array}$ & $\begin{array}{c}\text { OPN } \\
\text { expression } \\
\text { increased; } \\
\text { CD44 } \\
\text { reduced; } \\
\text { integrin } \\
\text { avb3 } \\
\text { scattered }\end{array}$ & $\begin{array}{c}\text { PLGA and ACC } \\
\text { have increased } \\
\text { OPN expression } \\
\text { vs NSGT }\end{array}$ & Limited \\
\hline $\begin{array}{l}\text { Cytokeratin } \\
\text { Vimentin }\end{array}$ & $\begin{array}{l}\text { Cytokerati } \\
\text { n: Keratin } \\
\text { containing } \\
\text { intermediate }\end{array}$ & $\begin{array}{c}\text { CK: Expressed } \\
\text { in epithelial } \\
\text { tissues }\end{array}$ & $\begin{array}{l}\text { Positive } \\
\text { staining; } \\
\text { CK8 and }\end{array}$ & $\begin{array}{c}\text { Vimentin positive } \\
\text { in PLGA, and } \\
\text { weak in ACC }\end{array}$ & $\begin{array}{l}\text { Vimentin } \\
\text { staining may } \\
\text { reliably } \\
\text { differentiate }\end{array}$ \\
\hline
\end{tabular}




\begin{tabular}{|c|c|c|c|c|c|}
\hline & $\begin{array}{c}\text { filament } \\
\text { proteins } \\
\text { Vimentin: } \\
\text { intermediate } \\
\text { filament } \\
\text { protein }\end{array}$ & $\begin{array}{c}\mathrm{V}: \text { expressed in } \\
\text { mesenchymal } \\
\text { cells }\end{array}$ & $\begin{array}{c}\text { CK18 } \\
\text { increased. } \\
\text { Positive } \\
\text { staining }\end{array}$ & & $\begin{array}{c}\text { between } \\
\text { PLGA and } \\
\text { ACC }\end{array}$ \\
\hline CEA & $\begin{array}{l}\text { Glycol- } \\
\text { protein }\end{array}$ & $\begin{array}{l}\text { Functions in cell } \\
\text { adhesion; } \\
\text { biomarker for } \\
\text { colon cancer and } \\
\text { ovarian cancer }\end{array}$ & Variable & $\begin{array}{c}\text { CEA stains } \\
\text { positive in ACC, } \\
\text { but is decreased } \\
\text { and/or variable in } \\
\text { PLGA }\end{array}$ & Limited \\
\hline $\begin{array}{c}\text { SMA, } \\
\text { MSA, } \\
\text { galactin-3, } \\
\text { cyclin D1, } \\
\text { GFAP, } \\
\text { EMA }\end{array}$ & $\begin{array}{l}\text { Ubiquitous } \\
\text { proteins }\end{array}$ & $\begin{array}{c}\text { Found in } \\
\text { muscle and } \\
\text { non-muscle } \\
\text { cell tissues }\end{array}$ & $\begin{array}{c}\text { SMA: } \\
\text { decreased } \\
\text { MSA: } \\
\text { decreased } \\
\text { GFAP: } \\
\text { variable } \\
\text { EMA: } \\
\text { increased }\end{array}$ & $\begin{array}{l}\text { ACC: increased } \\
\text { expression of } \\
\text { SMA, galectin-3 } \\
\text { and cyclin D1 } \\
\text { versus PLGA }\end{array}$ & Limited \\
\hline $\begin{array}{c}\text { Maspin \& } \\
\text { MCM2 }\end{array}$ & $\begin{array}{c}\text { Maspin: } \\
\text { mammary } \\
\text { serin protease } \\
\text { inhibitor } \\
\text { MCM2: } \\
\text { Mini } \\
\text { chromosome } \\
\text { maintenance } \\
\text { proteins }\end{array}$ & $\begin{array}{c}\text { Maspin: } \\
\text { prevents apoptosis } \\
\text { and decreases cell } \\
\text { invasion } \\
\text { MCM2: } \\
\text { Marker for cell } \\
\text { proliferation due to } \\
\text { role in DNA } \\
\text { replication }\end{array}$ & Variable & $\begin{array}{c}\text { PLGA and ACC } \\
\text { variably stain for } \\
\text { maspin and } \\
\text { MCM2; ACC } \\
\text { increased cell } \\
\text { proliferation } \\
\text { profile vs PLGA }\end{array}$ & Limited \\
\hline
\end{tabular}




\subsubsection{Genetic studies in PLGA}

\subsection{Translocation, $t(11 ; 19)$}

Genetic translocation $\mathrm{t}(11 ; 19)$ has been identified in MEC and was not found to be present in PLGAs[30].

\subsection{Gene fusions}

\subsection{MYB-NFIB}

The MYB-NFIB gene fusion has been identified in ACC, and therefore, Persson et al. chose to investigate this fusion in PLGA[34]. Their 2011 study revealed the MYB-NFIB fusion was only present in 1 of 9 PLGA cases; they felt this highlighted the diagnostic difficulties in separating PLGA from ACC[34]. Ultimately, they concluded the PLGA genome was genetically stable[34].

\subsection{ARID1A-PRKD1 and DDX3X-PRKD1}

ARID1A and DDX3X encode proteins that are involved in DNA repair, and loss of their function would result in aberrant DNA repair[26]. Furthermore, ARID1A has already been identified to have a role in gynecologic malignancies[26]. The PRKD1 gene encodes a kinase protein, which has been implicated in a variety of malignant processes, including: colorectal, breast, esophageal, laryngeal, and others[26, 27, 37]. Moreover, PRDK1 kinases partake in signal transduction, trafficking, migration, differentiation and proliferation of cells, as well as cell adhesion[28, 37]. In 2014, Weinreb et al. searched for novel gene fusions in 2 cases of PLGA and 2 cases of CAMSG using next generation RNA sequencing[26]. Fusion ARID1A-PRKD1 was found in one CAMSG case, and a DDX3X-PRKD1 fusion was located in the other CAMSG case[26]. No fusions were found in the classic PLGA cases[26]. Weinreb et al. were able to conclude that recurrent genetic rearrangements of PRKD1-3 and specific gene fusions ARID1APRKD1 and DDX3X-PRKD1 are associated with PLGA, in particular the CAMSG variant[26].

\subsection{PRDK1 hotspot mutation}

In their 2014 multi-centre study, Weinreb et al. identified the PRDK1 hotspot mutation encoding p.Glu710Asp in PLGA[27]. By sequencing the genome of 3 PLGA cases, two heterozygous single nucleotide variants were found in the PRDK1 gene, resulting in the same amino acid substitution and consequential increased PRKD1 activity[27]. Subsequently, each PLGA in their tumour bank were examined for this mutation, and it was present in $72.9 \%$ of 
cases[27]. The hotspot mutation was significantly associated with metastasis-free survival and the group concluded it may offer a neoplastic advantage to PLGA tumour cells[27]. 


\subsection{Kallikreins (KLKs)}

Human kallikreins are secreted serine proteases, which demonstrate a range of physiologic and pathologic functions[49]. They are one of 178 human serine proteases, specifically belonging to the S1A subfamily[50]. Human kallikreins are divided into two categories: plasma kallikrein (KLKB1) and tissue kallikreins (KLK1-15)[51].

\subsubsection{Plasma Kallikrein}

KLKB1 is encoded by a single gene on chromosome 4q35, which consists of 15 exons and does not share similarities with the tissue kallikrein family[51, 52]. Mature plasma kallikrein functions as a major component of the plasma kallikrein-kinin system (KKS), releasing lysylbradykinin from high-molecular weight kininogen[53]. The KLKB1 gene consists of 15 exons and does not share similarities with the tissue kallikrein family[51, 52].

\subsubsection{Tissue Kallikreins}

\subsubsection{General Overview}

Human tissue kallikreins are a single family of 15 highly conserved trypsin and chymotrypsin-like serine proteases[54-56]. KLK1-15 are mapped to chromosomal locus 19q13.4 (Figure 2.1.2.1), which is the richest gene-containing chromosome, containing 261558 base pairs[50, 53, 57, 58]. Furthermore, KLKs are encoded by the largest contiguous cluster of proteaseencoding genes in the human genome, and uniquely, they are not interrupted by any other nonKLK genes[49, 50, 57, 59, 60]. KLK genes are arranged closely, with as little as $1.5 \mathrm{~kb}-32.5 \mathrm{~kb}$ between genes, and specific KLK gene lengths range from 4-10kb[50, 53]. The KLK tandem cluster of genes is flanked by the testicular acid phosphatase gene (ACPT) on the centromeric end and by the cancer associated gene (CAG), as well as Siglec-9 on the telomeric end[50].

KLK genes share many similar structural features including: exon and intron organization, conservation of intronic intervals, and exon lengths[60]. KLK gene transcripts code for a single chain serine protease pre-proenzyme of a fixed length, between 248 and 293 amino acids[50, 57]. The KLK genes and translated proteins share a high degree of homology; KLK proteins have an amino acid sequence homology of $\sim 40-80 \%$, with KLK2 and KLK3 having the highest degree of similarities[50]. A common characteristic of KLK proteins is their signal peptide motif (16-57AA), which conveys that all KLK proenzyme forms are to be secreted[50]. All KLKs have 10-12 cysteine residues, which are thought to form disulfide bones, important to maintain the correct conformation of the protein[50]. 
Figure 1.2.2.1 The human tissue kallikrein gene cluster. This figure was originally published in Journal of Biological Chemistry. Sotiropoulou G, Pampalakis G, Diamandis EP. Functional roles of human kallikrein-related peptidases. 2009; 284(48): 32989-94. The figure is being reproduced for educational purposes only and not for any commercial use. Figure is included in the M. Sc. dissertation with attribution.

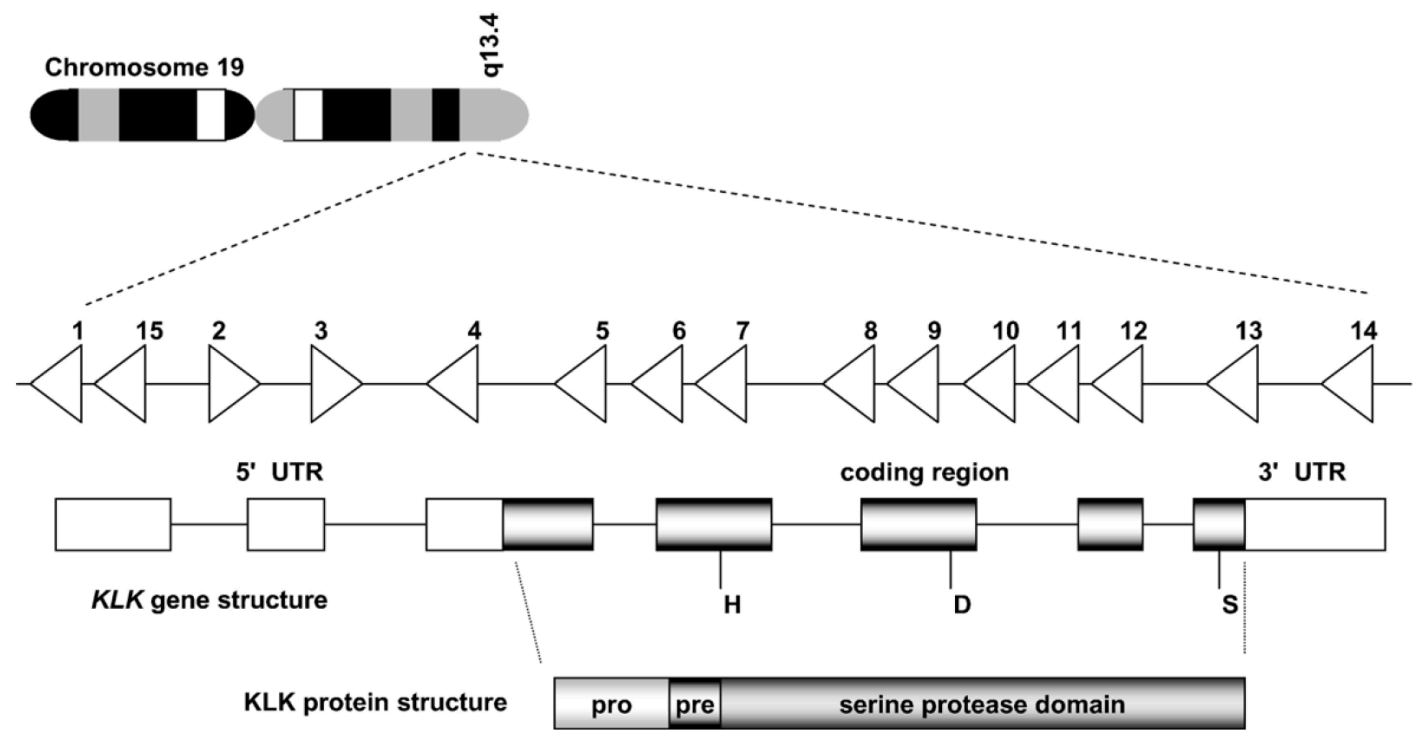


Ultimately, KLKs are secreted serine proteases with a diverse expression and many physiologic, as well as pathologic roles[49]. Moreover, KLKs are versatile signalling molecules[60]. While they demonstrate expression in a wide variety of tissues, KLKs are primarily expressed by secretory epithelial cells within glandular epithelia of many organs[49, 53, 56, 59].

\subsubsection{Historical Development}

The first kallikrein, KLK1, was identified in the 1930s by Kraut, Frey, and Werle[49]. The group termed the proteolytic enzyme "kallikreas", the Greek word for pancreas, due to its high pancreatic expression[ 49,61$]$. It wasn't until 40 years later that "prostate specific antigen", PSA, was discovered as an identification agent in semen by forensics scientists[49]. It was later renamed KLK3[62]. Initially, it was believed that KLK1-3 were the only members of the KLK family; but in the late 1990s, 12 novel KLK genes were discovered through examination of the whole genetic locus[49,53]. Several groups reported other genes mapping to 19q13.4, and ultimately, all 15 KLK members were cloned[53]. KLK15 was the last member to be cloned, and this was completed in 2001[49, 53]. A detailed map of the KLK gene locus was created by Borgono and Diamandis in 2004[57, 63, 64].

Anecdotally, kallikreins were divided up into classical and non-classical groups[57]. KLK1-3 were denoted as classical, as these were the first members of the KLK family discovered[53]. The non-classical group contains KLK4-15, as they were identified at a later date[57, 63].

With significant advancements in the development of the kallikrein genetic family, a comprehensive nomenclature system was proposed in a 2006 review by Lundwall et al[61]. KLK1 was the only KLK gene to retain the "kallikrein" name, denoted as kallikrein 1[63]. However, as the remaining proteins in the KLK family do not display kininogenase activity, KLK2-15 were termed "kallikrein-related peptidases", followed by their genetic number symbol[61, 63]. For example, KLK2 was re-named kallikrein-related peptidase 2[61]. This classification system also differentiates between gene and protein denotation; genes are written in italicized text (e.g. $K L K 1$ ), whereas proteins are written in standard text (e.g. KLK1)[61].

\subsubsection{Kallikreins as proteases at the genomic, mRNA, and protein level}

Kallikreins are serine proteases, specifically belonging to the S1A subfamily of serine proteases[50]. They may display trypsin or chymotrypsin-like activity, or both[54, 65]. KLKs share characteristic features, some of which overlap with all serine proteases, and those that are 
unique to the KLK family. KLKs demonstrate invariant residues, they have an active site catalytic triad $\left(\mathrm{His}^{57}, \mathrm{Asp}^{102}, \mathrm{Ser}^{195}\right)$, and a conserved Gly, which stabilizes the peptide bond during hydrolysis[57]. Unique features of the KLK family were well documented by Yousef and Diamandis in their 2002 comprehensive review of KLKs as cancer biomarkers. These include: i) KLK genes are formed by 5 codons, with the first codon always containing a 5' untranslated region, followed by a methionine start codon about 50bp away from the previous exon, and lastly, a stop codon about $156 \mathrm{bp}$ away from the beginning of the last coding exon; ii) the catalytic triad $\left(\mathrm{His}^{57}, \mathrm{Asp}^{102}, \mathrm{Ser}^{195}\right)$ is conserved, histidine is always placed at the end of the second coding exon, the aspartate is in the middle of the third coding exon, and the serine at the beginning of the fifth coding exon; iii) the substrate binding pocket amino acid is either aspartate, representing trypsinlike specificity (KLK1,2,4,5,6,8,10,11,12,13,14,15), or it is another amino acid, representing chymotrypsin activity (KLK3,7,9) or other activity; iv) KLK proteins contain 10-12 cysteine residues, with conserved positioning, forming 5-6 disulfide bonds; v) KLKs are under steroid hormone control[51, 53, 66].

Many KLK genes exhibit copy number variations, which result from the use of alternative and multiple promotors, based on their 5'untranslated regions[60, 67]. Furthermore, the 15 transcripts from the KLK genes may be alternatively spliced, producing many different mRNA variants, thought to encode truncated proteins[49-51, 53]. The most common alternative splicing events are skipped exons and exon extension, with exon truncation and intron retention succeeding[49]. KLK3 is known to have at least 10 distinct mRNA variations, resulting from alternative splicing[49]. Following an alternative splicing event, the mRNA variant may be translated into functionally distinct proteins[49]. For example, KLK7 demonstrates mRNA variants with different patterns of tissue localization[67]. Furthermore, these variants may have roles in pathologic disease, and malignancies, as the consequential protein may have additional functional roles, may lack classic KLK properties, or may be rendered non-functional[49]. It has been stated that the product of alternative splicing most often encodes inactive KLK isoforms[60].

The involvement of serine proteases in cascade pathways has been well established; substrates of serine proteases are often other serine proteases, which are activated from their inactive form, into an active protein[53]. An example is the coagulation cascade. Similarly, kallikreins are thought to participate in a variety of complex proteolytic cascade pathways, involved in the regulation of physiologic and pathologic processes[54]. These include: semen 
liquefaction, skin desquamation, neurodegeneration and tumour promoting or inhibiting effects[49]. The hypothesis that KLKs participate in proteolytic cascades is supported by the coexpression of numerous kallikreins in the same tissue, and the evidence that some kallikreins activate each other[53]. For example, KLK3 can be activated by KLK15 and KLK4 has been shown to activate KLK3[53]. Furthermore, KLKs may participate in proteolytic cascades that involve nonkallikrein serine proteases; KLK3 can inactivate the $\mathrm{N}$ terminal fragment of the parathyroid hormone related protein[53].

\subsubsection{Activation of tissue kallikreins}

The activation of KLK enzymes occurs through a complex proteolytic cleaving process, a cascade referred to as the "KLK Activome" (Figure 2.1.2.2)[60]. Coordinated activation occurs through this complex network and results in the activation of KLK enzymes that go on to regulate normal and pathological processes[60]. As noted above, KLK genes are transcribed into a pre-proenzyme, which is a zymogen, as it is inactive in this form; this is single chained and of fixed AA length[57]. This pre-pro-enzyme goes on to be proteolytically processed to an enzymatically inactive pro-KLK, and these are secreted into the extracellular space by cleaving an aminoterminal signal peptide[57]. Ultimately, the pro-KLK is activated to a mature peptidase extracellularly by cleaving the amino-terminal propeptide[51, 60]. KLKs may be auto-activated, activated by another KLK, or activated by a different protease altogether[57, 63]. Proteases implicated in the activation of KLKs include matrix metallopeptidases and the proteases of the thrombostasis axis[59].

\subsubsection{Regulation of kallikreins}

The regulation of kallikreins occurs at various levels of their processing and activation into functional proteases. This includes transcriptional, post-transcriptional and/or post-translational levels, and therefore, resultant aberrations in their expression are seen with dysregulation at any of these steps[60]. Kallikreins show differential expression, which may be tissue dependent, and while some regulatory factors are unknown, others have been well studied[53, 66].

At the transcription level, steroid hormones are considered to be the primary regulatory mechanism of KLK gene expression[51, 64, 68]. Moreover, epigenetic mechanisms, specifically DNA methylation is also thought to have an important role in KLK transcription[60].

It has been well established that in endocrine tissues (e.g. breast, prostate, ovarian tissues), all KLK expression is regulated by specific hormones including: androgens, estrogens, progestins, 
Figure 1.2.2.2 KLK Activome and regulatory KLK cascades in normal physiology and disease. This figure was originally published in Biochimica et Biophysica Acta (BBA)-Reviews on Cancer. Pampalakis G, Sotiropoulou G. Tissue kallikrein proteolytic cascade pathways in normal physiology and cancer. 2007; 1776 (1):22-31. The figure is being reproduced for educational purposes only and not for any commercial use. Figure is included in the M. Sc. Dissertation with attribution.

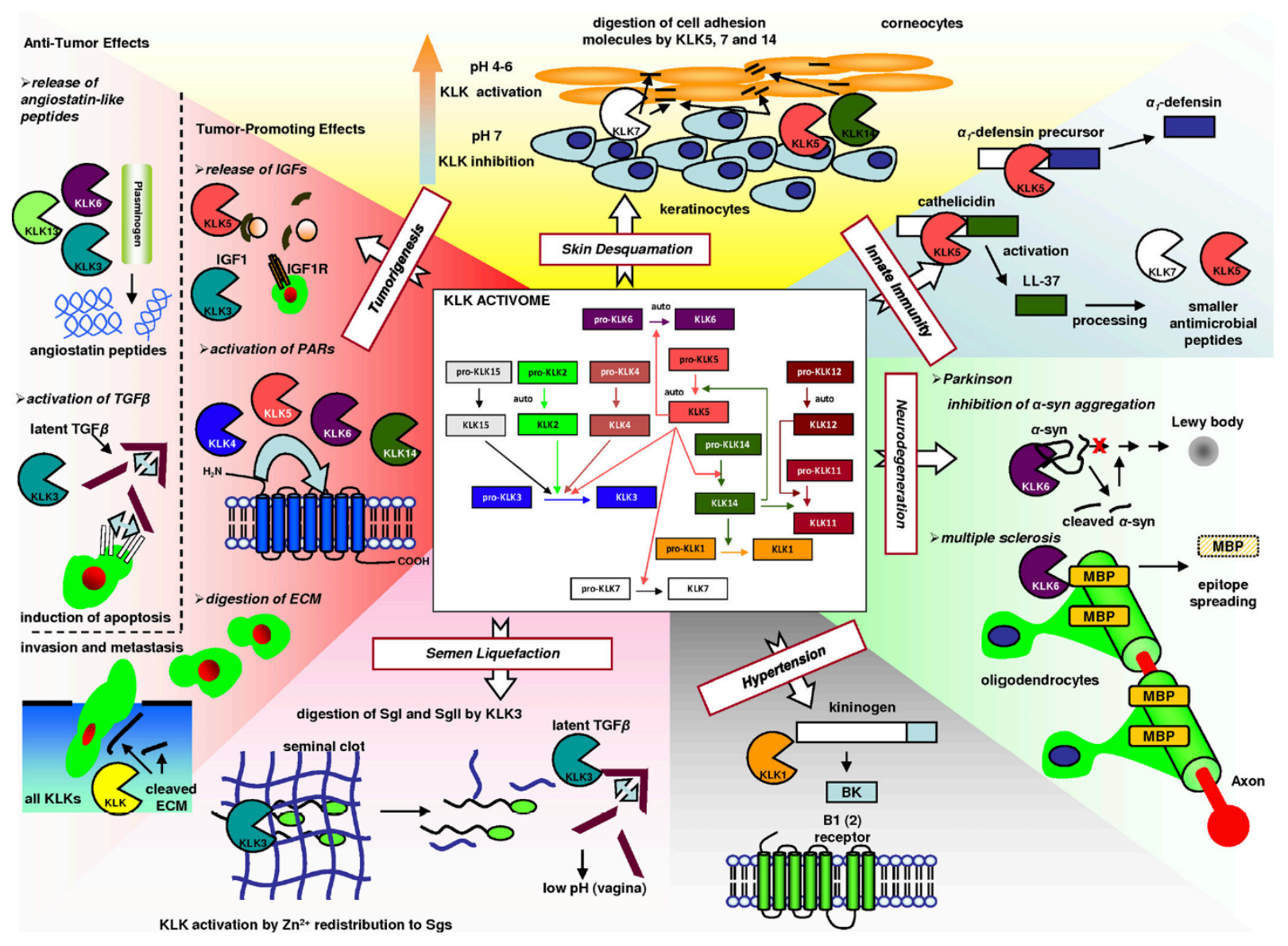


glucocorticoids, and mineralcorticoids[56, 66, 69]. This is mediated directly by nuclear receptors, which bind ligands, translocate to the nucleus and bind to cis-acting DNA sequences, known as hormone response elements (HRE)[69]. These are found in the promoter/enhancer regions of many KLK genes, including KLK2 and KLK3, and transcription is stimulated[66]. Indirect modulation of transcription does not involve HRE, rather it involves a hormone-receptor complex interacting with various transcriptional factors, resulting in trans-transcription[69].

Of note, the centromeric and telomeric KLK groups, KLK1-4 and KLK13-15 respectively, are primarily upregulated by androgens, and the central KLK group (KLK5-12) is primarily upregulated by estrogens[53]. Interestingly, the same KLK gene may be upregulated by two separate hormones, in site-specific tissue; in prostate and breast cancer cell lines, KLK4 is upregulated by androgens, whereas in endometrial cell lines, it is upregulated by estrogens[53, 69]. An exception is found in KLK1, which does not demonstrate hormone control in various tissues, specifically uterine, renal, and salivary gland tissues[50].

Vitamin D signalling has also been well established as a transcriptional regulatory mechanism of KLK expression[60]. Vitamin D3 upregulates KLK6 in various cancer cell lines, including: head and neck, prostate, colon[66]. In normal keratinocytes, vitamin D3 has demonstrated regulatory control over KLK10, in addition to KLK6, and thus, they have both been implicated in skin carcinogenesis[55, 66].

Retinoic acid also contributes to the regulation of KLK genes. This may be accomplished through a retinoic response element alone, or in combination with a series of receptors[66]. Retinoic acid demonstrates differential regulation of kallikreins; KLK10 is upregulated in breast cancer cells; however, KLK2 and KLK3 is downregulated in prostate cancer cells[66].

Epigenetic mechanisms demonstrate transcriptional regulation of KLK gene expression. DNA methylation modifications may silence certain KLK genes in cancer processes[60]. For example, hypermethylation is thought to silence KLK10 in both ovarian and prostate cancer[69, 70]. Furthermore, DNA methylation of the KLK genome has been shown in the aberrant KLK expression in acute lymphoblastic leukemia (ALL), prostate and breast cancer cells[51]. In ALL and breast cancer, hypermethylation of exon 3 significantly down regulates KLK10[69].

A body of evidence suggests there is post-transcriptional regulation of KLKs by microRNAs (miRNAs), which are small non-coding RNAs that regulate gene expression[70]. 
These miRNAs function by partially annealing to their target RNA sequence, and decreasing protein translation via an RNA-induced silencing complex (RISC)[70]. It has been observed that one miRNA may target several KLK regions, therefore, may control multiple KLK proteins simultaneously, silencing translation[70].

Another element of KLK regulation is at the post-translational level. Protease activation is an irreversible process and therefore, the regulation of proteolytic cascades is tightly controlled[58, 64]. Several mechanisms have been implicated in the prevention of unwanted enzymatic degradation of proteins, which include: zymogen activation, internal cleavage, and endogenous inhibitors[64, 69]. Zymogen activation has been described previously, and occurs through a diverse proteolytic cleavage cascade[69]. It should be noted that all pro-KLKs, with the exception of KLK4, require the activity of trypsin-like serine protease for activation, and these include: trypsin, enterokinase, trypsin-like KLKs, and auto-activation[69]. Internal cleavage has been noted as a mechanism of inactivation in 6 of the 15 mature KLKs; cleavage occurs at the activate protease either by autolysis or alternative proteases, resulting in degradation of the KLK protein[69]. Endogenous inhibitors known to regulate serine proteases, such as KLKs, include: serpins and alpha-2 macroglobulin, both plasma inhibitors[69]. Serpins interact with KLKs in complex pathways to deform and inactivate serine protease, whereas alpha-2 macroglobulin prevents other proteases from binding the KLK by steric hindrance[69]. Microenvironments contribute to KLK activity regulation, including the presence of certain ions and the $\mathrm{pH}$ of the tissues[58]. High concentration of $\mathrm{Zn}$ ions in prostate tissue inhibits enzymatic activity of many KLKs, whereas lower $\mathrm{Zn}$ ion concentrations are found in prostate cancer, contributing to higher KLK activity[51].

\subsubsection{Physiologic function of kallikreins}

KLKs are expressed in a wide variety of tissues in the body, including, but not limited to pancreas, heart, lung, CNS, salivary glands, thyroid, breast, testis, ovaries and prostate[53, 56, 57, 71]. An exhaustive list of tissues expressing KLKs is presented in Figure 2.1.2.3, adapted from Yousef and Diamandis' 2001 review of KLKs[71]. Notably, it also demonstrates that KLKs may be co-expressed in normal tissues, but that this expression occurs at different levels[60, 71]. The physiologic roles of KLKs have been best established for KLK1-3[53]. Physiologic processes that KLKs are involved in include: tissue kallikrein-kinin system, skin desquamation, innate immunity, semen liquefaction, enamelogenesis, and degradation/remodeling of the extracellular matrix 
(ECM) $[53,55]$. Additionally, KLKs help regulate blood pressure, and are involved in electrolyte balance in ECM remodeling, prohormone processing, and neural plasticity[49].

KLK1

The highest expression of KLK1 is found in the pancreas, kidney, and salivary glands; it has also been found in sweat glands, pituitary gland, intestines, uterus, prostate, testis, breast, placenta, and neutrophils[50, 71]. The primary function of KLK1 is its involvement in the tissue KKS as a kininogenase enzyme, releasing lysyl-bradykinin from low-molecular weight kininogen[53]. It is also known to cleave pro-insulin, pro-renin, LDL, the precursor for atrial natriuretic factor, vasoactive intestinal peptide, procollagenase, and angiotensinogen[50].

KLK2

KLK2 shows highest expression in the prostate, and is also found in breast, salivary gland, and thyroid tissue[71]. It plays a role in seminal plasma liquefaction; however, it is a smaller role than that of KLK3[53, 57].

\section{$K L K 3$}

The prostate is where KLK3 is most highly expressed, but it is also found in breast, thyroid, tracheal, and lung tissues[71]. KLK3 has been found in several fluids apart from its high concentration in semen, including breast cyst fluid, nipple fluid, milk of lactating women, and amniotic fluid[53]. KLK3 has a primary role in seminal plasma liquefaction, and through hydrolysis, liquefies the seminal plasma clot after ejaculation[53, 57].

\section{KLK4}

The highest expression of KLK4 is found in the prostate; it has also been found in breast, thyroid, testis, uterine, adrenal, colon, and spinal cord tissues[71]. Furthermore, KLK4 is thought to have a primary role in the biologic function of enamel maturation and tooth development[50]. Specifically, KLK4 degrades enamelin to allow for apatite growth[50].

\section{KLK5}

The highest expression of KLK5 is found in breast, brain, testicular, and skin tissues; it has also been found in salivary glands, thymus, CNS, prostate, thyroid, esophageal and tracheal tissues[71, 72]. KLK5 takes part in the skin desquamation proteolytic cascade in the stratum corneum, along with KLK7[57, 68]. It also has a role in seminal plasma liquefaction[57]. 
KLK6

The highest expression of KLK6 is found in CNS, breast, renal and uterine tissue; it has also been found in salivary glands, the spleen, heart, thymus, prostate, liver, thyroid, placenta, trachea and testis[71, 73]. KLK6 is secreted by oligodendrocytes and plays a primary role in remyelination and in maintaining a normal myelinated state[74].

\section{KLK7}

The highest expression of KLK7 is found in skin, CNS, renal and breast tissues; it has also been found in salivary glands, thymus, uterus, thyroid, placenta, trachea, testis and ovaries[71]. Others have reported high expression in normal cervix, ovaries, testes, esophagus, stomach and low expression in normal colon[68]. KLK7 has shown strong staining patterns for NSGT[67]. KLK7 has a significant role in skin desquamation, and demonstrates co-expression with other KLKs in this proteolytic function[57, 68]. KLK5 and KLK7 function to degrade corneodesmosomes, which interconnect the stratum corneum; this degradation is a pre-requisite for skin desquamation[68]. Furthermore, KLK7 is co-expressed with KLK14 for additional skin desquamation activity[55].

\section{$K L K 8$}

The highest expression of KLK8 is found in CNS, skin and ovarian tissues; it has also been found in esophagus, testis, tonsillar, renal, breast, and salivary gland tissue[54, 71]. KLK8 has been demonstrated in a number of bodily fluids: breast milk, amniotic fluid, seminal fluid, and serum[54].

\section{KLK9}

The highest expression of KLK9 is found in the thymus, testis, CNS and trachea; is has also been found in breast, prostate, salivary glands, ovaries and skin[71].

\section{KLK10}

The highest expression of KLK10 is found in breast, ovarian, testicular, and prostate tissues; it has also been found in the small intestine, lung, colon, pancreas, uterus, CNS, salivary glands and trachea[71]. KLK10 has demonstrated high expression in the islets of Langerhans in the pancreas, and may have a role in regulation of insulin, glucagons, somatostatin, and pancreatic polypeptide[55]. KLK10 also participates in the proteolytic process of skin desquamation, which may be mediated through the processing of desmoglein1 (DSG1)[55]. 


\section{KLK11}

The highest expression of KLK11 is found in brain, skin, salivary gland, stomach, uterus, lung, thymus, prostate, spleen, liver, small intestine, and trachea; it has also been found in the heart, fetal liver, breast, thyroid, and skeletal muscle[71].

\section{KLK 12}

The highest expression of KLK12 is found in salivary glands, stomach, uterus, trachea, prostate, thymus, lung, colon, brain, breast, and thyroid; it has also been found in testis, pancreas, small intestine, and spinal cord[71].

\section{KLK 13}

The highest expression of KLK13 is found in breast, prostate, salivary glands, and testis; it has also been found in the lung, heart, adrenal, colon, thyroid, and tracheal tissues[71]. Along with KLK10, KLK13 has demonstrated high expression in the islets of Langerhans in the pancreas, and may have a role in regulation of insulin, glucagons, somatostatin, and pancreatic polypeptide[55].

\section{KLK14}

The highest expression of KLK14 is found in the CNS; it has also been found in breast, thyroid, uterus, thymus, colon, spleen, placenta, small intestine, kidney and bone marrow tissues[71]. Others have reported high expression in normal brain tissue, along with prostate, testis, and thymus, with low expression in normal colon tissues[68]. Moderate immunohistochemical staining with KLK14 has been seen in salivary gland tissue[75]. KLK14 is involved in skin desquamation, and as noted previously, demonstrates co-expression with KLK7 in this proteolytic activity[57]. Moreover, KLK14 is thought to contribute to the hemostasis of seminal plasma[68].

\section{KLK 15}

The highest expression of KLK15 is found in the thyroid, salivary glands, and prostate; it has also been found in adrenal, colon, testicular, and renal tissues[71]. 
Figure 1.2.2.3 KLK expression in human tissues. This figure was originally published in Endocrinology Reviews. Yousef GM, Diamandis EP. The new human tissue kallikrein gene family: structure, function, and association to disease. 2001;22(2): 184-204. The figure is being reproduced for educational purposes only and not for any commercial use. Figure is included in the M. Sc. Dissertation with attribution.

FIG. 5. Schematic representation of tissue kallikrein expression in various tissues. Higher level of expression is shown in bold. For more information and discussion, see text and Table 6 .

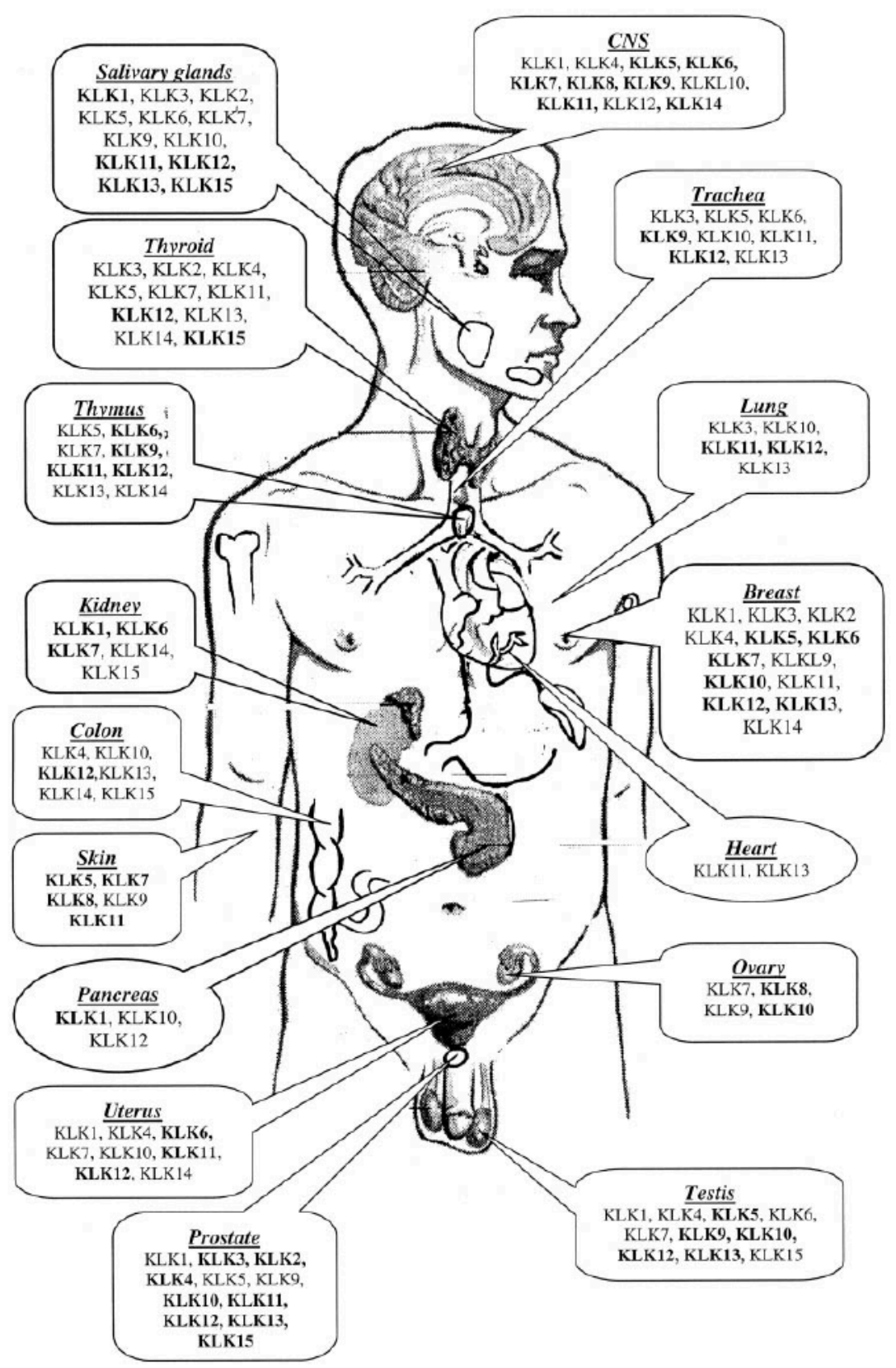




\subsubsection{Kallikreins in pathologic states}

Dysregulation of KLK expression leads to various pathologic states and aberrant regulation of KLKs has been implicated in a variety of diseases. This includes hypertension, renal disease, skin disorders, inflammation, neurodegenerative disease, and cancer[57, 60]. As demonstrated previously, KLKs show co-expression in physiologic states, as such, when KLKs are dysregulated, the co-expressed KLKs are coordinated[55].

Specific kallikreins have been implicated in certain diseased states. The aberrant regulation of KLK1 is associated with skin abnormalities[50]. KLK7 dysregulation has been implicated in chronic itchy dermatitis, psoriasis, and atopic dermatitis[50]. KLK8 has notable upregulation in conditions with hyperkeratotic features, such as seborrheic keratosis, psoriasis vulgaris, lichen planus, and squamous cell carcinoma, as compared to normal skin tissue, where minimal KLK8 is localized[50]. Aberrant expression of KLK14 results in pathologic skin conditions like atopic dermatitis, acute eczematous atopic skin[68].

KLK6 has been suggested as a potential biomarker for Alzheimer's disease, as decrease levels of KLK6 in CSF have been observed in Alzheimer's patients, and therefore, it has been suggested as a risk factor for this disease[50, 60]. KLK8 has been noted to be upregulated in the hippocampus of patients with Alzheimer's disease[50]. KLK10 upregulation, along with KLK7 co-expression and upregulation, has been linked with Alzheimer's disease[50, 55]. Additionally, KLK6 dysregulation has been implicated in Parkinson's disease[50]. KLK6, KLK7, and KLK10 expression has been demonstrably lower in patients with frontotemporal dementia[50].

Many KLKs demonstrate aberrant expression in malignant pathologic processes, and as such, this will be discussed in a separate section.

\subsubsection{Kallikreins and malignancy}

KLKs have been shown to be aberrantly regulated in almost all human solid tumours, and in particular, dysregulation of KLKs in steroid-dependent cancers (e.g. breast, prostate, ovarian) has been well documented[58, 76].

KLKs 1,3,5-10, and 12-15 have demonstrated aberrant expression in breast cancer cells[50, $58,64]$. KLK6 becomes downregulated in metastatic breast cancer cells, when compared to primary breast cancer cells and normal breast tissue[73]. KLK7 is downregulated in breast cancer tissue; however, contradictory reports are found in the literature[67, 68, 77]. KLK10 and 12 are 
associated with breast cancer, and demonstrate downregulation[53, 55]. KLK13 is downregulated in a subset of breast carcinoma[53]. KLK14 is over expressed in breast cancer cells[68].

KLKs 2-11, and 13-15 have been found aberrantly expressed in ovarian cancer cells[58, 64]. For example, KLK4 is expressed in ovarian cancer, but it not seen in normal ovarian tissue[50]. KLK5 demonstrates higher expression in late stage serous ovarian carcinoma[73]. KLK6, 7, 8, 13 and 14 demonstrate over-expression in ovarian cancer[53, 67, 68, 76, 77].

KLKs 2-6, 10,11, and 13-15 have demonstrated dysregulation in prostate cancer[58, 64]. In prostate cancer, serum levels of KLK3 may be dramatically increased; KLK3 expression is primarily confined to the glandular ducts and when glandular architecture is lost in malignancy, it is postulated KLK3 is released into the blood stream[56]. In the prostate tumour cells, KLK3 expression is downregulated[64]. KLK7 is downregulated in prostate cancer cells[68, 77]. KLK14 is expressed in prostate cancer to a similar degree that KLK2 and 3 are over-expressed[68, 75].

In lung adenocarcinoma, KLK5, 7 and 8 antibody staining was positive in the nucleus of the tumour cells $[67,75]$. KLK5 is relatively downregulated in testicular cancer, when compared to high levels of KLK5 expression in normal testis[53, 72]. KLK7 is upregulated in cervical, colon, intracranial, oral squamous cell and pancreatic cancer cells, and down regulated in melanoma and kidney cancer cells[67, 68,77]. KLK10 is upregulated in colon cancer cells, with advanced colorectal tumours demonstrated high KLK10 expression[55, 63]. Dysregulation of KLK10 has been linked with testicular cancer, and along with co-expression of KLK6, skin carcinomas[55]. KLK14 has also been demonstrably upregulated in salivary gland malignancies[68].

Aberrant KLK expression has been implicated in various malignant pathological processes, and various stages of cancer development[68]. KLKs have been postulated to maintain a dual role as both stimulatory and inhibitory factors that modulate tumour behaviour[67]. Furthermore, KLK dysregulation can promote carcinogenesis or inhibit cancer activities, and this may be tumour-site specific[55]. Experimental evidence has demonstrated that KLKs may influence malignant growth potential, angiogenesis, tumour invasion and metastasis via proteolytic cascades[55, 75]. Specifically, the proteolytic processing of growth factor-binding proteins, activation of growth factors and other proteases, releasing angiogenic or anti-angiogenic factors, and the degradation of ECM components may promote tumorgenesis[55, 75].

Specific KLKs have been implicated in tumour progression. KLKs 1-4,6,7, 13 and 15 function in ECM degradation, and angiogenesis, ultimately contributing to tumour invasion and 
metastasis[64, 76]. More specifically, KLK7 is known to degrade ECM components in pancreatic cancer cells, thereby promoting metastasis; fibronectin is degraded, which leads to tumorgenesis and desmosomal proteins are degraded, decreasing cell adhesion and promoting tumour invasion[67, 68]. KLK7 role in tumour invasion and progression has been suggested, as in prostate cancer cells, the protease induces epithelial to mesenchymal transition[68]. KLKs 1-3 are involved in tumour growth regulation via their actions on insulin growth factors[64]. KLK14, which is produced by colon tumour cells, has been shown to activate proteinase-activating receptors (PARs), contributing to tumorgenesis[68]. Interestingly, KLK3, 6, and 13 also show antiangiogenic properties[64].

\subsubsection{Kallikreins and salivary gland neoplasia}

The association between kallikreins and salivary gland tissue has been well established. Multiple KLKs have been found in NSGT, including KLK1,2,9,10,13; moreover, most KLKs have been detected in salivary gland tissues by RT-PCR and other methodology[73, 76]. Some KLKs have demonstrated high expression in NSGT, which may indicate an active KLK proteolytic cascade in these tissues[67].

A summary of the findings to date on KLKs in salivary gland benign and malignant neoplasia will now be presented. KLK3 has been found via in-situ hybridization in NSGT; however, this finding was not corroborated by Darling et al., who concluded KLK3 was not expressed in salivary gland tumours[72]. KLK5 is not expressed in NSGT; scant positive IHC staining has been seen for PA, ACC, ANOS, MEC, but none was deemed significant[72]. KLK6 is expressed in salivary gland tumours; however, it is downregulated as compared with NSGT and the IHC staining demonstrated in tumour cells is non-specific[73, 76]. KLK7 has been detected in NSGT, and has been associated with salivary gland neoplasms, including: PA, ACC, MEC[67]. Significantly higher staining with KLK7 antibody has been seen in PA and ACC, as compared with MEC, which demonstrated both ductal and non-ductal staining, but was akin to NSGT stain levels[67]. This finding suggests KLK7 may have a role in myoepithelial differentiation[67]. Moreover, the expression of KLK7 in both NSGT and tumour tissue is similar to KLK14, which suggests possible cascade effect leading to tumorgenesis[67]. Nuclear staining in salivary gland tumours has also been seen with KLK7 antibodies[67]. Interestingly, the level of KLK7 expression has not shown any association with tumour stage, grade, site of tumour, or patient demographics[67]. KLK8 has been detected in NSGT, and high levels of expression are seen in 
most salivary gland tumours[54]. Darling et al. found KLK8 antibody staining was significantly higher in ductal cells of NSGT and significantly higher in salivary gland malignancies[54]. KLK10 demonstrates strong expression in NSGT, and staining of malignancies with KLK10 antibody is not significantly different; however, PA demonstrates significantly lower expression than NSGT[55]. At the cellular stain level, KLK10 shows higher intensity staining in serous acinar cells, and equivalent mucous acinar and ductal cell staining, when compared to NSGT[55]. KLK13 has been linked to NSGT; PA shows lower KLK13 staining comparatively, whereas PLGA, ACC, ANOS stains significantly higher for KLK13 than NSGT[76]. Furthermore, KLK13 staining has been documented as higher in MEC and ACI (acinic cell), yet it is not significant[76]. KLK14 expression has been noted in NSGT, with over-expression noted in PA (statistically significant) and ACC, and decreased expression in MEC[75]. Furthermore, nuclear specific staining has been associated with KLK14 in salivary gland tumours[75]. Of interest, Darling et al. showed a correlation between KLK7, 10, and 14 expression in ACC[55].

To the authors knowledge, KLK expression has only been studied in PLGA by Darling et al., who examined the expression of KLK13 in 13 samples of PLGA[76]. They found KLK13 stained greater in malignant salivary gland tumours, than benign salivary gland tumours and normal salivary gland tissue[76].

\subsubsection{Kallikreins as biomarkers}

Biomarkers have been widely adopted in medicine for the detection and measuring of biologic or disease states[78]. Biomarkers objectively measure substances, structures or processes in the body that influence or predict the incidence of outcome or disease[78]. Biomarkers have the potential to be used clinically in the diagnosis, prognosis, and recurrence of disease, with the goal of reducing mortality[78]. Ideally, a tumour biomarker would have the following characteristics: (1) expression in the pre-malignant or early malignant stage of the disease, (2) expressed in all patients with the specific malignancy at detectable levels, (3) accessible and non-invasive, (4) the quantity of expression equating to tumour bulk, clinical behaviour, or disease progression, (5) demonstrates a relatively short-half live to yield changes when disease in remission and/or to monitor disease progression, (6) measurable with a standardized, reproducible, and valid objective and quantitative assay[79]. Ultimately, biomarkers which are used for diagnostic and prognostic purposes, as well as for drug targeted therapies, would ideally be both highly specific and 
sensitive[80]. Biomarkers may be categorized into pharmacodynamic, prognostic, or predictive[80].

Kallikreins have emerged as powerful tumour markers[57]. The most well-known biomarker is KLK3, also known as prostate specific antigen (PSA), and it has been regarded as the most valuable biomarker in clinical practice for prostate cancer diagnosis and monitoring of high risk populations $[49,57,60,76]$. A serum PSA test indicates a measurement of the "total" immunereactive concentration of PSA in serum or plasma[56]. Implemented since the late 1980s, the PSA test, along with improved prostate cancer treatments, has contributed to a decrease age-adjusted death rate from prostate cancer of $40 \%$ in the United States[56]. The PSA test was validated by two high-quality European randomized controlled trials in the 1990s, demonstrating significant reduction in mortality in prostate cancer by screening men 55-69 years every two to four years and men 50-64 every two years[56]. Controversy over the widespread use of PSA screening arose with the U.S. trial, "Prostate, Lung, Colorectal, and Ovarian Cancer Screening Trial (PLCO)", as it concluded there was no statistically significant different in prostate-specific mortality risk between those screened and those who were not[56].

Much controversy continues to exist on routine PSA screening, and pros and cons for PSA testing have been put forth. The potential benefits from PSA testing may include detection of disease prior to metastatic spread, earlier detection leading to more treatable disease and overall mortality reduction from prostate cancer; other benefits include the potential to diagnose benign prostatic hyperplasia (BPH)[56, 81]. Limitations of PSA screening include its lack of specificity, as many biologic conditions can cause an increase in PSA levels, such as BPH, increased age, prostatitis, and transient increase of PSA with ejaculation[81]. Obese men often demonstrate lower PSA levels, and certain drugs may also affect PSA levels (e.g. 5-alpha-reductase inhibitors)[81]. The PSA assay is not diagnostic alone, and if malignancy is suspected, additional tests will be required (e.g. tissue biopsy); moreover, a single PSA test will not provide information on the aggressiveness of disease. Harmful outcomes from the use of PSA include detecting prostate cancer which would not have become clinically significant in the patient's lifetime, and therefore put the patient through treatment they may not have required[81]. If the PSA is not elevated, this may provide false reassurance to the patient, as disease could still be present[81]. There is also potential for false-positives, leading to unnecessary biopsies with accompanying serious 
complications, over diagnosis, unneeded treatment with potential harmful sequelae (e.g impotence), and considerable anxiety[56, 81].

This significant argument both for and against the routine use of PSA testing continues to be controversial and in 2012, the United States Preventative Services Task Force recommended against PSA screening; however, the American Urological Association (AUA) and the American Cancer Society (ACS) continue to recommend PSA testing[82]. In an effort to increase the specificity of PSA testing, logistic regression models that use the ratio of KLK2 to free PSA and the ratio of free PSA to total PSA have been useful in differentiating between BPH and prostate cancer[83].

Additional KLKs have been suggested as possible biomarkers in prostate cancer. KLK5 and KLK11 have been shown to be favourable prognostic markers in prostate cancer; KLK15 has been noted as an unfavourable prognostic marker[50,53].

KLKs have also been put forth as potential biomarkers for a variety of other malignancies. In ovarian cancer, KLK4-7, 10, 11, and 15 have all shown to be markers of unfavourable prognosis $[50,53,72,75]$. KLK4 has been determined to be an independent indicator of poor prognosis in grade 1 and 2 ovarian tumours[50]. KLK7 has contradictorily been noted as both a favourable and unfavourable marker of prognosis; Dorn et al. reported that patients with high expression of KLK7 had significantly two-fold lower risk of death, and that KLK7 was significantly associated with overall and disease free survival[77]. KLK8,9,13, and 14 have been linked as favourable prognostication factors in ovarian cancer[50, 53]. KLK8 and KLK13 are upregulated in ovarian tumours and it's higher expression has been found to be favourable[76]. Devetzi et al. concluded that KLK5, 11 and 14 are markers for ovarian cancer diagnosis, KLK6,8 and 10 are markers for ovarian cancer diagnosis, prognosis and monitoring of disease[68].

In breast cancer, KLK5,7,10 and 14 have all shown to be markers of unfavourable prognosis[50, 53, 72]. KLK10 and 14, while noted as poor prognostic factors, have also been demonstrably downregulated[50]. KLK10 was also found to be a predictor of invasiveness in ductal breast carcinoma[53]. In contrast, while it is noted to be unfavourable above, KLK7 has also been reported as a favourable prognostic marker in breast cancer[67]. Additional favourable prognostic markers include: KLK15[50, 53].

In colon cancer, KLK7, 10, and 14 have been shown as markers of unfavourable prognosis[55, 68]. Specifically, KLK7 has been implicated as an unfavourable marker for overall 
survival in colorectal cancer[68]. KLK10 and KLK14 are upregulated in colon cancer cells, and high expression of these proteases is seen in advance colorectal tumours, with higher KLK10 and KLK14 expression associated with decreased disease-free survival and overall survival rates[55, 63, 68]. Lastly, in pancreatic ductal adenocarcinoma, KLK6 and 10 are co-expression and noted to confer a poor prognosis[55].

KLKs may also prove useful as potential targets for therapy and monitoring disease progression. PSA is once again an example of this, as there has been significant work on PSA targeted drug therapy, and sequential PSA testing is considered valuable post prostate cancer treatment, as a rising level often indicates recurrence[81]. Furthermore, KLK4 has been shown to be a protein marker for resistance to paclitaxel therapy in the treatment of ovarian cancer[50]. In ovarian cancer, KLK7 may be useful in predicting surgical success outcomes, and may also have value in assessing response to chemotherapy and/or the overall and disease-free survival[77].

To date, no KLK has been used as a biomarker in salivary gland malignancies. However, as most KLKs have been detected in salivary glands, this lends them to being useful as biomarkers of salivary gland malignancy, with potential to aid in diagnosis, prognosis and monitoring of disease[73]. 


\subsection{Hypothesis, Rationale and Aims}

\subsubsection{Hypothesis}

In this study, we hypothesize that human tissue kallikreins (KLK) are aberrantly expressed in polymorphous low-grade adenocarcinoma (PLGA), as compared to normal salivary gland tissue (NSGT). We further hypothesized that KLK expression, whether increased or decreased, may be demonstrated specifically in tumour cells.

\subsubsection{Rationale}

The diagnosis of PLGA, the second most common malignant salivary gland tumour of the minor glands, can often be challenging. This may be attributed to its various histologic appearances, which overlap with other salivary gland neoplasia. It is well established that delayed diagnosis of malignancies results in poorer patient outcomes, as well as increases patient morbidity[1].

KLKs have been recognized as valuable tumour biomarkers, as they demonstrate aberrant regulation in malignant processes[67]. The most well-known is KLK3, or prostate specific antigen, which has contributed advancements to the diagnosis and monitoring of prostate adenocarcinoma, while also generating a potential therapy target[49].

KLKs have been extensively studied in many glandular tumours, including breast and prostate carcinoma. KLK expression has previously been shown in NSGT[73, 76]. Furthermore, aberrant regulation of KLKs has been linked to other salivary gland tumours. This suggests their potential use as biomarkers in salivary gland neoplasms[67]. KLK levels in PLGA may lend themselves as diagnostic markers and prognostic markers to better recognize PLGA and differentiate tumour clinical behaviour. Lastly, the detection of KLKs in serum or other bodily fluids may provide a rapid and minimally invasive means of diagnosis in PLGA.

To date, examination of KLK expression in PLGA is limited to KLK13 only. To the authors knowledge, this study is the first to look at the expression of KLK1-15 in PLGA, both at the level of mRNA and protein.

\subsubsection{Aims}

1. To determine levels of KLK (KLKs1-15) mRNA in formalin fixed paraffin embedded PLGA tissue samples, using real time polymerase chain reaction. 
2. To determine if KLK expression is tumour cell-specific, by analyzing immunohistochemical expression of specific KLKs (KLK 7, KLK8, KLK10, KLK11, and KLK14) in PLGA tissue samples. The staining scores of each PLGA sample will then be compared to specific KLK mRNA levels. 


\section{Chapter 2}

\subsection{Experimental Materials and Methods}

\subsection{Tissue Specimens}

\subsubsection{Tumour Criteria}

Cases of polymorphous low-grade adenocarcinoma were retrieved from the archives between 1987-2013 at University Hospital, London Health Sciences Centre and the Division of Oral Pathology, Schulich School of Medicine \& Dentistry, Western University. Original hematoxylin and eosin $(\mathrm{H} \& \mathrm{E})$ stained slides were reviewed to confirm a diagnosis of PLGA, and to verify enough tumour tissue for experimental use. Blocks of formalin-fixed, paraffin-embedded (FFPE) PLGA tissue were obtained for suitable cases. Some samples required re-embedding in paraffin wax and repeat $H \& E$ stain to confirm enough tumour tissue for our studies. Cases that did not have an original slide or FFPE blocks were omitted. A total of 19 PLGA tumours were obtained.

\subsubsection{Patient data collection from PLGA samples}

Data was obtained from each PLGA case. This included patient demographics (age, gender), tumour clinical features and microscopic findings. Specific clinical features recorded were the tumour site and whether not the tumour was a recurrence. Histologic findings noted were morphology (e.g. trabecular, cribriform), perineural invasion, encapsulation, and degree of infiltration. Table 3.1.1 lists patient demographics, including sex, age, location of the tumour and year of biopsy for each PLGA sample. 
Table 2.1.1: Patient Demographics for PLGA Samples

\begin{tabular}{|c|c|c|c|c|}
\hline $\begin{array}{c}\text { Sample } \\
\#\end{array}$ & $\begin{array}{c}\mathrm{Pt} \\
\text { Age }\end{array}$ & Sex & Location & $\begin{array}{c}\text { Year } \\
\text { of } \\
\text { Bx }\end{array}$ \\
\hline 1 & 56 & $\mathrm{~F}$ & $\begin{array}{l}\text { Posterior } \\
\text { palate }\end{array}$ & 1994 \\
\hline 2 & 51 & $\mathrm{~F}$ & Soft palate & 2009 \\
\hline 3 & 78 & $\mathrm{~F}$ & $\begin{array}{l}\text { L posterior } \\
\text { hard palate }\end{array}$ & 2002 \\
\hline 4 & 77 & $\mathrm{M}$ & $\begin{array}{c}\mathrm{R} \text { buccal } \\
\text { mucosa }\end{array}$ & 2001 \\
\hline 5 & 67 & $\mathrm{M}$ & $\begin{array}{l}\text { Upper lip } \\
\text { Mucosa }\end{array}$ & 2008 \\
\hline 6 & 50 & $\mathrm{~F}$ & $\begin{array}{l}\text { L hard } \\
\text { palate }\end{array}$ & 2009 \\
\hline 7 & 59 & $\mathrm{M}$ & $\begin{array}{l}\text { L soft } \\
\text { palate }\end{array}$ & 2005 \\
\hline 8 & 76 & $\mathrm{M}$ & $\begin{array}{c}\mathrm{L} \text { upper } \\
\text { lip }\end{array}$ & 2013 \\
\hline 9 & 63 & $\mathrm{~F}$ & $\begin{array}{c}\text { Hard and } \\
\text { soft palate } \\
\text { jxn }\end{array}$ & 2003 \\
\hline 10 & 49 & $\mathrm{~F}$ & $\begin{array}{c}\mathrm{R} \text { buccal } \\
\text { mucosa }\end{array}$ & 2009 \\
\hline 11 & 17 & $\mathrm{~F}$ & $\begin{array}{l}\text { mid hard } \\
\text { palate/soft } \\
\text { palate jxn }\end{array}$ & 2007 \\
\hline 12 & 65 & $\mathrm{~F}$ & $\begin{array}{l}\text { L hard } \\
\text { palate }\end{array}$ & 2009 \\
\hline 13 & 83 & $\mathrm{M}$ & $\begin{array}{l}\text { Sublingual } \\
\text { gland }\end{array}$ & 2002 \\
\hline 14 & 76 & $\mathrm{M}$ & Soft palate & 2004 \\
\hline 15 & 38 & $\bar{F}$ & $\begin{array}{l}\text { L buccal } \\
\text { vestibule }\end{array}$ & 2007 \\
\hline 16 & 54 & $\mathrm{~F}$ & $\begin{array}{c}\mathrm{R} \\
\text { hard/soft } \\
\text { palate jxn }\end{array}$ & 2010 \\
\hline 17 & 65 & $\mathrm{~F}$ & $\begin{array}{l}\mathrm{R} \text { buccal } \\
\text { mucosa }\end{array}$ & 1992 \\
\hline 18 & & $\mathrm{~F}$ & $\begin{array}{c}\text { L buccal } \\
\text { mucosa }\end{array}$ & 1989 \\
\hline 19 & 61 & $\mathrm{~F}$ & $\begin{array}{l}\text { R soft } \\
\text { palate }\end{array}$ & 1991 \\
\hline
\end{tabular}


Table 2.1.2: Patient Demographics for NSGT Samples. This table was originally produced in Expression of kallikrein-related peptidases (KLKs) in Adenoid Cystic Carcinoma. Kerr, Zachary R. Electronic Thesis and Dissertation Reporitory. Paper 4096. The table is being reproduced for educational purposes only and not for any commercial use. Figure is included in the M. Sc. dissertation with attribution.

\begin{tabular}{|c|c|c|c|}
\hline$\underset{\#}{\text { Sample }}$ & $\begin{array}{c}\mathrm{Pt} \\
\text { Age }\end{array}$ & Sex & Location \\
\hline 1 & 75 & $\mathrm{~F}$ & Left gingiva \\
\hline 2 & 38 & $\mathrm{~F}$ & $\begin{array}{c}\text { Left lower lip } \\
\text { mucosa }\end{array}$ \\
\hline 3 & 53 & $\mathrm{~F}$ & Lower lip \\
\hline 4 & 20 & $\mathrm{M}$ & $\begin{array}{l}\text { Right lower } \\
\text { lip }\end{array}$ \\
\hline 5 & 24 & M & $\begin{array}{l}\text { Right buccal } \\
\text { mucosa }\end{array}$ \\
\hline 6 & 68 & $\mathrm{~F}$ & Left lower lip \\
\hline 7 & 24 & $\mathrm{~F}$ & $\begin{array}{l}\begin{array}{l}\text { Floor of } \\
\text { mouth }\end{array}\end{array}$ \\
\hline 8 & 20 & $\mathrm{~F}$ & Lower lip \\
\hline 9 & 47 & $\mathrm{~F}$ & Lower lip \\
\hline 10 & 42 & $\mathrm{~F}$ & $\begin{array}{l}\text { Right lower } \\
\text { lip }\end{array}$ \\
\hline 11 & 18 & M & Left lower lip \\
\hline 12 & 68 & M & Uvula \\
\hline 13 & 55 & $\mathrm{M}$ & $\begin{array}{c}\text { Right lower } \\
\text { lip }\end{array}$ \\
\hline 14 & 33 & $\mathrm{~F}$ & Lower lip \\
\hline 15 & 58 & $\mathrm{~F}$ & $\begin{array}{c}\text { Left hard } \\
\text { palate }\end{array}$ \\
\hline
\end{tabular}




\subsubsection{Tissue sectioning}

The regions representative of PLGA tissue on the H\&E stained slides were circled and matched to the same region on the FFPE tissue block. A scalpel was used to encircle the tumour tissue by scoring the paraffin. A microtome (Microm HM 325, GMI Inc., Ramsey, MN, USA, SKU\# 824330 1006) was used to prepare $3 \times 10 \mu \mathrm{m}$ tissue curls from each of the 19 PLGA PPFE tissue blocks. The tissue samples were not selected for tumour sample only; therefore, specimens consisted of tumour tissue and surrounding non-tumour tissues. The specimens were then placed in $1.5 \mathrm{~mL}$ collection tubes.

\subsubsection{Normal Tissues}

Previous work on characterizing KLK mRNA expression in NSGT has been completed in the Division of Oral Pathology, Schulich School of Medicine \& Dentistry, Western University. Kerr et al. used 15 samples of NGST, all from minor salivary gland tissue. Demographic information for the NSGT Specimens is listed in Table 3.1.2. The same experimental design to determine KLK expression in PLGA was used for the NSGT samples, and this is outlined below [84]. These results were used as comparison against PLGA tumour tissue results.

\subsection{RNA isolation from formalin-fixed, paraffin-embedded tissue}

\subsubsection{Deparaffinization}

For each sample of PLGA tumour, one $3 \times 10 \mu \mathrm{m}$ curl of FFPE tissue was placed in a 1.5 $\mathrm{mL}$ reaction tube and $800 \mu \mathrm{L}$ of Xylene was added. The tube was vortexed and incubated for 5 minutes. Subsequent centrifugation was completed for 2 minutes at maximum speed (12000-14000 $\mathrm{x} g$ ) and the supernatant was discarded via aspiration. Deparaffinization steps were repeated. Following deparaffinization, $800 \mu \mathrm{L}$ of absolute ethanol was added and the pellet was dislodged. Samples were centrifuged at maximum speed and the supernatant was discarded. Next, $800 \mu \mathrm{L}$ of $70 \%$ ethanol was added to the tube. Following another centrifugation, the samples were lysed using tissue lysis buffer (Roche Applied Science, Mannheim, Germany, Catalogue number: 04823125 001).

\subsubsection{RNA Isolation Protocol}

High Pure FFPE RNA Micro Kit (Roche Applied Science) was used to isolate RNA from each of the samples. Following tissue digestion, proteinase $\mathrm{K}$ was added to the tubes and the 
samples were incubated for 3 hours at $55^{\circ} \mathrm{C}$. Next, $200 \mu \mathrm{L}$ of Binding Buffer and $200 \mu \mathrm{L}$ of ethanol (absolute) was added. Proteinase $\mathrm{K}$ is a broad-spectrum serine protease, which is added to digest protein and remove contamination from the preparation of nuclei acids; proteinase $\mathrm{K}$ rapidly inactivates nucleases which may otherwise degrade DNA or RNA during purification. Ultimately, this enzyme inactivates RNases and DNases improving the stability of these nucleic acids, and removes contaminates yielding pure DNA and RNA[85]._Following this step, the lysate was added into the upper reservoir of the RNA column tube. Genomic DNA was eliminated using DNase solution. All other steps were performed as suggested by the manufacturer. RNA isolated was stored at $-80^{\circ} \mathrm{C}$ until time of analysis.

\subsubsection{RNA Quantification and cDNA synthesis}

Isolated total RNA was quantified using Qubit Fluorometer (Invitrogen, Carlsbad, CA, Catalogue no Q32866). The Qubit Fluorometer is able to accurately detect RNA concentrations of $10 \mathrm{pg} / \mathrm{uL}$ to $1 \mathrm{ug} / \mathrm{L}$. A fluorescent dye binds specifically to RNA; initially these dyes have low fluorescent properties, but emit a higher signal once bound to RNA, which is quantifiable. Based on the lowest RNA yield, minimum of 0.32ng of total RNA was selected for cDNA synthesis. The iScript cDNA synthesis kit (Bio-Rad Laboratories (Canada) Ltd. Mississauga, ON, Catalogue number: 1708890) was used to synthesis complementary DNA (cDNA) from previously isolated RNA.

\subsection{SYBR Green Real Time Polymerase Chain Reaction (PCR)}

The CFX Connect PCR Detection System (Bio-Rad Laboratories (Canada) Ltd, Mississauga, ON) was used to measure transcript levels. Source of primers is indicated in Table 3.3.1. PCR reaction consisted of $10 \mu \mathrm{L} \mathrm{RT}^{2}$ SYBR ${ }^{\circledR}$ Green qPCR Mastermix (Qiagen, Toronto,

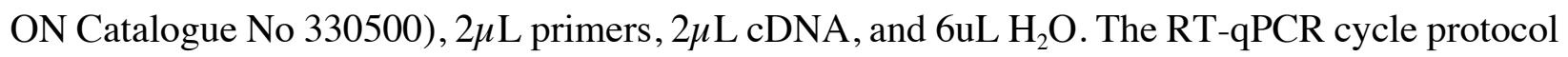
was completed as follows: one cycle of 10 minutes at $95^{\circ} \mathrm{C}$ for activation of Taq DNA polymerase, 40 cycles of $15 \mathrm{~s}$ at $95^{\circ} \mathrm{C}$ and 40 cycles of 1 minute at $60^{\circ} \mathrm{C}$ for DNA amplification. Melting curve analysis was included in all qPCR studies. 
Table 2.3.1: Qiagen Catalogue numbers for primer assays used in Custom PCR Plate

\begin{tabular}{|c|c|}
\hline Primer Assay & Catalogue Number \\
\hline KLK1 & QT00020664 \\
\hline KLK 2 & QT00088466 \\
\hline KLK3 & QT00027713 \\
\hline KLK4 & QT00495159 \\
\hline KLK5 & QT00010437 \\
\hline KLK6 & QT00013972 \\
\hline KLK7 & QT00028343 \\
\hline KLK8 & QT00017689 \\
\hline KLK9 & QT00057190 \\
\hline KLK10 & QT00039816 \\
\hline KLK11 & QT00011011 \\
\hline KLK12 & QT00067977 \\
\hline KLK13 & QT00029876 \\
\hline KLK14 & QT00039928 \\
\hline KLK15 & QT00035735 \\
\hline$\beta$-actin & QT01680476 \\
\hline
\end{tabular}




\subsection{Data analysis for PCR}

Data was analyzed by $\Delta \Delta \mathrm{C}_{\mathrm{T}}$ using CFX Manager. $\underline{\mathrm{C}}_{\mathrm{T}}$ is defined as the threshold cycle, which occurs when the fluorescence level reaches a certain amount in the PCR experiment[86]. $\underline{\Delta \Delta C_{T}}$ is a method of relative quantification, and calculates relative gene expression in a target and reference samples in comparison to a data normalizing gene[86]. Data was normalized to $\beta$-actin and normal salivary gland tissue mRNA was used as the comparator for $\Delta \Delta \mathrm{C}_{\mathrm{T}}$

\subsection{Statistical Analysis}

For each KLK, the mean of mRNA expression in tumour samples was calculated, as was the standard error of mean. Data was tested for normality and non-parametric statistical analysis was determined to be appropriate. Statistical testing was performed with Mann-Whitney $U$ Test and significance was set at $\mathrm{p}<0.05$.

\subsection{Assay Methods}

\subsubsection{Immunohistochemistry sample selection}

Samples were selected for immunohistochemistry after analyzing KLK mRNA levels from PCR data. Samples exhibiting relatively lower or higher mRNA levels of specific KLK were included. Table 3.6.1 outlines the samples used for immunohistochemistry experiments.

\subsubsection{Immunohistochemistry}

For the immunohistochemistry experiments, a standard immunoperoxidase staining method was employed. An indirect technique was used to localize tissue expression of KLK 7, 8, 10, 11, and 14 in PLGA tissue samples. Positive controls (Table 3.6.2.1) and negative controls (no primary antibody) were included for all staining experiments.

\subsubsection{Antibody Selection}

For our study, the primary antibodies were donated by Dr. E. P. Diamandis, Department of Laboratory Medicine and Pathobiology at the University of Toronto, Toronto, Ontario. These antibodies included rabbit polyclonal antibodies produced in mammalian stable cell lines, against KLKs (KLK 7,8,10,11,14). The production of these KLK antibodies has been fully described by 
Diamandis et al. (Reference: Diamandis EP, et al. Pathology and Genetics of human kallikrein 6 (zyme/protease M/neurosin) and preliminary clinical applications. Clin Biochem. 2000;33:369$75)$. 
Table 2.6.1: IHC samples

\begin{tabular}{|c|c|c|}
\hline $\begin{array}{c}\text { Specific KLK } \\
\text { Antibody }\end{array}$ & Sample \# & Sample \# \\
\hline & LOW LEVEL & HIGH LEVEL \\
\hline KLK7 & 6 & 16 \\
\hline KLK8 & 6,16 & 11 \\
\hline KLK 10 & 11 & 6,10 \\
\hline KLK 11 & 6 & 11 \\
\hline KLK 14 & 6 & 11 \\
\hline
\end{tabular}

Table 2.6.2.1: Positive Controls for Selected KLK Antibodies

\begin{tabular}{|c|c|}
\hline Kallikrein antibody & Positive control \\
\hline KLK 7 & Adenoid cystic carcinoma \\
\hline KLK 8 & Skin \\
\hline KLK 10 & Pormal salivary gland \\
\hline KLK 11 & Skin \\
\hline KLK 14 & \\
\hline
\end{tabular}

Table 2.6.2.2: Specific KLK antibody dilutions

\begin{tabular}{|c|c|c|}
\hline Kallikrein Antibody & Antibody titre & Incubation \\
\hline KLK 7 & $1: 3200$ & Overnight at $4^{\circ} \mathrm{C}$ \\
\hline KLK 8 & $1: 100$ & Overnight at $4^{\circ} \mathrm{C}$ \\
\hline KLK 10 & $1: 1200$ & Overnight at $4^{\circ} \mathrm{C}$ \\
\hline KLK 11 & $1: 2400$ & Overnight at $4^{\circ} \mathrm{C}$ \\
\hline KLK 14 & $1: 3200$ & Overnight at $4^{\circ} \mathrm{C}$ \\
\hline
\end{tabular}




\subsubsection{Paraffin Sections}

Formalin-fixed, paraffin-embedded PLGA tissue blocks were obtained. A microtome (Microm HM 325, GMI Inc., Ramsey, MN, USA, SKU\# 824330 1006) was used to prepare $5 \mu \mathrm{m}$ thick serial sections, which were transferred to a water bath at $45^{\circ} \mathrm{C}$, mounted on positively charged microscopic slides and oven-dried overnight via incubation at $37^{\circ} \mathrm{C}$. The following solution immersions were completed to de-paraffinize and rehydrate the tissue sections: 3 changes of xylene for 5 minutes, $100 \%$ ethanol for 3 minutes, $95 \%$ ethanol for 3 minutes, $70 \%$ ethanol for 1 minute, $100 \%$ distilled water for 3 minutes. Quenching was completed with 3\% hydrogen peroxide in methanol for 5 minutes, followed by rinsing in $100 \%$ distilled water, and PBS.

\subsubsection{Staining procedure}

The prepared tissue sections for each PLGA sample were subjected to antigen retrieval. Slides were placed in citrate buffer ( $\mathrm{pH}$ 6.0), at $125^{\circ} \mathrm{C}$ in a de-cloaking chamber. The slides were rinsed in water and PBS for 5 minutes. We blocked the slides using $10 \%$ horse serum at room temperature for 30 minutes. After blocking, appropriately diluted primary antibodies for the KLK were added to the slides according to conditions outlined in Table 3.7.2.2. Detection was performed ImmPRESS ${ }^{\circledR}$ Reagent Kit (Vector Laboratories, Burlingame, CA, Catalogue No: MP7401). The slides were then stained with 3,3'-diaminobenzidine tetrahydrochloride (DAB Peroxidase Substrate Kit, Vector Laboratories, Burlingame, CA, Catalogue No: SK-4100) for 10 minutes at room temperature. Slides were then counterstained with hematoxylin, dehydrated, and mounted using Cytoseal® (VWR, Mississauga, Ontario, Catalogue No: 48212-154).

\subsection{Data collection and statistical analysis for immunohistochemistry}

\subsubsection{Scoring Criteria}

The KLK staining of each PLGA sample was viewed under brightfield microscopy and assessed semi-quantitatively, using a well-documented method, as described by Allred et al. $[76$, 87]. This was completed by an Oral Pathologist and the graduate student author. A proportion score and intensity score, displayed in Tables 3.7.1.1 and 3.7.1.2 respectively, was used to evaluate each stained tissue sample. The proportion score indicates the estimated fraction of positive staining tumour cell nuclei (0-5), while the intensity score evaluates the average staining intensity of tumour cell nuclei. An overall staining score (OSS) was then generated, ranging from 0-8, for 
each sample. A negative score is represented as 0 , and positive scores range from 2-8[87]. Figure 2.7.1.1 demonstrates a pictorial interpretation of the Allred scoring system[88]. 
Table 2.7.1.1: Proportion score for estimated fraction of immunoreactive tumour cells

\begin{tabular}{|c|c|}
\hline Score & Proportion of cells stained \\
\hline 0 & 0 \\
\hline 1 & $<1 / 100$ \\
\hline 2 & $1 / 100-1 / 10$ \\
\hline 3 & $1 / 10-1 / 3$ \\
\hline 4 & $1 / 3-2 / 3$ \\
\hline 5 & $>2 / 3$ \\
\hline
\end{tabular}

Table 2.7.1.2: Intensity score for tumour cells

\begin{tabular}{|c|c|}
\hline Score & Staining Intensity \\
\hline 0 & None \\
\hline 1 & Weak \\
\hline 2 & Intermediate \\
\hline 3 & Strong \\
\hline
\end{tabular}


Figure 2.7.1.1 Diagrammatic Representation of Interpretation of Allred Scores. This figure was originally published in Journal of Pakistan Medical Association. Qureshi, A. and Pervez, S. Allred scoring for ER reporting and its impact in clearly distinguishing ER negative from ER positive breast cancers. 60:350; 2010. The figure is being reproduced for educational purposes only and not for any commercial use. Figure is included in the M. Sc. Dissertation with attribution.

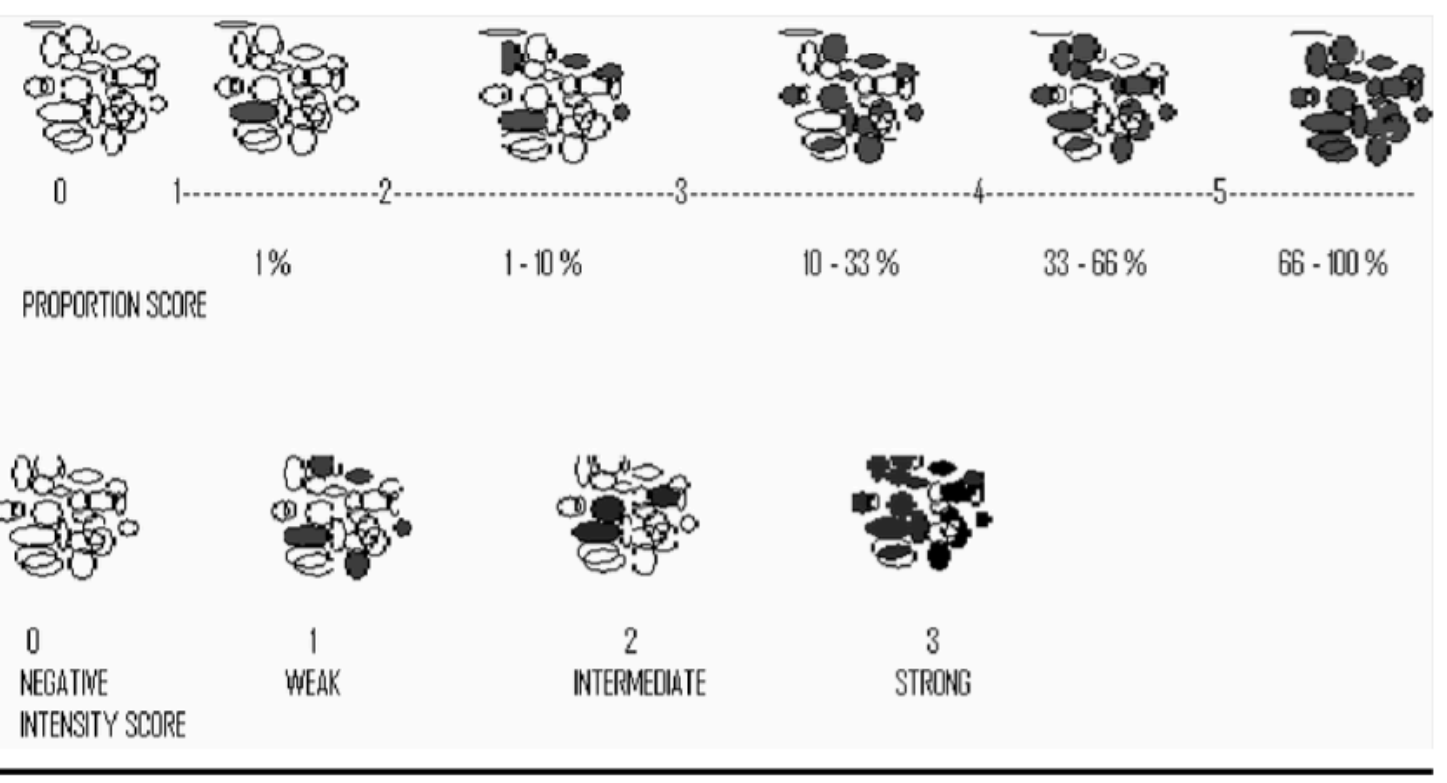




\section{Chapter 3}

\subsection{Results}

\subsection{RNA isolation}

The RNA isolated from PLGA samples is shown in Table 4.1.1. In samples 14, 18, and 19, the RNA amount was not detectable. The average amount of RNA obtained from the remaining 16 samples was $0.297 \mu \mathrm{g} / \mathrm{mL}$. Equal amount of RNA was used to synthesize cDNA for qPCR studies.

\subsection{Expression of KLKs in cDNA of PLGA}

The expression of KLK mRNA in samples of PLGA was examined for KLK1-15. All samples of PLGA tissue demonstrated expression of at least four KLKs and as many as thirteen KLKs. The percentages of PLGA tissues exhibiting each KLK are listed in Table 4.2.1. KLK7 was the least likely to be expressed in the samples, detectable in just $18.8 \%$ cases. KLK6, 11, and 13 were present in $25 \%$ cases. Whereas, KLK1 and 2 were most commonly expressed.

\subsection{Expression of KLKs in PLGA compared to normal salivary gland tissue (NSGT)}

The mean expression of each KLK was calculated for all PLGA samples. Figures 4.3.14.3.15 demonstrate KLK mRNA expression in PLGA tissues compared to NSGT. The data was tested for normality and statistical significance was determined using Mann Whitney U Test. For each KLK, the mean mRNA expression obtained from biological replicates was found to be greater in the PLGA samples compared to NSGT. This was statistically significant for 1, 4, 10, 12, 15 . The relative fold change of mRNA expression for each KLK in PLGA versus NSGT is demonstrated in Figure 4.3.16. to illustrate the overall profile. 
Table 3.1.1 RNA quantification by Qubit Fluorometer for each PLGA tissue sample.

\begin{tabular}{|c|c|}
\hline $\begin{array}{l}\text { Sample } \\
\text { Number }\end{array}$ & $\begin{array}{c}\text { RNA } \\
\mu \mathrm{g} / \mathrm{mL}\end{array}$ \\
\hline 1 & $\mathbf{0 . 0 9 1}$ \\
\hline 2 & $\mathbf{0 . 1 2 1}$ \\
\hline 3 & $\mathbf{0 . 0 7 5}$ \\
\hline 4 & $\mathbf{0 . 0 7 2}$ \\
\hline 5 & $\mathbf{0 . 2 1 4}$ \\
\hline 6 & $\mathbf{0 . 8 9 8}$ \\
\hline 7 & $\mathbf{0 . 1 3 9}$ \\
\hline 8 & $\mathbf{0 . 0 6 5}$ \\
\hline 9 & $\mathbf{0 . 3 2 2}$ \\
\hline 10 & $\mathbf{0 . 2 4 4}$ \\
\hline 11 & $\mathbf{1 . 0 4}$ \\
\hline 12 & $\mathbf{0 . 2 3 8}$ \\
\hline 13 & $\mathbf{0 . 5 2 0}$ \\
\hline 14 & too low \\
\hline 15 & $\mathbf{0 . 1 2 0}$ \\
\hline 16 & $\mathbf{0 . 4 2 6}$ \\
\hline 17 & $\mathbf{0 . 1 6 3}$ \\
\hline 18 & too low \\
\hline 19 & too low \\
\hline
\end{tabular}


Table 3.2.1 Percentages of PLGA cases with detectable KLK mRNA. These percentages are generated by the number of case samples (out of 16 total) which demonstrated mRNA for each $K L K$.

\begin{tabular}{|c|c|}
\hline KLK & PLGA \% \\
\hline KLK1 & 87.5 \\
\hline KLK2 & 87.5 \\
\hline KLK3 & 62.5 \\
\hline KLK4 & 43.8 \\
\hline KLK5 & 68.8 \\
\hline KLK6 & 25 \\
\hline KLK7 & 18.8 \\
\hline KLK8 & 31.3 \\
\hline KLK9 & 50 \\
\hline KLK10 & 62.5 \\
\hline KLK11 & 25 \\
\hline KLK12 & 68.8 \\
\hline KLK13 & 25 \\
\hline KLK14 & 37.5 \\
\hline KLK15 & 37.5 \\
\hline
\end{tabular}


Figure 3.3.1: Mean value of KLK1 mRNA expression in PLGA vs NSGT. Statistical significance determined by Mann Whitney U Test $(p<0.05)$

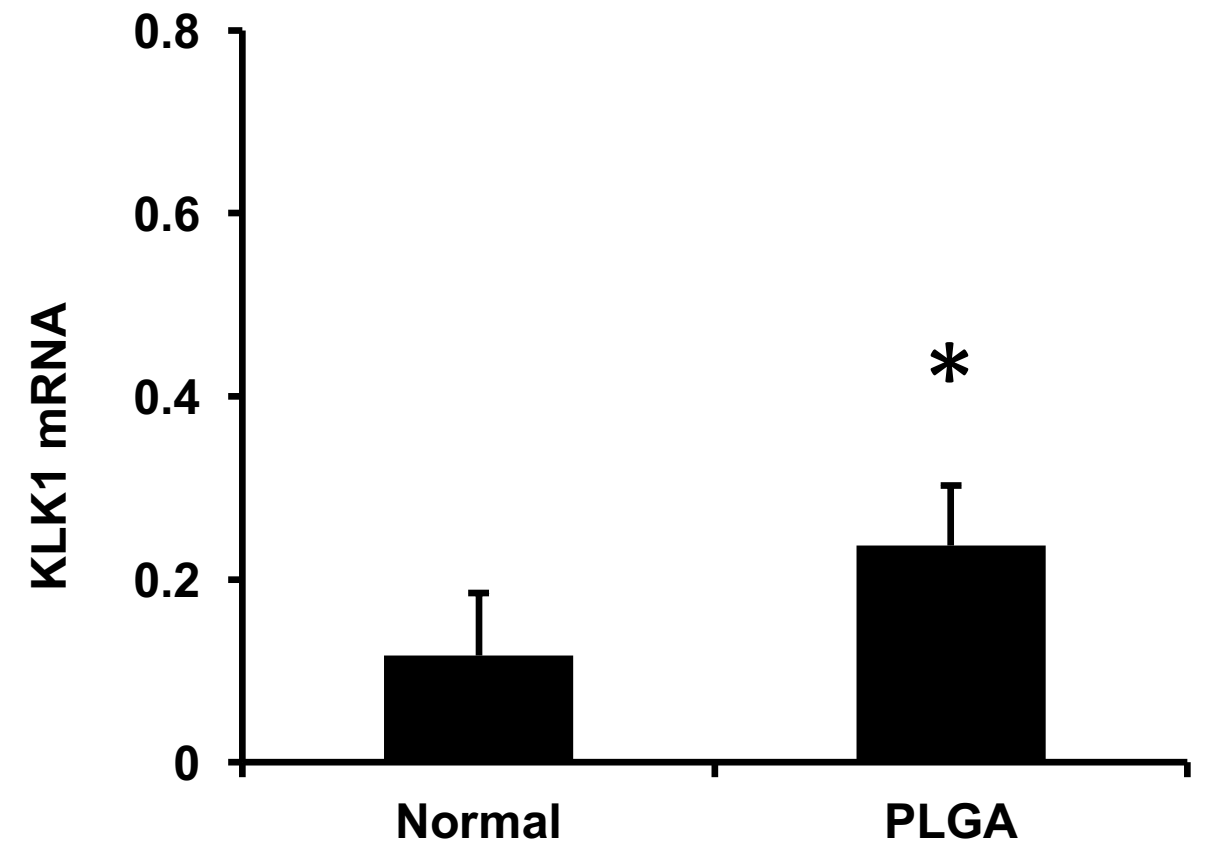

Figure 3.3.2: Mean value of KLK2 mRNA expression in PLGA vs NSGT. Statistical significance determined by Mann Whitney U Test $(p<0.05)$

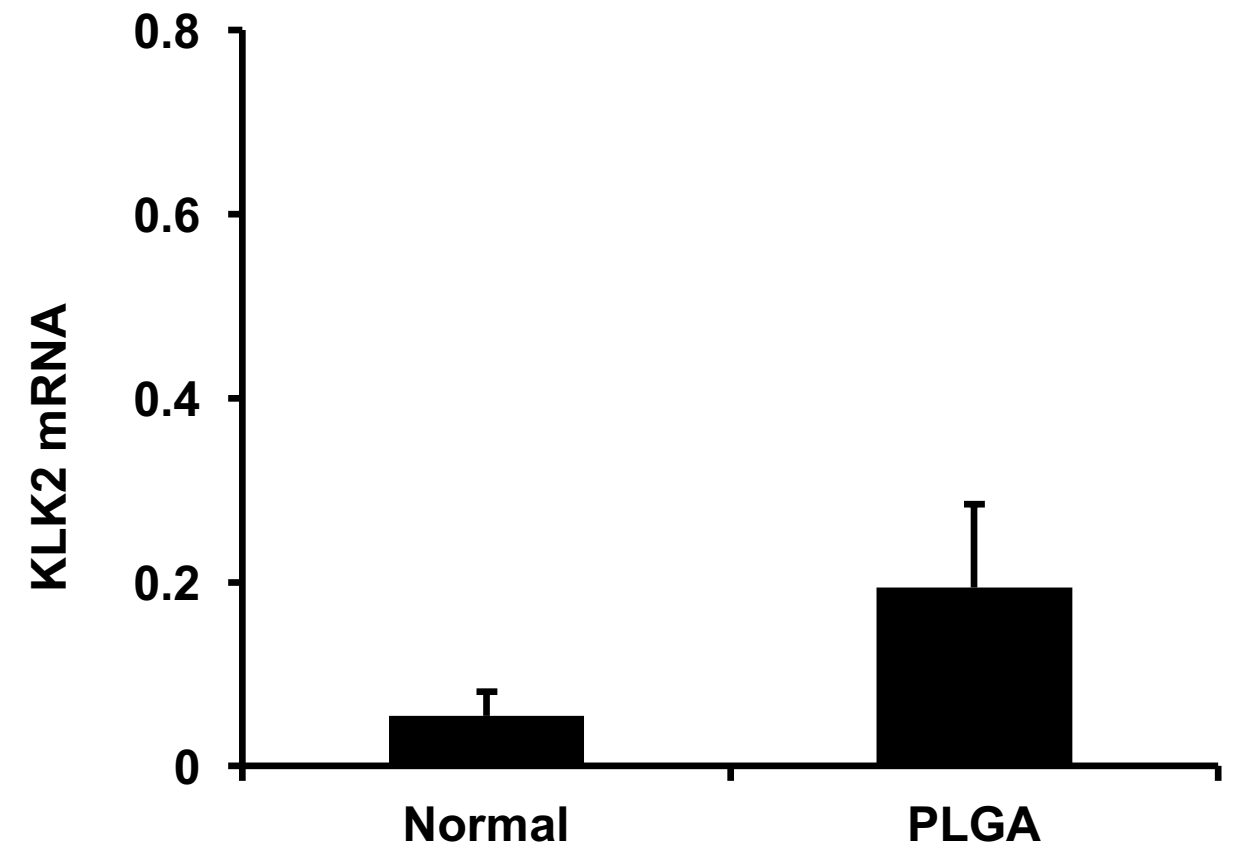


Figure 3.3.3: Mean value of KLK3 mRNA expression in PLGA vs NSGT. Statistical significance determined by Mann Whitney U Test $(p<0.05)$

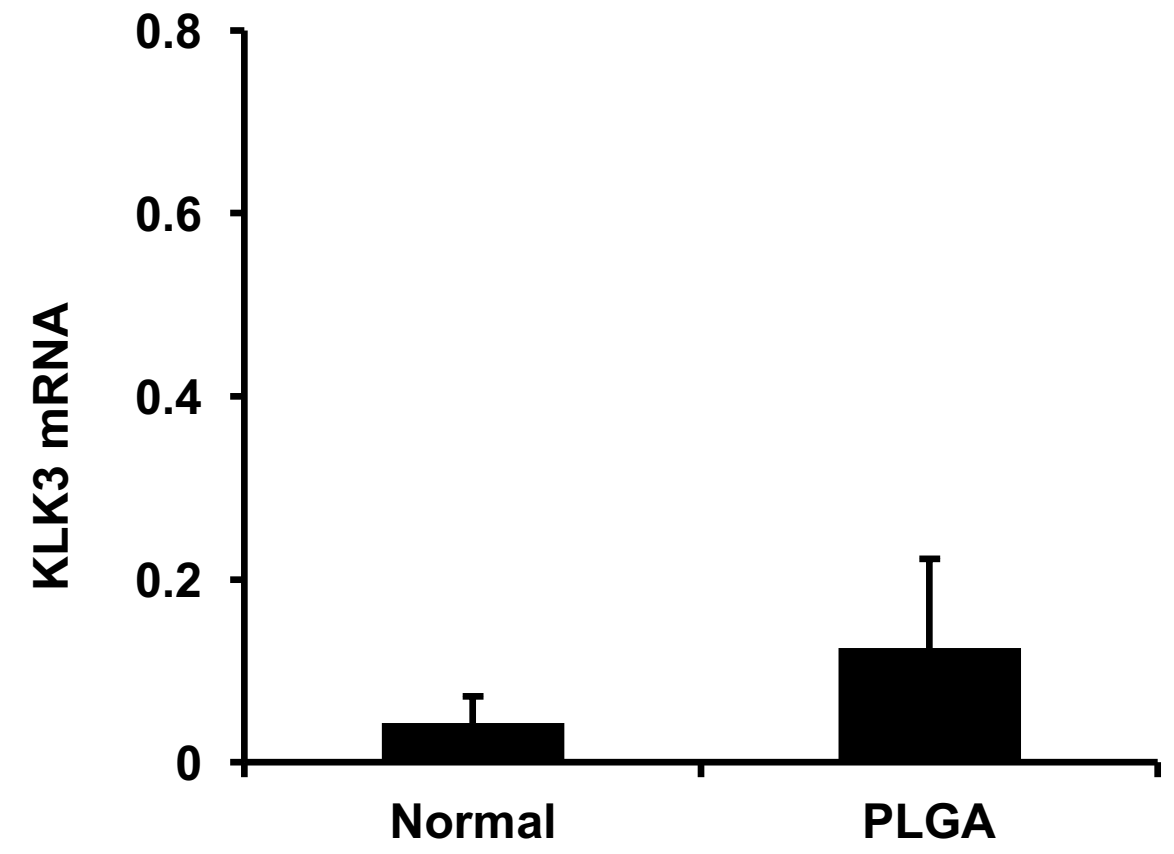

Figure 3.3.4: Mean value of KLK4 mRNA expression in PLGA vs NSGT. Statistical significance determined by Mann Whitney U Test $(p<0.05)$

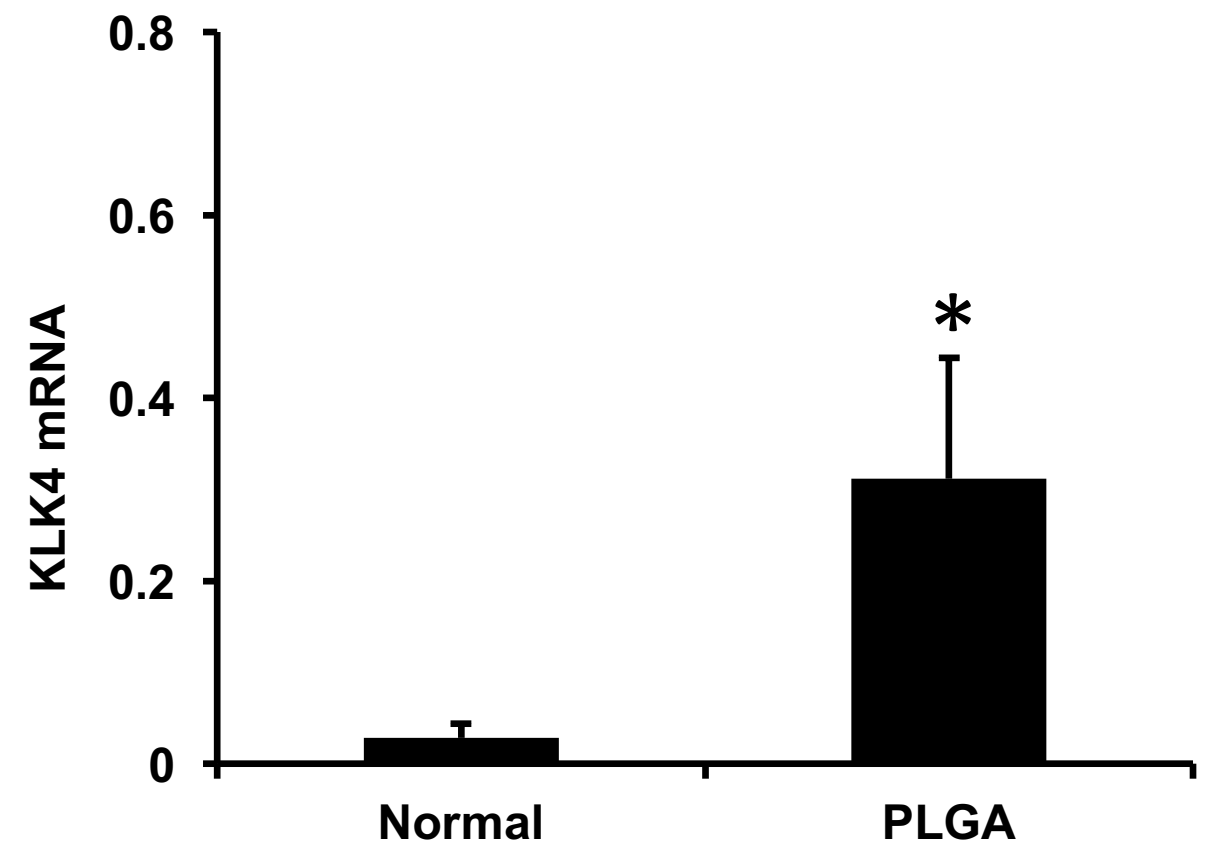


Figure 3.3.5: Mean value of KLK5 mRNA expression in PLGA vs NSGT. Statistical significance determined by Mann Whitney U Test $(p<0.05)$

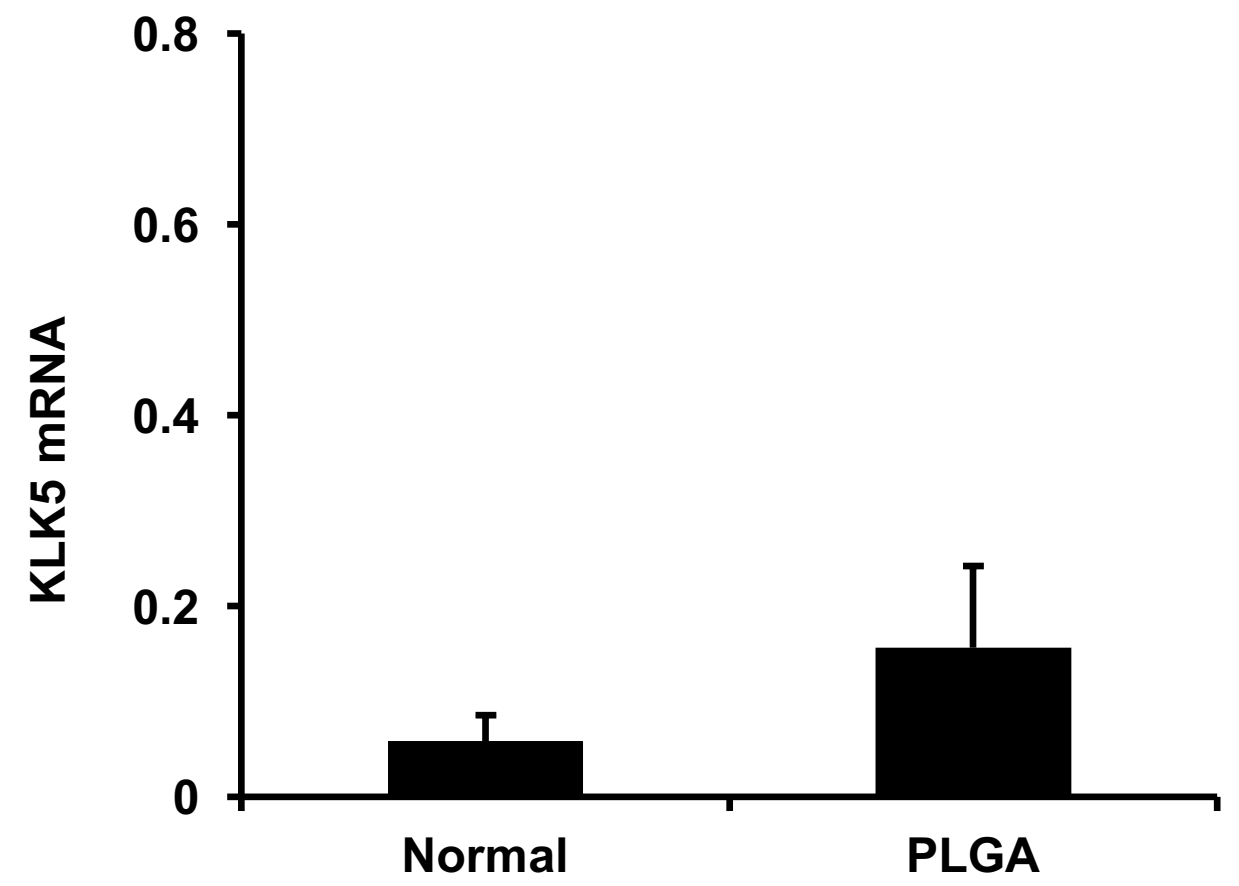

Figure 3.3.6: Mean value of KLK6 mRNA expression in PLGA vs NSGT. Statistical significance determined by Mann Whitney U Test $(p<0.05)$

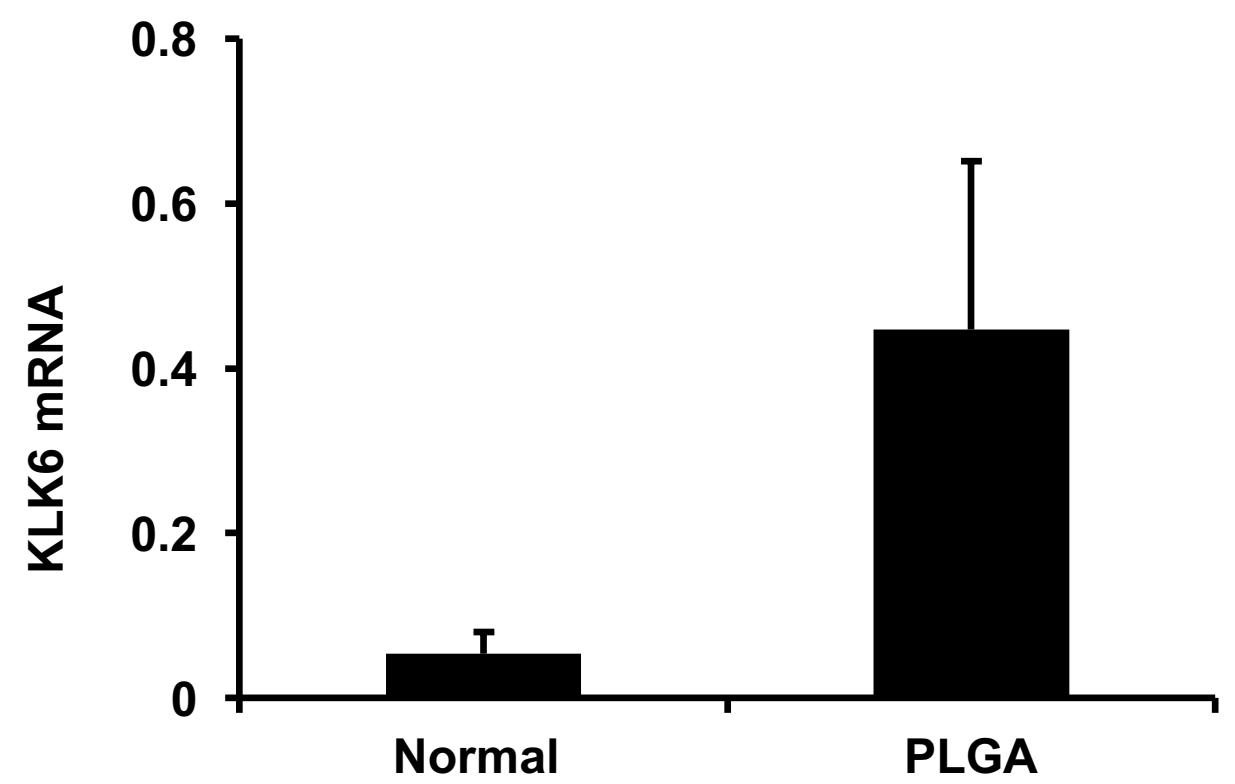


Figure 3.3.7: Mean value of KLK7 mRNA expression in PLGA vs NSGT. Statistical significance determined by Mann Whitney U Test $(p<0.05)$

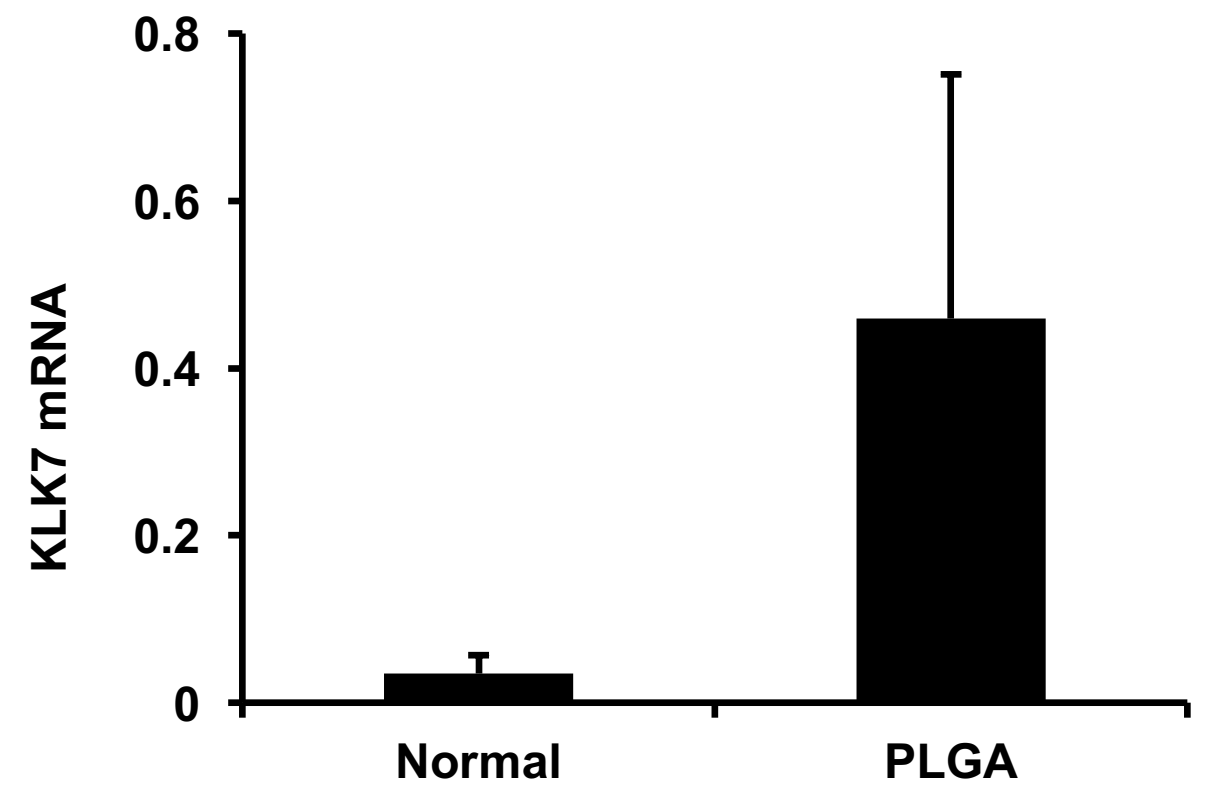

Figure 3.3.8: Mean value of KLK8 mRNA expression in PLGA vs NSGT. Statistical significance determined by Mann Whitney U Test $(p<0.05)$

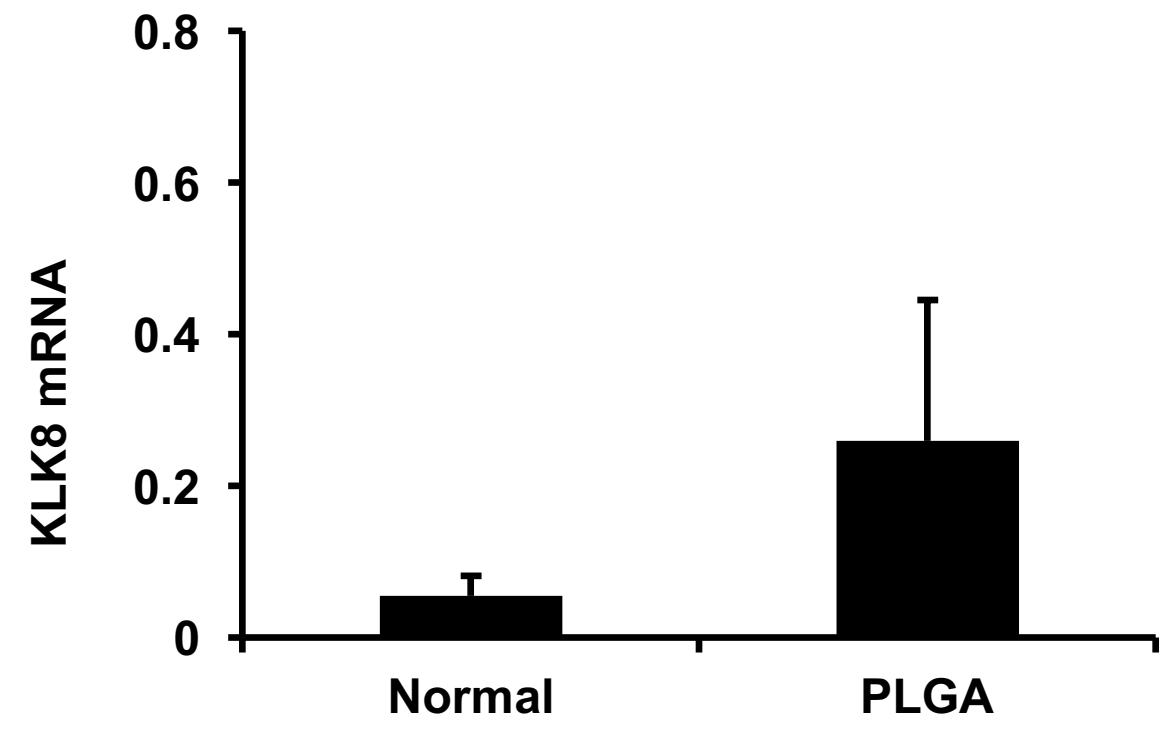


Figure 3.3.9: Mean value of KLK9 mRNA expression in PLGA vs NSGT. Statistical significance determined by Mann Whitney U Test $(p<0.05)$

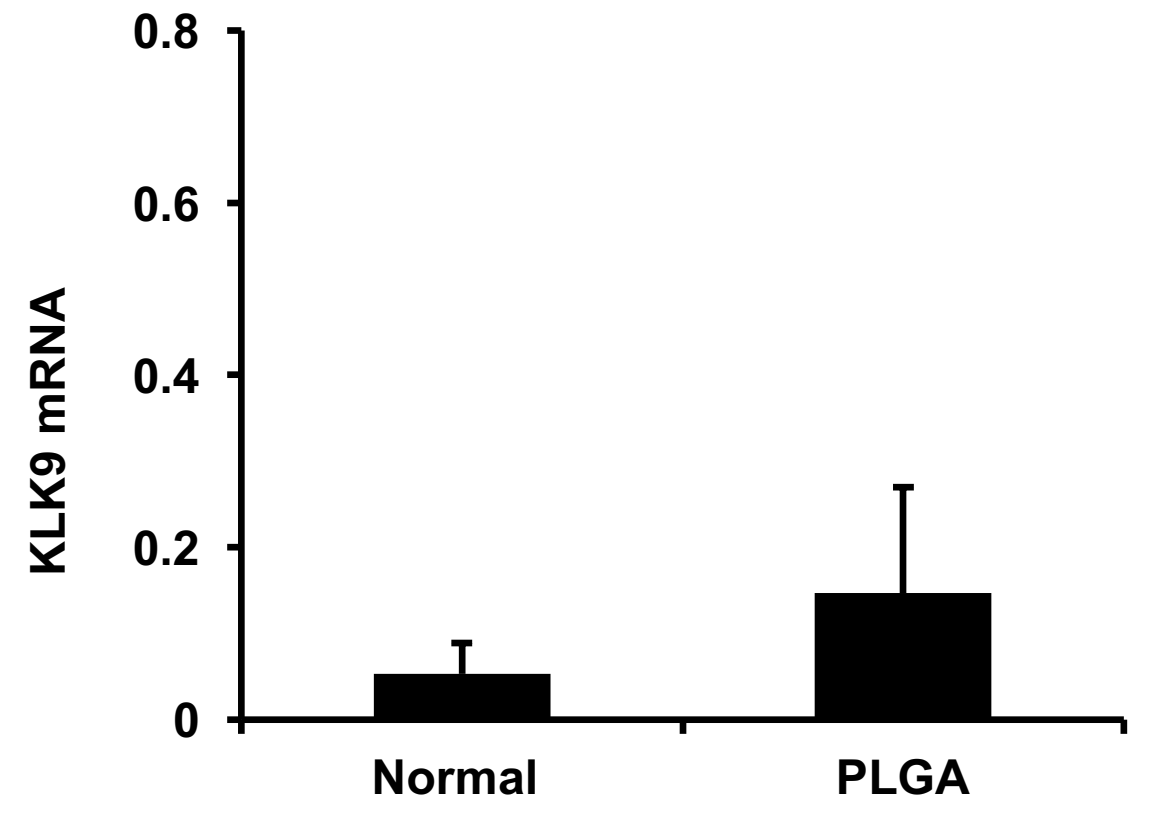

Figure 3.3.10: Mean value of KLK10 mRNA expression in PLGA vs NSGT. Statistical significance determined by Mann Whitney U Test $(p<0.05)$

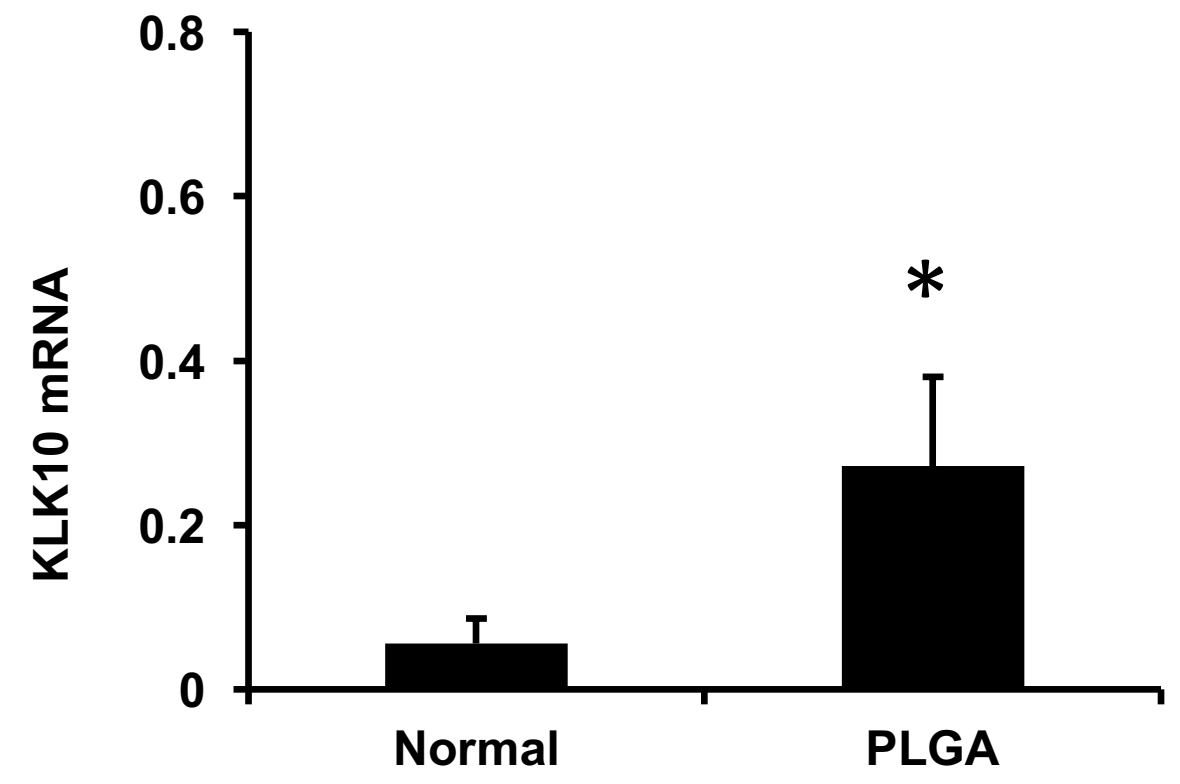


Figure 3.3.11: Mean value of KLK11 mRNA expression in PLGA vs NSGT. Statistical significance determined by Mann Whitney U Test $(p<0.05)$

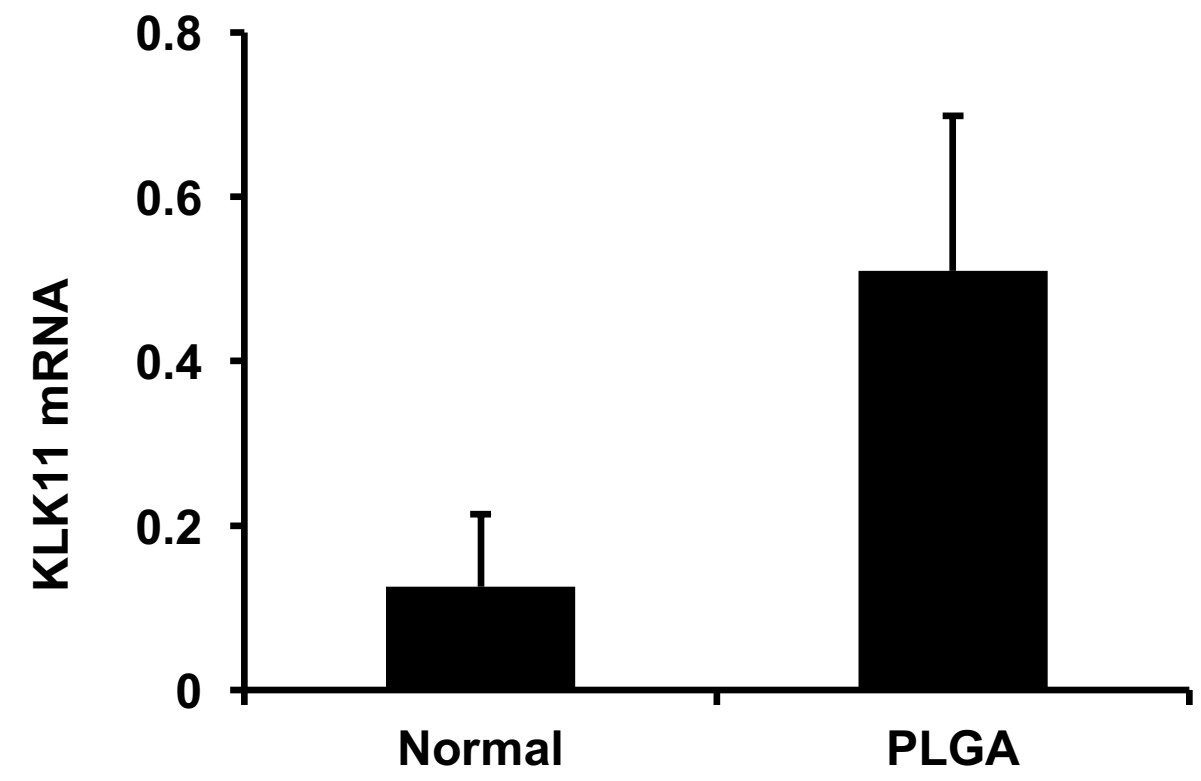

Figure 3.3.12: Mean value of KLK12 mRNA expression in PLGA vs NSGT. Statistical significance determined by Mann Whitney U Test $(p<0.05)$

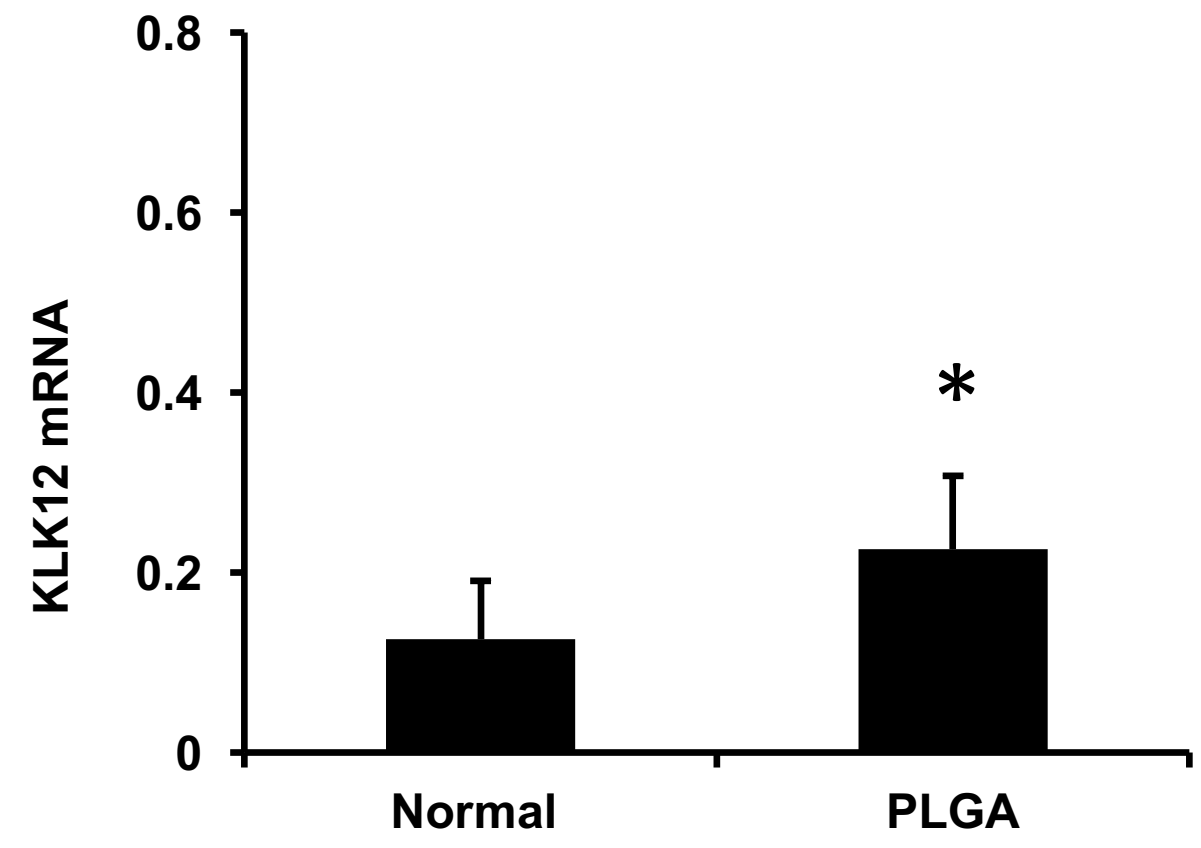


Figure 3.3.13: Mean value of KLK13 mRNA expression in PLGA vs NSGT. Statistical significance determined by Mann Whitney U Test $(p<0.05)$

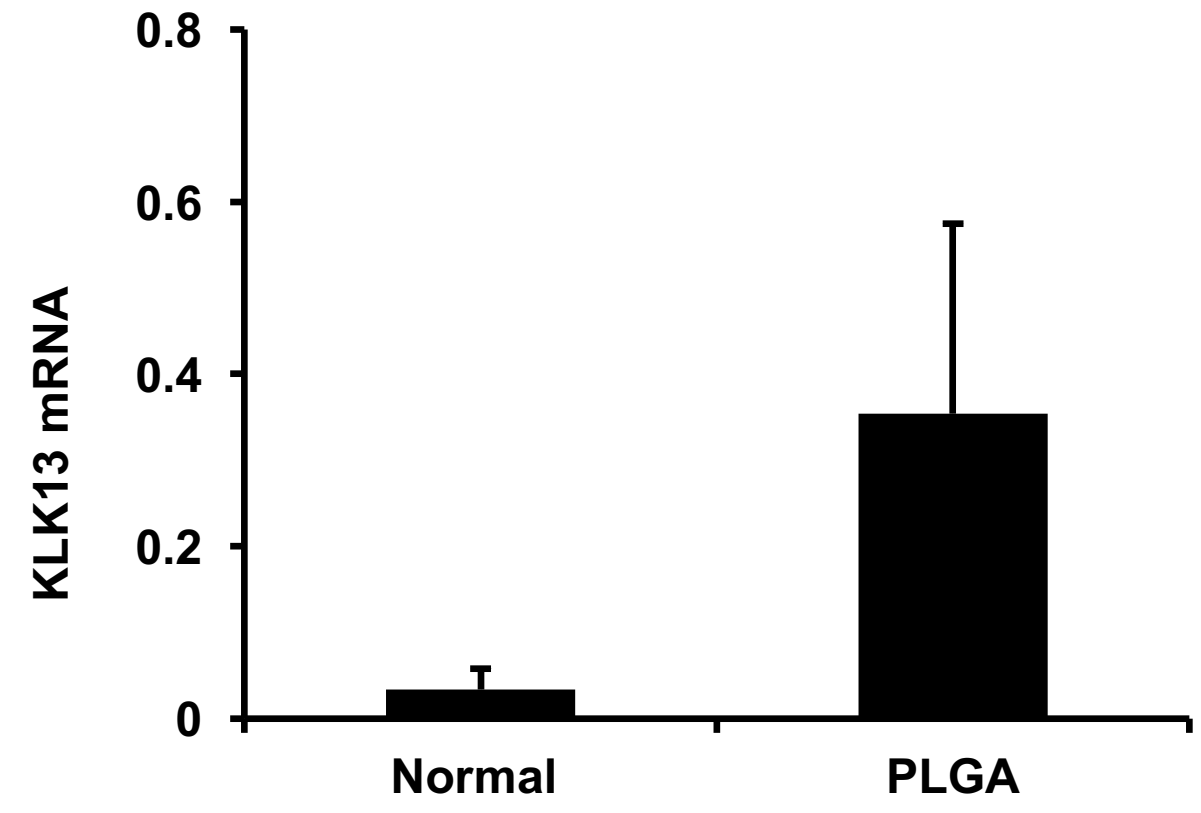

Figure 3.3.14: Mean value of KLK14 mRNA expression in PLGA vs NSGT. Statistical significance determined by Mann Whitney U Test $(p<0.05)$

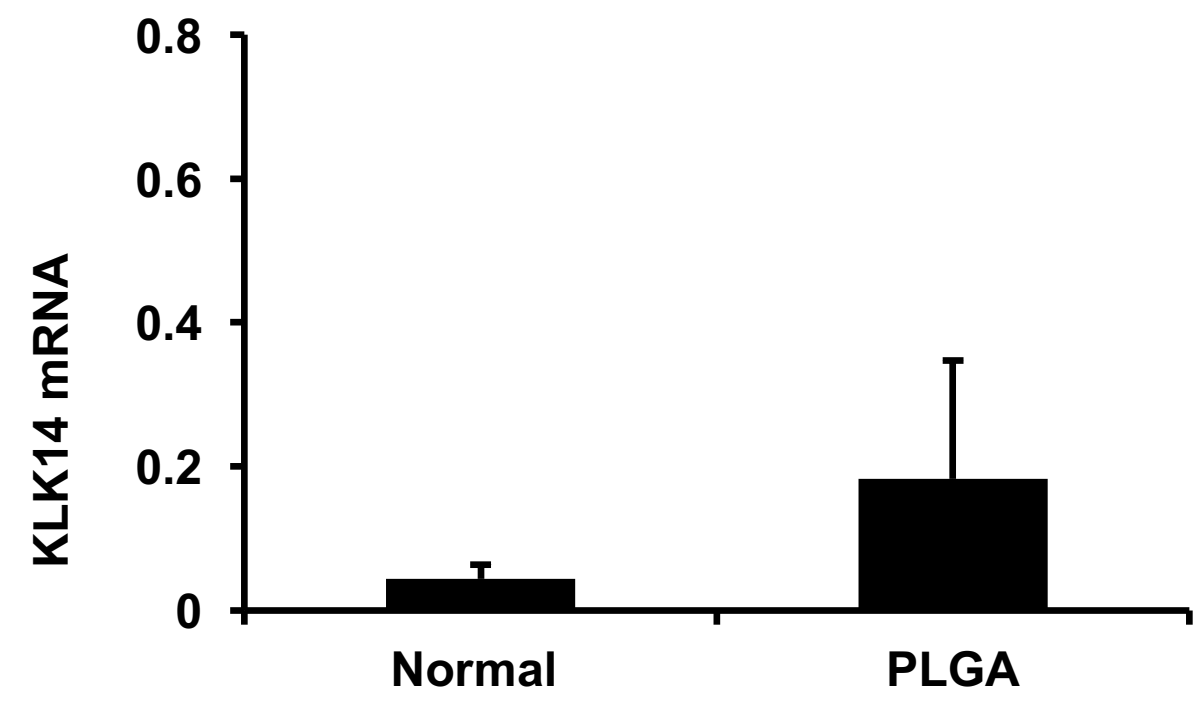


Figure 3.3.15: Mean value of KLK15 mRNA expression in PLGA vs NSGT. Statistical significance determined by Mann Whitney U Test $(p<0.05)$

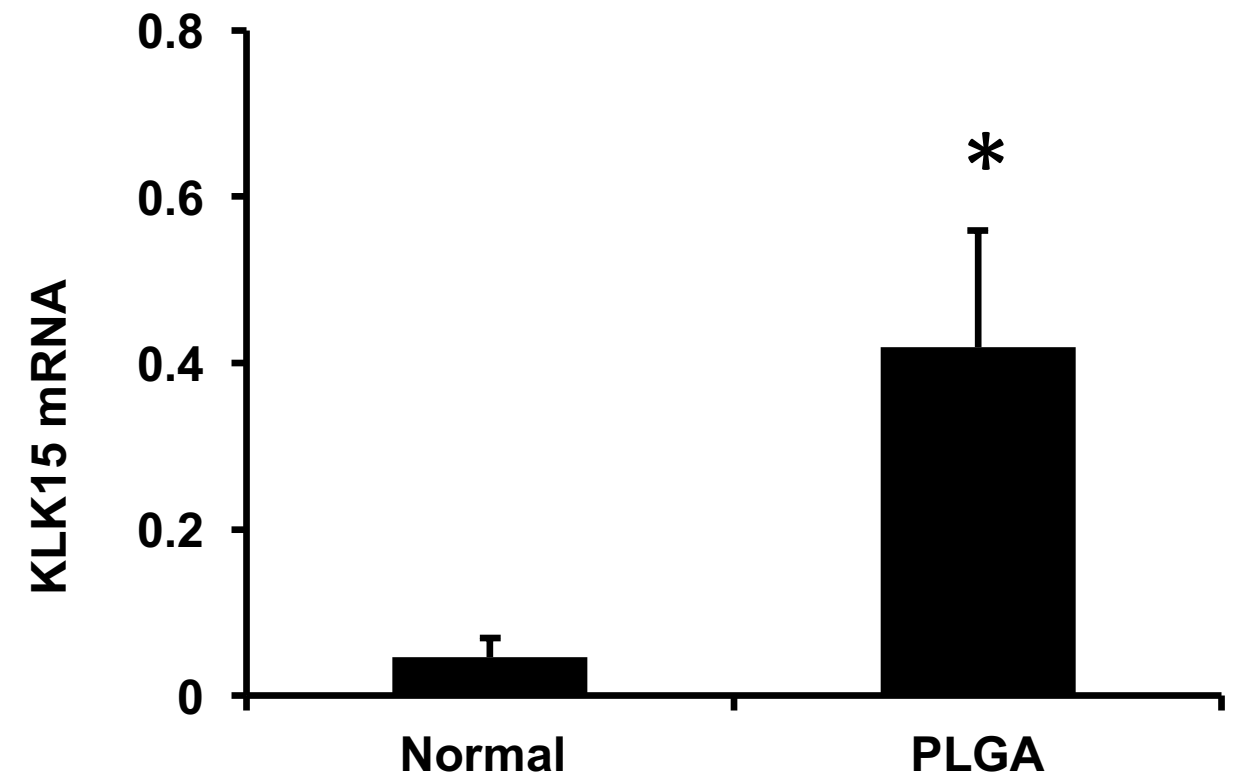

Figure 3.3.16: Relative fold increase of mRNA levels of KLK1-15 in PLGA tissue as compared with normal salivary gland tissues. Statistical significance determined by Mann Whitney U Test ( $p<0.05$; illustrated by asterisk). Standard error of mean (SEM) is demarcated by the error bars.

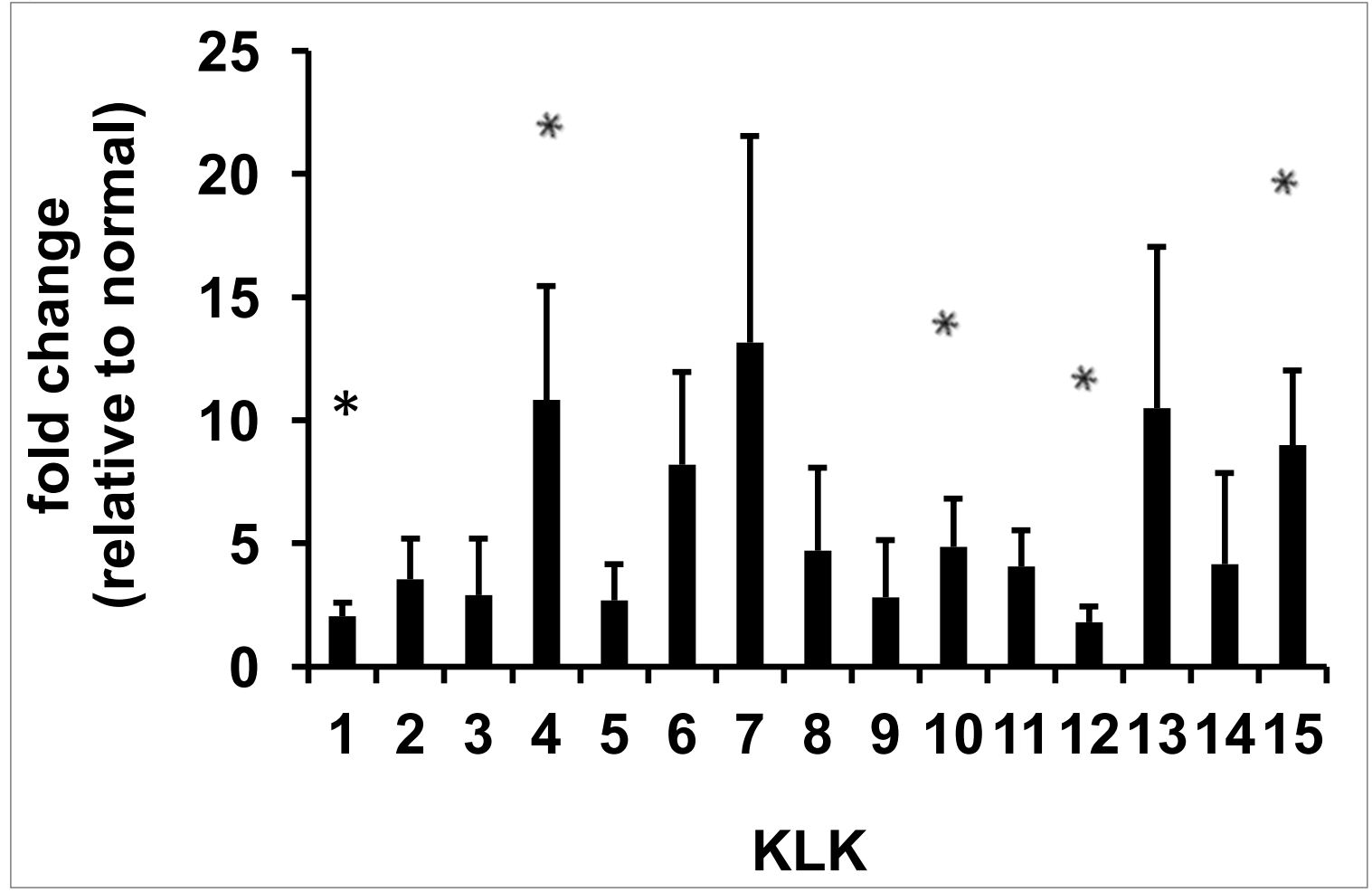


Table 3.3.1 Calculated p-values, as determined by Mann Whitney $U$ Test, for the comparison of expression of KLK1-15 in PLGA tissues and NSGT.

\begin{tabular}{|c|c|}
\hline KLK Gene & p-value \\
\hline KLK1 & 0.00672 \\
\hline KLK2 & 0.82588 \\
\hline KLK3 & 0.59612 \\
\hline KLK4 & 0.03236 \\
\hline KLK5 & 0.238 \\
\hline KLK6 & Sample number low \\
\hline KLK7 & Sample number low \\
\hline KLK8 & 0.15854 \\
\hline KLK9 & 0.71138 \\
\hline KLK10 & 0.00804 \\
\hline KLK11 & Sample number low \\
\hline KLK12 & 0.0536 \\
\hline KLK13 & Sample number low \\
\hline KLK14 & 0.88076 \\
\hline KLK15 & 0.00386 \\
\hline & \\
\hline & \\
\hline & \\
\hline & \\
\hline & \\
\hline & \\
\hline & \\
\hline & \\
\hline & \\
\hline & \\
\hline & \\
\hline & \\
\hline & \\
\hline & \\
\hline
\end{tabular}




\subsection{Immunohistochemical staining results}

Representative immunohistochemical staining images are shown in Figures 4.4.1-4.4.5 of PLGA tissue samples stained for specific KLKs. For each KLK antibody, at least one PLGA sample demonstrating relatively low mRNA expression and one PLGA sample demonstrating relatively high mRNA expression are presented. Negative controls for each PLGA sample were completed with addition of primary antibody and images and are displayed in Figure 4.4.6. Furthermore, positive control tissues were stained for their respective KLK antibody and are presented in Figure 4.4.7. ACC was used as a positive control for a KLK7, skin was used as a positive control for KLK8 and KLK14, NSGT was used as a positive control for KLK10, and prostate tissue was used as a positive control for KLK11.

The IHC staining results are outlined in Table 4.4.1. Samples demonstrating relatively high KLK expression exhibited staining of all tumour cells (grade 5) and the intensity grade of the stains varied from 1-3. Samples demonstrating relative low KLK expression exhibited staining of most tumour cells (grades 4-5) and the intensity grade of the stains varied from $<1-3$. With respect to localization of a specific KLK, the samples with higher mRNA expression demonstrated equivalent or increased grade of immunohistochemical staining, as compared to samples with lower mRNA expression. Most of the KLK immunoreactivity in PLGA samples was primarily cytoplasmic, with some exceptions. Nuclear staining pattern was seen with KLK7 (samples 6\&16), KLK11 (samples 6\&11), and KLK14 (samples 6\&11). KLK10 exhibited inflammatory cell staining in sample 10, and epithelial cell staining in sample 11. All samples noted negative stromal staining. 
Figure 3.4.1 Immunohistochemical localization of KLK7 in PLGA. Sample 6 (a) had relatively low KLK7 mRNA expression on PCR, while Sample 16 (b) had relatively high KLK7 mRNA expression on PCR. \{images taken at 200x magnification; blue = hematoxylin nuclear stain; brown = diaminobenzidine $/ D A B$ chromogen $\}$.
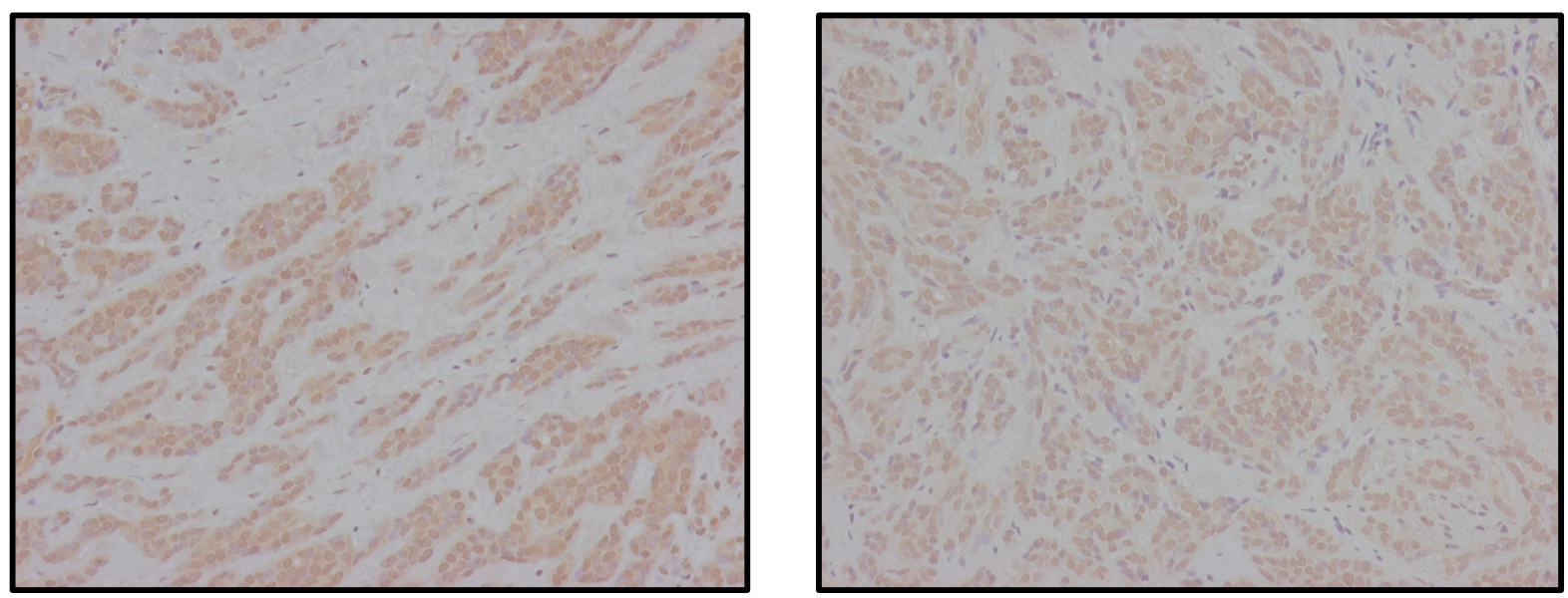

(a)

(b) 
Figure 3.4.2 Immunohistochemical localization of KLK8 in PLGA. Samples 6 and $16(a) \&(b)$ had relatively low KLK8 mRNA expression on PCR, while Sample 11 (c) had relatively high KLK8 mRNA expression on PCR. \{images taken at 200x magnification; blue = hematoxylin nuclear stain; brown = diaminobenzidine/DAB chromogen $\}$.

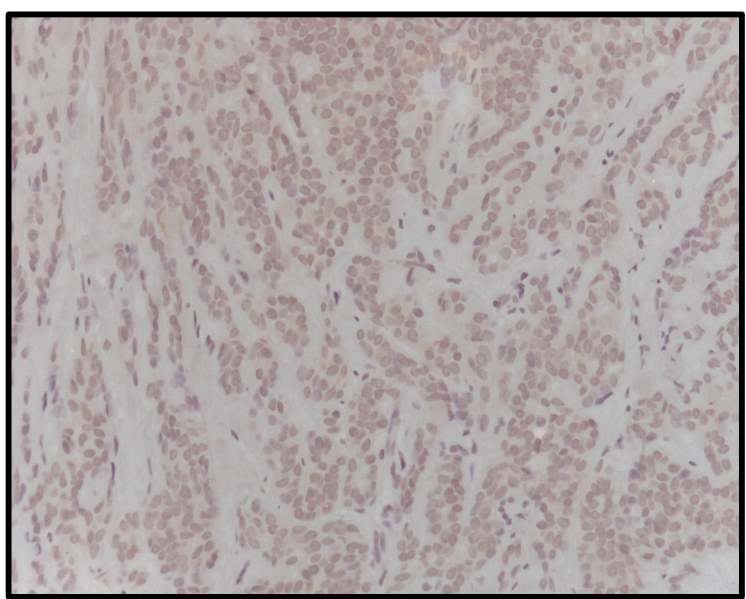

(a)

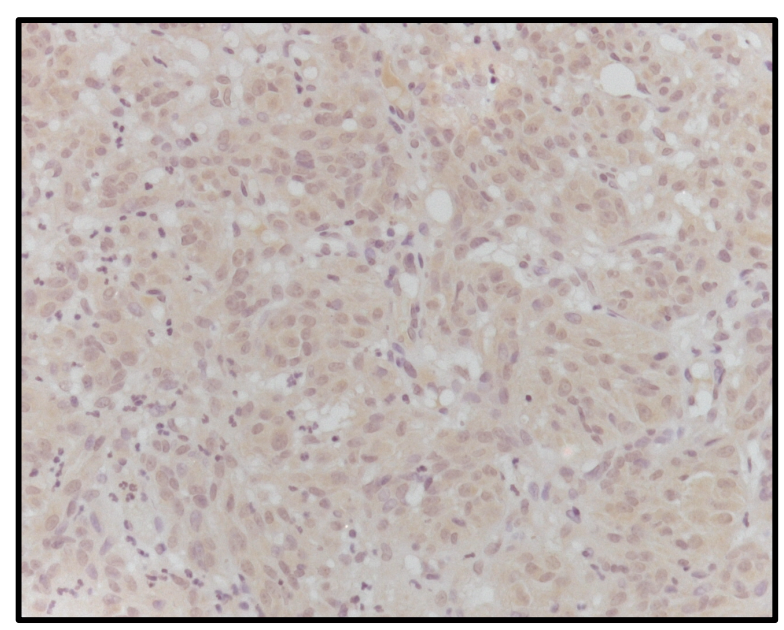

(c)

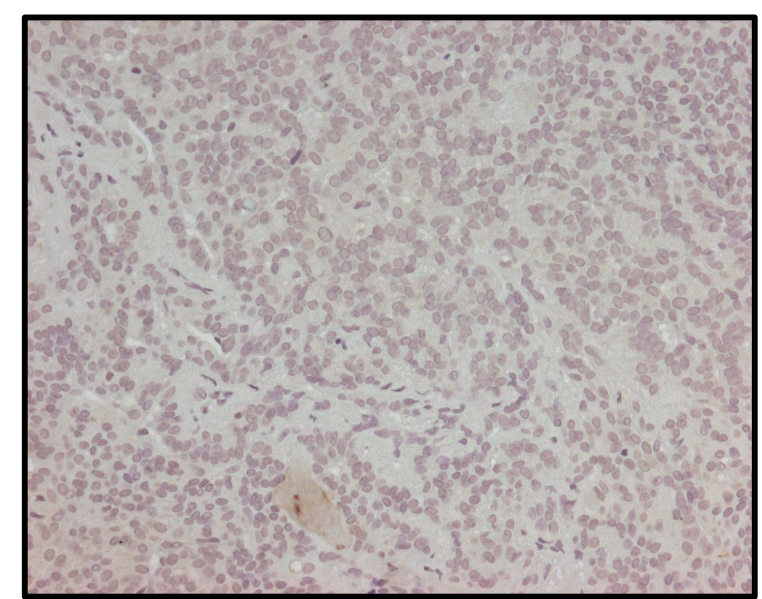

(b) 
Figure 3.4.3 Immunohistochemical localization of KLK10 in PLGA. Sample 11 (a) had relatively low KLK10 mRNA expression on PCR, while Samples $6(b)$ and $10(c)$ had relatively high KLK10 mRNA expression on PCR. \{images taken at 200x magnification; blue = hematoxylin nuclear stain; brown = diaminobenzidine $/ D A B$ chromogen $\}$.

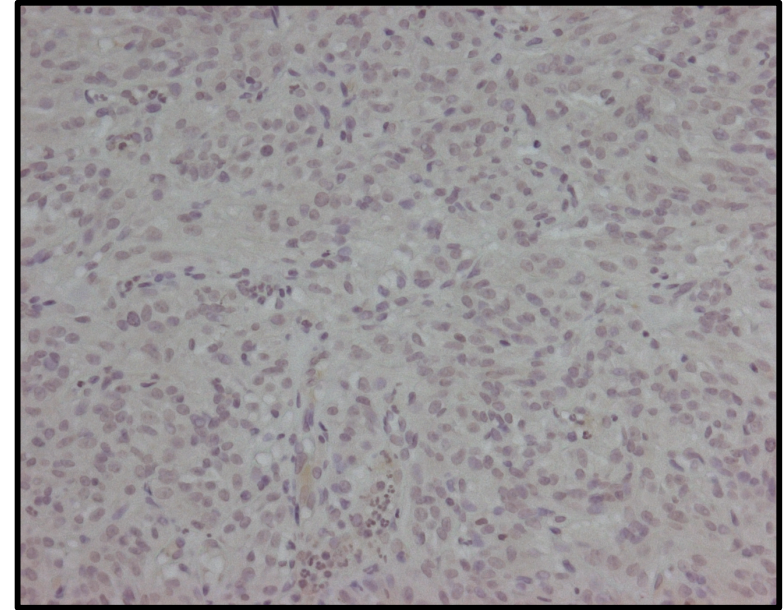

(a)

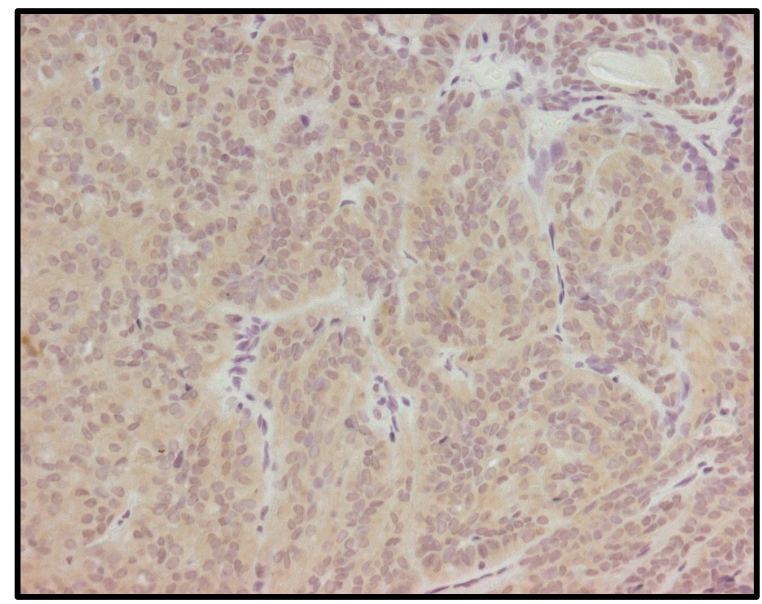

(c)

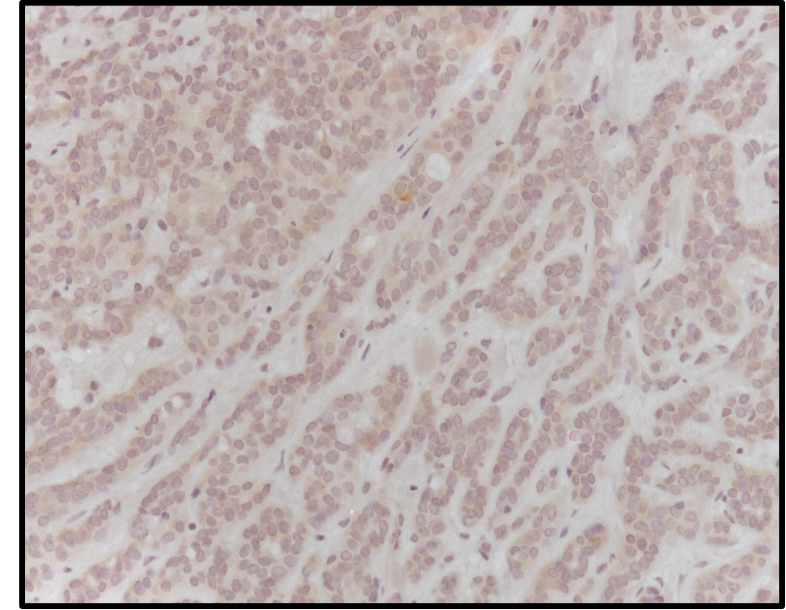

(b) 
Figure 3.4.4 Immunohistochemical localization of KLK11 in PLGA. Sample 6 (a) had relatively low KLK11 mRNA expression on PCR, while Sample 11 (b) had relatively high KLK11 mRNA expression on PCR. \{images taken at 200x magnification; blue = hematoxylin nuclear stain; brown = diaminobenzidine $/ D A B$ chromogen $\}$.

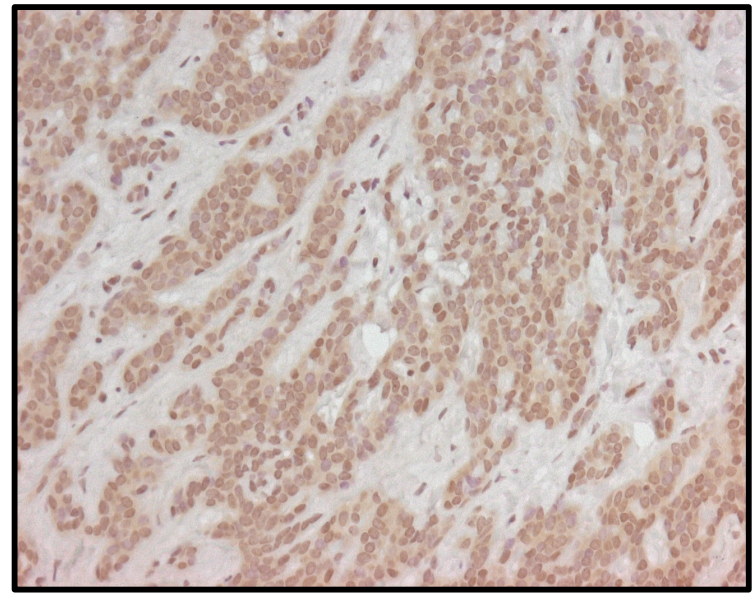

(a)

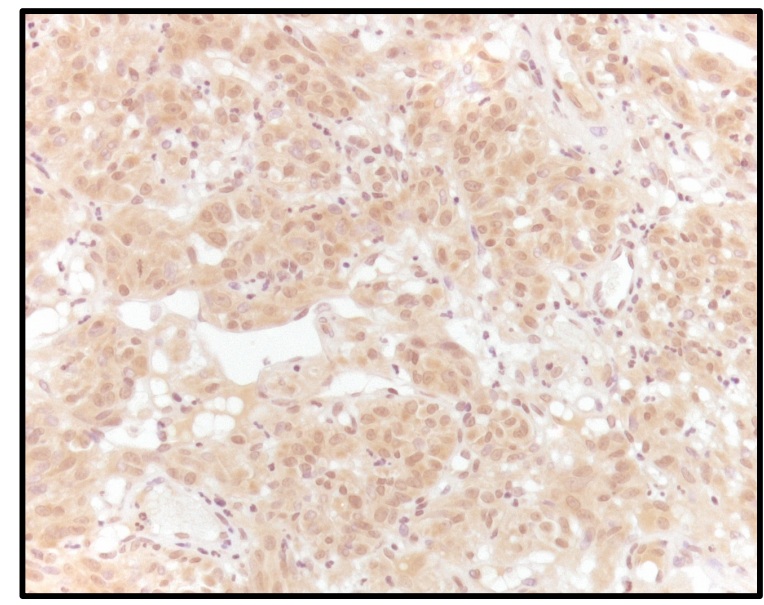

(b) 
Figure 3.4.5 Immunohistochemical localization of KLK14 in PLGA. Sample 6 (a) had relatively low KLK14 mRNA expression on PCR, while Sample 11 (b) had relatively high KLK14 mRNA expression on PCR. \{images taken at 200x magnification; blue = hematoxylin nuclear stain; brown = diaminobenzidine $/ D A B$ chromogen $\}$.

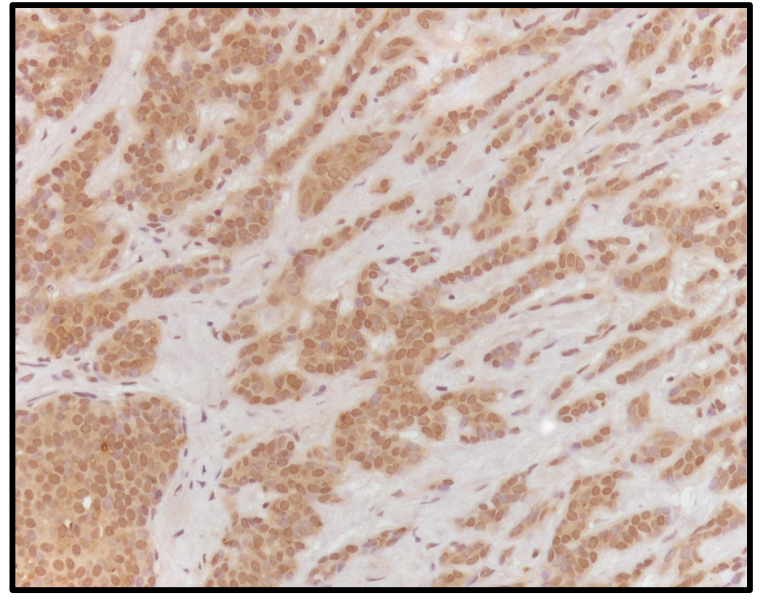

(a)

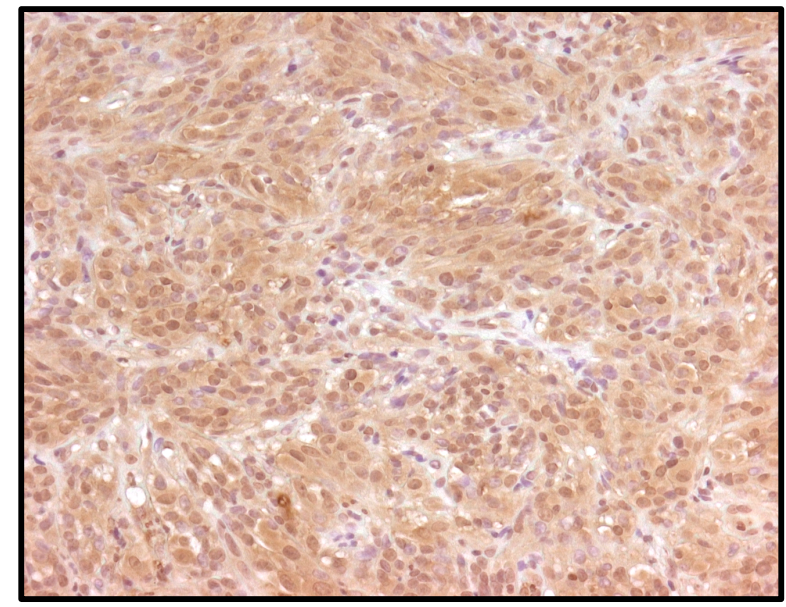

(b) 
Figure 3.4.6 Negative controls for KLK staining. Below (a)-(d) demonstrate IHC on Samples 6, 10,11 , and 16 respectively, completed without KLK (primary) antibody \{images taken at $200 x$ magnification; blue = hematoxylin nuclear stain; brown = diaminobenzidine $/ D A B$ chromogen $\}$.
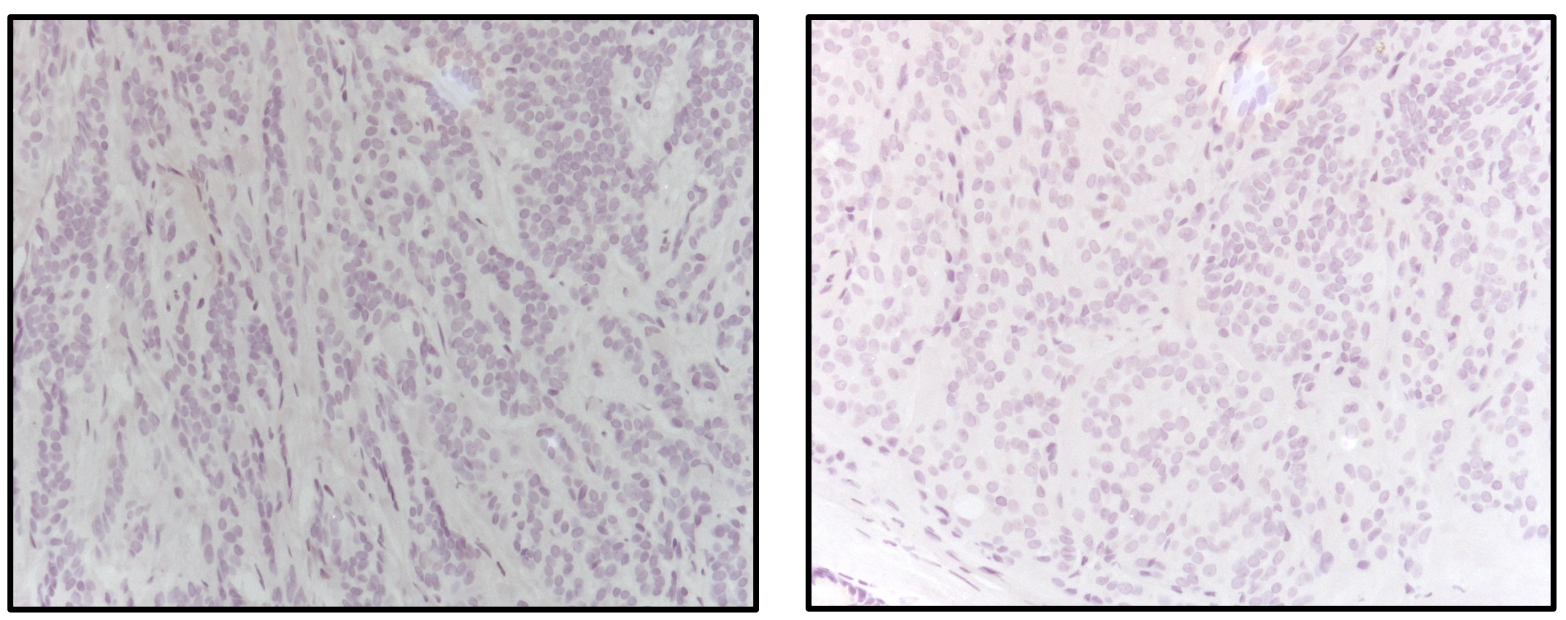

(a)

(b)
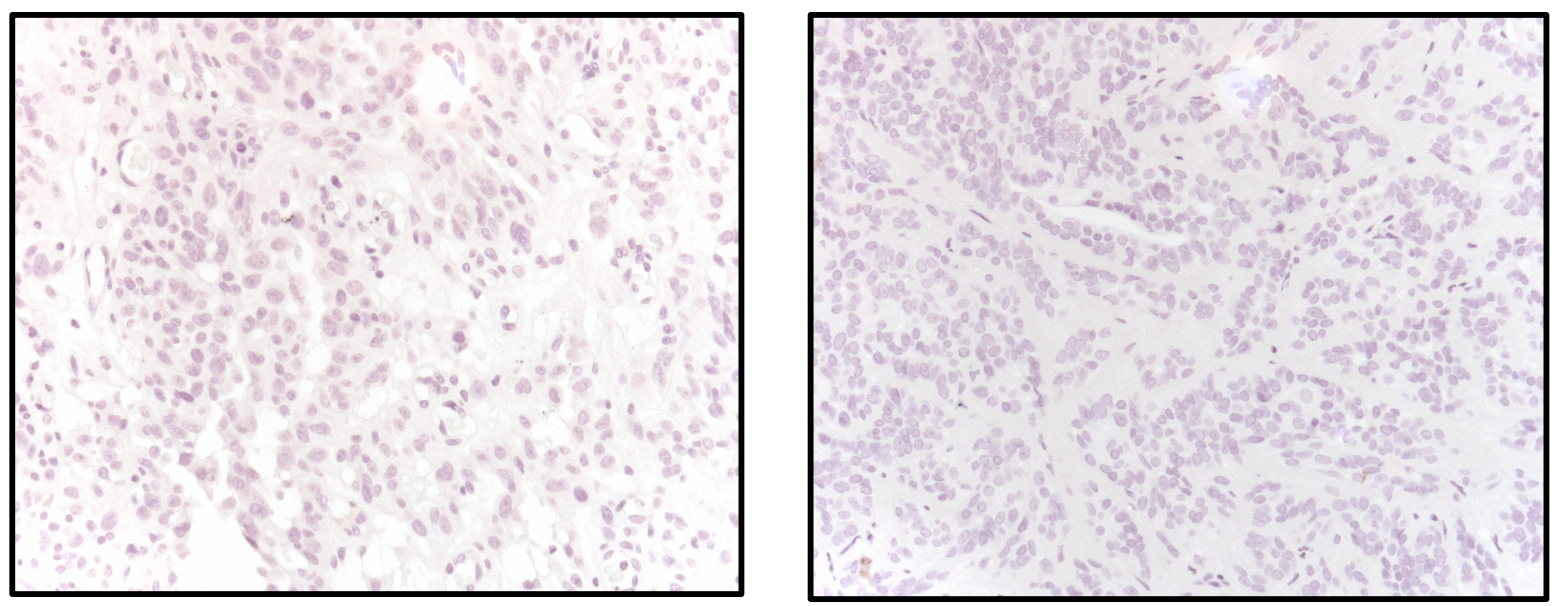

(c)

(d) 
Figure 3.4.7 Immunohistochemical localization of $\mathbf{K L K}$ in controls. Representative immunohistochemical stain images of tissues with known KLK expression are shown. ACC (a) was used as a KLK7 control, Skin (b)\&(e) was used as a control for KLK8 and 14 respectively, NSGT (c) was used as a KLK10 control, and prostate (d) was used as a KLK11 control \{images taken at $200 x$ magnification; blue $=$ hematoxylin nuclear stain $;$ brown $=$ diaminobenzidine $/ D A B$ chromogen\}.

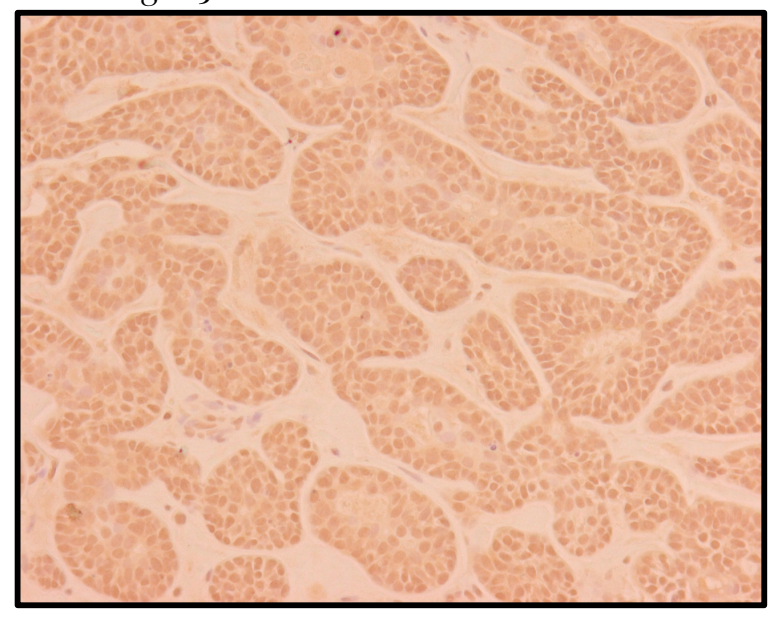

(a)

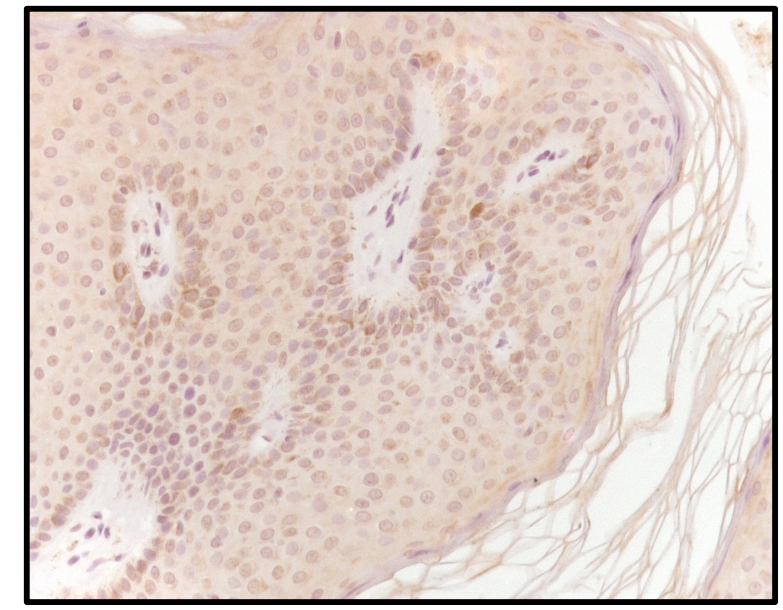

(b)

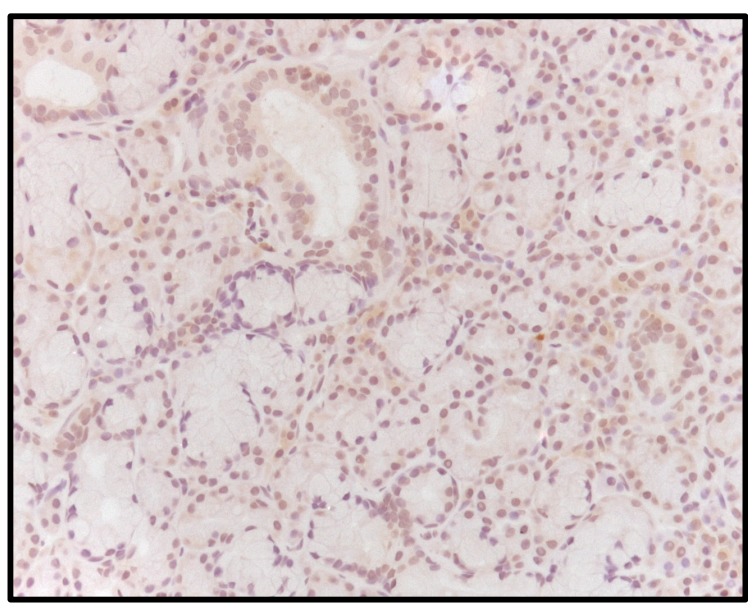

(c)

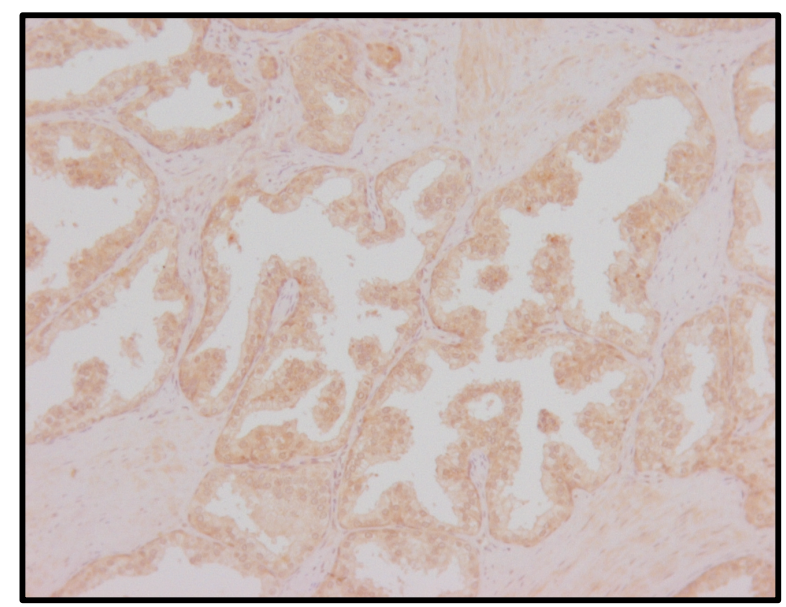

(d) 


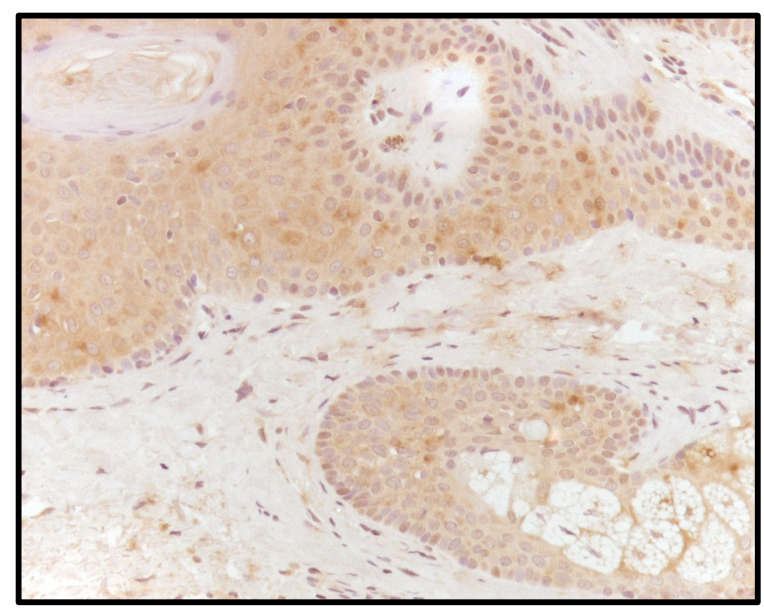

(e) 
Table 3.4.1 Immunohistochemistry stain results. IHC proportionality grade, intensity and overall score are recorded below, along with specific staining characteristics seen in each sample.

\begin{tabular}{|c|c|c|c|c|c|c|c|}
\hline Antibody & $\begin{array}{c}\text { Sample } \\
\#\end{array}$ & $\begin{array}{c}\text { Level } \\
\text { of } \\
\text { mRNA }\end{array}$ & $\begin{array}{c}\text { IHC } \\
\text { Grade }\end{array}$ & $\begin{array}{c}\text { IHC } \\
\text { Intensity }\end{array}$ & $\begin{array}{l}\text { IHC } \\
\text { Score }\end{array}$ & $\begin{array}{c}\text { Stromal } \\
\text { Stain }\end{array}$ & OTHER \\
\hline KLK7 & 6 & low & 5 & 2 & 7 & - & $\begin{array}{l}\text { Cytoplasmic and } \\
\text { nuclear staining }\end{array}$ \\
\hline KLK7 & 16 & high & 5 & 2 & 7 & - & $\begin{array}{l}\text { Cytoplasmic and } \\
\text { nuclear staining }\end{array}$ \\
\hline KLK8 & 6 & low & 4 & $\mathbf{1}$ & 5 & - & $\begin{array}{c}\text { Primarily } \\
\text { cytoplasmic } \\
\text { staining }\end{array}$ \\
\hline KLK8 & 16 & low & 4 & 1 & 5 & - & $\begin{array}{c}\text { Primarily } \\
\text { cytoplasmic } \\
\text { staining }\end{array}$ \\
\hline KLK8 & 11 & high & 5 & 1 & 6 & - & $\begin{array}{l}\text { All cytoplasmic } \\
\text { staining }\end{array}$ \\
\hline KLK10 & 11 & low & 5 & 1 & 6 & - & $\begin{array}{l}\text { Epithelial positive } \\
\text { cells }\end{array}$ \\
\hline KLK10 & 6 & high & 5 & 1 & 6 & - & $\begin{array}{l}\text { All cytoplasmic } \\
\text { staining }\end{array}$ \\
\hline KLK10 & 10 & high & 5 & 1 & 6 & - & $\begin{array}{c}\text { All cytoplasmic } \\
\text { staining; } \\
\text { inflammatory } \\
\text { cells staining } \\
\text { positively }\end{array}$ \\
\hline KLK11 & 6 & low & 5 & 2 & 7 & - & $\begin{array}{c}\text { Primary } \\
\text { cytoplasmic } \\
\text { staining; many } \\
\text { nuclei staining }\end{array}$ \\
\hline KLK11 & 11 & high & 5 & 3 & 8 & - & $\begin{array}{c}\text { Primary } \\
\text { cytoplasmic } \\
\text { staining; some } \\
\text { positive and } \\
\text { negative nuclei }\end{array}$ \\
\hline
\end{tabular}




\begin{tabular}{|c|c|c|c|c|c|c|c|}
\hline KLK14 & 6 & low & 5 & 3 & 8 & - & $\begin{array}{c}\text { Primarily } \\
\text { cytoplasmic } \\
\text { staining; some } \\
\text { nuclei staining }\end{array}$ \\
\hline KLK14 & 11 & high & 5 & 3 & 8 & - & $\begin{array}{c}\text { Primarily } \\
\text { cytoplasmic } \\
\text { staining; much } \\
\text { nuclear staining }\end{array}$ \\
\hline
\end{tabular}

Table 3.5.1 Summary of PCR and IHC results

\begin{tabular}{|c|c|c|c|c|c|c|c|c|c|c|}
\hline & \multicolumn{2}{|c|}{$\begin{array}{c}\text { Total PLGA } \\
\text { Samples }\end{array}$} & \multicolumn{2}{|c|}{ Case 6} & \multicolumn{2}{|c|}{ Case 10} & \multicolumn{2}{|c|}{ Case 11} & \multicolumn{2}{|c|}{ Case 16} \\
\hline & $\begin{array}{l}\text { average } \\
\text { level of } \\
\text { mRNA }\end{array}$ & $\begin{array}{l}\text { Median } \\
\text { value of } \\
\text { mRNA }\end{array}$ & mRNA & $\begin{array}{l}\text { IHC } \\
\text { score }\end{array}$ & mRNA & $\begin{array}{l}\text { IHC } \\
\text { score }\end{array}$ & mRNA & $\begin{array}{l}\text { IHC } \\
\text { score }\end{array}$ & mRNA & $\begin{array}{l}\text { IHC } \\
\text { score }\end{array}$ \\
\hline KLK7 & 0.45908 & 0.37725 & $\begin{array}{c}\text { Low, } \\
0.0\end{array}$ & 7 & & & & & $\begin{array}{c}\text { High, } \\
0.377251\end{array}$ & 7 \\
\hline KLK8 & 0.25982 & 0.09694 & $\begin{array}{c}\text { Low, } \\
0.0969368\end{array}$ & 5 & & & $\begin{array}{c}\text { High, } \\
1.0\end{array}$ & 7 & $\begin{array}{c}\text { Low, } \\
0.1049704\end{array}$ & 5 \\
\hline KLK10 & 0.27191 & 0.12312 & $\begin{array}{c}\text { High, } \\
\mathbf{0 . 2 2 5 2 3 4}\end{array}$ & 6 & $\begin{array}{c}\text { High, } \\
0.138793\end{array}$ & 6 & $\begin{array}{c}\text { Low, } \\
0.048942\end{array}$ & 6 & & \\
\hline KLK11 & 0.51035 & 0.44622 & $\begin{array}{c}\text { Low, } \\
0.0\end{array}$ & 7 & & & $\begin{array}{c}\text { High, } \\
1.0\end{array}$ & 8 & & \\
\hline KLK14 & 0.18320 & 0.02862 & $\begin{array}{c}\text { Low, } \\
0.02862\end{array}$ & 8 & & & $\begin{array}{c}\text { High, } \\
1.0\end{array}$ & 8 & & \\
\hline
\end{tabular}




\subsection{PCR and IHC Correlation}

The results from PCR KLK mRNA quantification and IHC staining were compared and the findings are summarized in Table 4.5.1. 


\section{Chapter 4}

\subsection{Discussion}

\subsection{Increased mRNA levels of KLKs in PLGA}

Our study confirms the hypothesis that KLKs are aberrantly expression in PLGA. Through qPCR, we demonstrated that KLK mRNA levels are increased in PLGA compared to normal salivary gland tissues. This upregulation was statistically significant for KLK1, KLK4, KLK10, KLK12, and KLK15, as determined by Mann Whitney U Test $(\mathrm{p}<0.05)$. We also noted greater variability in mRNA levels of KLK6, KLK7, KLK11 and KLK13; indicative of lower percentages of samples expressing these KLKs: $25 \%, 18.8 \%, 25 \%$ and $25 \%$, respectively.

\subsection{IHC demonstrates PLGA tumour cell-specific staining pattern}

To address whether KLK upregulation in PLGA samples was specific to the tumour cells, we performed immunohistochemistry. For these studies, we randomly selected patient samples showing relatively high and low mRNA levels (arbitrary) for KLK for which antibodies were available. These KLKs included KLK7, KLK8, KLK10, KLK11, and KLK14. PLGA samples were stained and evaluated, using a well-documented system[76]. Proportion scores for each PLGA case stained with KLK antibody noted most tumour cells were staining positive (proportion score 5), save for two samples with KLK8 demonstrating scores of 4, indicating slightly less percentage of tumour cells which were immunoreactive. Intensity scores varied between cases. These results confirmed our hypothesis that tumour cells are the primary source of KLK mRNA.

\subsection{KLK mRNA profile of PLGA vs ACC}

Our laboratory has recently profiled ACC samples for KLK mRNA levels, providing us with a unique opportunity to compare the profile to PLGA [84]. ACC samples exhibited significantly lower levels of KLK1, KLK8, KLK11 and KLK14 compared to NSGT; the remaining KLKs were expressed at levels comparable to that of NSGT[84]. In the present study, KLK1, KLK4, KLK10, KLK12, and KLK15 were found to be significantly upregulated when compared to NSGT. These differences, particularly KLK1, may be useful in distinguishing PLGA from ACC, which can pose a diagnostic challenge due to their histomorphologic resemblance[14, 34]. 
Microscopically, both PLGA and ACC exhibit diffusely invasive borders, solid and cribriform growth patterns, and perineural invasion[35]. ACC is more common in major salivary glands, which is a distinguishing feature versus PLGA's predilection for the minor salivary glands; smaller cell size with less cytoplasm and nuclear features may also differentiate ACC from PLGA[6, 9]. Due to their prognostic distinctions, ACC having a worse prognosis and more aggressive clinical course as compared to PLGA, misdiagnosis between these two tumours would be an erroneous pitfall[9]. KLK1 mRNA was present in 73\% of ACC samples studied by Kerr et $a l$, and in the present study, KLK1 mRNA was expressed in 87.5\% of PLGA samples[84]. Given KLK1 was found to be significantly downregulated in ACC and significantly upregulated in PLGA, this difference may lend itself to establishing a diagnostic panel, differentiating these two salivary gland tumours.

\subsection{Analysis of IHC staining of KLKs in PLGA}

Overall, each sample with a relatively higher expression of KLK mRNA stained equivalently or with a higher IHC score than the samples which had relatively lower KLK mRNA expression. For KLK7, sample 6 demonstrated no mRNA expression, and sample 16 showed relatively higher expression; however, both samples had equivalent IHC scores of 7. Similarly, for KLK10, sample 11 had relatively low mRNA expression in comparison to samples 6 and 10, yet the IHC score for all samples was 6. Furthermore, for KLK14, sample 6 had relatively low mRNA expression in comparison to sample 11; IHC scores for both samples were 8. A small increase was seen between samples for KLK11, with sample 6 demonstrating undetectable mRNA and an IHC score of 7, while sample 11 having relatively higher mRNA expression and an IHC score of 8 . The most significant difference was seen with KLK8; sample 6 and sample 16 demonstrated relatively lower mRNA levels and had IHC scores of 5, while sample 11 had relatively high mRNA and an IHC score of 7.

Additional IHC staining results note that all samples demonstrated negative stromal staining. Most samples exhibited primarily cytoplasmic staining for KLK. Nuclear staining was seen for KLK7, KLK11 and KLK14. KLK10 demonstrated positive epithelial cell staining in sample 11, while inflammatory cells stained positive for KLK10 in sample 10. Nuclear staining with KLK7 in PLGA mirrors previous IHC results from PA, ACC, and MEC samples from our laboratory[67]. 
It is currently not clear as to why a sample with no demonstrable KLK mRNA on PCR would stain positively for KLK protein. There could be a number of factors involved. For example, immunoreactivity may represent sequestered protein rather than tumour-expressed protein. The reactivity may also suggest high endogenous peroxidase activity in the PLGA specimens; although, this may usually be confined to red and white blood cells[89]. Furthermore, this could be attributed to nonspecific staining of the PLGA tissue samples. Tissue handling, including fixative exposure and tissue desiccation may also contribute to non-specific staining.

The no to minimal differences in IHC scores between samples with low and high mRNA expression may be explained by a number of postulations. PCR determines the amount of mRNA, which may not perfectly correlate with the amount of protein assessed by IHC. Tumour cells may be increasing mRNA stability which may lead to higher levels of transcripts. It is also possible that since KLKs are secreted proteases, the rate of secretion may outpace translation. However, these interesting avenues need further testing.

\subsection{IHC staining of KLKs in salivary gland neoplasia}

Darling et al., and Hashem et al. have completed significant work on KLK IHC staining profiles of salivary gland neoplasia, as well as NSGT, including most of the KLKs used in this study (KLK7, 8, 10 and 14). Hashem et al. noted KLK7 was significantly overexpressed in PA and ACC (OSS 7.0 and 7.5 respectively), when compared to NSGT (OSS 6.5)[67]. Furthermore, MEC (OSS 6.33) was not significantly different from NSGT. The PLGA cases in this study, whether they had relatively low or higher mRNA expression, both had OSS of 7.0, which we can extrapolate as significantly increased as compared to NSGT. In previous work by Darling et al., KLK8 was shown to be expressed in NSGT (OSS 7.0), and to demonstrate equal or increased OSS in most malignancies: ACC (OSS 7.0+/-1.4), PLGA (OSS 6.9+/-0.5), ACI (OSS 7.0+/-0.8), ANOS (OSS 7.6+/-0.7), and MEC (OSS 7.5+/-0.5)[54]. In the present study, OSS in relative lowexpressing KLK8 mRNA samples was 5, and in relatively higher expressing KLK8 mRNA samples was 7, which is reasonably consistent with previous work. Darling et al. also described KLK10 as found in NSGT (OSS 6.0), and no significant differences in KLK10 expression were seen in malignancy: ACC (OSS 5.8), MEC (OSS 6.3)[55]. PLGA was not investigated in Darling et al.'s study; however, in the present study, the OSS for KLK10 of our PLGA samples were consistent with the other salivary gland malignancies studied (OSS 6 for all three cases). Hashem 
et al. noted KLK14 was present in NSGT (OSS 6.5), and that, while KLK14 was upregulated in PA (OSS 7.25), there was no significant differences seen in salivary gland malignancies: MEC (OSS 6.14), ACC (OSS 6.8)[55, 75]. KLK14 stains in our PLGA samples demonstrated OSS of 8, despite differences in mRNA levels. Taken together, KLK14 may be recognized as over-expressed in PLGA. Darling et al. noted KLK7, 10 and 14 appeared to be correlated in their expression in ACC, all demonstrating no significant difference from NSGT. This same correlation does not seem evident in our staining of PLGA; KLK7 and 14 show similar IHC profiles, but KLK10 shows lower staining scores.

Additional IHC include nuclear staining seen with KLK7, KLK11 and KLK14. This could suggest a role for these specific KLKs in transcription. Moreover, we could extrapolate that in PLGA tumours, specific KLKs are active at the nuclear level to aberrantly regulate transcription, leading to tumour pathogenic behaviour. Inflammatory cell staining was observed with KLK10, which could demonstrate its involvement with an inflammatory process, contributing to malignant features in the PLGA tumour.

In our experiment, we did not compare NSGT and PLGA staining, as we were interested in correlated data from PCR (mRNA expression levels) with IHC, look to elucidate tumour specific staining. However, by review previous works that have used the same IHC protocol and staining scoring systems, this present study has added value to further characterizing KLK IHC staining profiles in salivary gland neoplasia.

\subsection{Study Limitations}

A limitation to this experimental design is that we are unable to detect whether the KLK protein is indeed active, we are only able to localize the protein. It is well established that KLKs go through an extensive processing in order to be activated; this occurs through the "KLK Activome"[60]. KLK genes are transcribed into a pre-pro-enzyme, which goes on to be proteolytically processed into an inactive pro-KLK, which become secreted by cleaving their amino terminal signal peptide[57]. Lastly, the pro-KLK is activated into a mature peptidase extracellularly, by the cleavage of the amino terminal propeptide[51, 60]. This cleavage may be done by the KLK itself, a different KLK, or a different protease[57,63]. To determine the amount of active KLK peptidases, one may consider measuring for the peptidase that leads to the final activation cleavage process. 
Another limitation to the study design was the decision to utilize the entire tissue $3 \times 10 \mu \mathrm{m}$ tissue curls from the PLGA tissue samples, rather than selecting out for tumour tissue only. Therefore, in addition to tumour cells, stromal cells and normal salivary gland tissue were undeniably used in the experimentations, and this may have introduced a source of variability into the results.

An additional limitation to the experimental design was the PLGA tissue samples coming from FFPE, stored in archives over a range of years (1987-2013). There has been suggestion that perhaps the length of storage of FFPE has effect on extracting macromolecules; however, in 2013, Kokkat, et al., demonstrated no significant difference between macromolecules extracted from FFPE blocks stored from a decade in comparison to current year blocks[90]. Some of our tissue samples were stored greater than 12 years, and perhaps this affected our results and could account for lack of specific KLK expression in our PLGA tissue samples. RNA does degrade over its storage time; however, partially degraded samples may still be used in downstream experiments, such as PCR[90]. Moreover, cross-linking as a result of the fixation process affects RNA extraction, but the molecules remain recoverable, in fragmented forms, which are useable for analysis, including determining mRNA expression[91]. It could be postulated that using fresh frozen tissue samples of PLGA tumour would yield more high quality nucleic acids, and this could have altered our results[91].

A limitation to be addressed is that the RT-PCR experiments carried out on NSGT samples were completed by our group prior to completing RT-PCR on the PLGA samples used in our study. These two data sets were compared, despite being run at different times. A criticism of this would be that these data sets do not represent experiments run under the same conditions, as there can be day to day changes in fluorescence. As a means to combat this, good PCR practice is maintained with ensuring the housekeeping gene ( $\beta$-actin) is 1-3 cycle thresholds of the normal. Repeating RT-PCR with both samples at the same interval may be of benefit and eliminate this weakness in our study.

Another limitation to our study includes KLK antibody availability, as the only antibodies accessible for this experiment were KLK7, KLK8, KLK10, KLK11, and KLK14. Unfortunately, all of these selected KLKs, except KLK10, are represented in the PLGA samples at low percentages. For example, KLK7 was only expressed in $18.8 \%$ of PLGA samples. The exception was KLK10, shown to be expressed in $62.5 \%$ of PLGA samples. 
Also, we chose to select representative PLGA samples for IHC, one with relatively higher mRNA expression for a specific KLK, and one for relatively lower mRNA expression for a specific KLK. This was done to address our aim of whether or not the increased expression of KLK mRNA was tumour specific. To further support our finding of IHC scores being equivalent or higher in those samples demonstrating relatively higher KLK mRNA as compared to those with relatively lower KLK mRNA expression, all of our PLGA tissue samples could have been stained with the available KLK antibodies.

Lastly, a limitation to our study includes our inability to designate a single KLK as a biomarker for PLGA. As we note, KLKs are co-expressed in salivary gland neoplasia and we suspect KLKs to be acting in proteolytic cascades[75]. Therefore, what holds more promise is developing a pattern of KLK expression seen in PLGA, in comparison to different salivary gland tumours.

\subsection{Future directions}

\subsubsection{PLGA and activation of a kallikrein protein cascade}

Gene expression of KLK1-15 was shown to be increased in PLGA tissue samples, relative to NSGT. This may indicate that all of the KLKs are involved in a complex proteolytic cascade in these salivary gland tumours, involving the transcription, translation and activation of each KLK. A method of confirming this increased transcription of the KLK chromosome locus in PLGA could involve examining the expression of the nearby genes for increased expression, mimicking that of KLKs, in PLGA tissue samples. On the centromeric end, the KLK chromosome locus 19q13.4 is flanked by testicular acid phosphatase (ACPT) and on the telomeric end, it is flanked by cancerassociated gene (CAG) and Siglec-9[50]. We could measure transcript levels of ACPT, CAG and Siglec-9 in PLGA samples to test this notion. If and when it is established that there is an increase of both KLK1-15 transcription and their flanking genes ACPT, CAG, Siglec-9, further experiments could confirm the mechanisms of aberrant transcriptional activity of this region. This could be achieved by investigating epigenetic alterations in PLGA tissue samples. Genomic imprinting is an epigenetic process, which may include DNA methylation, histone modification, and/or chromatin folding[92]. Imprinted genes are thought to occur in clusters and may have associations with signalling pathways[93]. Genomic imprinting is known to contribute to various human diseases, including Prader-Willi and Angelman's syndrome; it is also thought to be 
associated with the development and progression of malignancies[94]. Specifically, DNA methylation is often associated with shutting a gene "off" and therefore, DNA hypomethylation leads to an aberrant increase in gene transcription, thought to be implicated in cancer development and progression[94]. Methylation assays could be utilized for the KLK chromosome locus 19q13.4, and surrounding regions, in PLGA samples[92]. Results of DNA hypomethylation would indicate increased transcription of this locus in the development of PLGA tumours. Taken together, this increased expression of the KLK chromosome locus and surrounding genes, with epigenetic modifications to promote increased transcription, would support an active proteolytic cascade involving KLK1-15 in PLGA tumours.

\subsubsection{KLK upregulation and PRDK1 Hotspot Mutation in PLGA}

PRKD1 is a gene that encodes a kinase, which has been implicated in a whole host of malignant processes, including: colorectal, breast, esophageal, laryngeal, and other cancers[26, 27, 37]. In 2014, Weinreb et al. identified a PRDK1 hotspot mutation encoding p.Glu710Asp in PLGA[27]. Upon examining their tumour bank, they found this hotspot mutation was present in $72.9 \%$ of cases[27]. Subsequently, the group concluded the PRDK1 mutation conferred a neoplastic advantage to the PLGA tumour cells, as there was a significant increase in metastaticfree survival time in those with the mutation[27]. Given that PLGA is primarily indolent in nature, with a low incidence of distant metastasis, this may speak to the nature of the malignancy itself, rather than the hotspot mutation[11].

It would be of value to examine the PLGA samples from our study for the PRDK1 hotspot mutation. This could be done by sequencing the PLGA samples, obtaining PRDK1 primers and completing PCR amplification to localize for the hotspot mutation. Subsequently, this could then be compared to our KLK data, examining the level of mRNA expression of particular KLKs in each sample of PLGA having the hotspot mutation. Taken together, we would expect the samples that have significant increased expression of KLKs would also express the PRDK1 hotspot mutation.

\subsubsection{PLGA cell lines, KLK overexpression and knockdown}

To better elucidate the function of KLKs in PLGA, it would be useful to study the effect of their activity or lack thereof on cancer cells. Previous studies have investigated the functional significance of select KLKs in cancer cell lines. In 1998, Goyal et al. transfected KLK10-negative 
breast tumour cell lines with KLK10, and injected the cells in nude mice. They found that KLK10 overexpression inhibited tumour growth suggesting a tumour suppression role of KLK10 in breast cancer[95]. More recently, $\mathrm{Hu}$ et al. performed a similar study in prostate cancer cells and also showed that KLK10 conferred a tumour suppression role [96].

To our knowledge, KLK expression, and the resultant behaviour, has not been examined in PLGA cell lines. When examining the consequences of PRDK1 mutation in cell behaviour, Weinreb et al. used non-malignant breast epithelial cell lines, as PLGA cell lines and nonmalignant minor salivary gland cell models were not available[27]. It would be ideal to have an established cell line from PLGA tumours; however, should this not be possible, there would be value in examining cell behaviour in non-malignant breast epithelial cell lines with modulated KLK expression. From the results of our study, it would be reasonable to examine either KLK1, $4,10,12$, or 15 , as they were statistically upregulated, when compared to NSGT. An expression vector, for example coding for KLK1, or an empty vector could be transfected into cells, and subsequent in vitro cell migration and invasion assays and cell proliferation assays would then be performed to examine cell behaviour. Cells expressing KLK1 and KLK1 knockdown cells would be compared. In addition, cells with modulated KLK may be injected in nude mice and characteristics such as tumour growth, invasion and metastasis would be examined and compared. A functional study such as this design could provide useful information for tumour characterization, prognosis, clinical behaviour, and potentially lead to therapeutic targets[96].

\subsubsection{Gender role in PLGA}

PLGA more commonly occur in females, with a female-to-male ratio of $2.15: 1[11,19]$. In our study, we presented 19 cases of PLGA, 13 of which were found in women, yielding an above average percentage of female patients. Given our results of increased expression of KLKs in PLGA, it is interesting to postulate why this gender over-representation may be and if this contributes to our overall results. It seems unclear as to why women are more likely than men to get PLGA; however, a reasonable thought could be the involvement of hormones in the regulation of tumour cells. Additionally, it would be useful to retrospectively examine the clinical features of each tumour sample. For example, determining if recurrences were seen more with female or male patients, or if clinical behaviour seemed to be gender specific. Unfortunately, with such a small sample size of 19, clinical significance would not be obtainable. Perhaps a multi-centre 
retrospective analysis of patients with PLGA and the role of gender on tumour characteristics would be a useful task.

\subsubsection{KLK as biomarkers in PLGA}

We note a limitation to our study was the inability to demonstrate a single KLK as a biomarker for PLGA; however, we have added to the KLK expression profile of PLGA, with hopes of further developing a recognizable KLK pattern in PLGA, when compared to other salivary gland neoplasia. A way to add information to KLK pattern in PLGA would be to examine released KLK in bodily secretions (e.g. saliva) in patients with known PLGA. FFPE tissue from the patient's tumour would be used to examine KLK mRNA expression; however, this would then be compared released KLK protein in saliva, as determined by ELISA, to note any significant differences. As described in previous sections, biomarkers have been categorized as pharmacodynamics, prognostic, and predictive. While it would be an aim of future directions to develop an efficacious biomarker for PLGA which is diagnostic, it would also be valuable to have a prognostic biomarker, which could indicate the likely clinical course of disease the patient would endure if not treated, and/or the likely outcome of disease apart from treatment selection. A biomarker for PLGA would be unlikely to be pharmacodynamic and/or predictive, given the use of drug therapy has no demonstrable benefit at present. Again, we anticipate that multiple KLKs are involved in functional protein cascades and this additional experimentation would aid in further developing the KLK profile in salivary gland pathology. 


\section{Chapter 5}

\subsection{Conclusion}

This study examined the expression of human tissue kallikreins in PLGA. Quantification of KLK1-15 mRNA in this tumour has not been reported to date. Through RT-qPCR, we demonstrated that KLK1, KLK4, KLK10, KLK12, and KLK15 expression is upregulated in PLGA. The average levels of KLK1, KLK4, KLK10, KLK12, and KLK15 mRNA expressed in PLGA tissue samples were increased relative to NSGT. Immunohistochemistry was carried out on PLGA samples showing relatively lower or higher mRNA KLK expression, and showed tumour cell-specific immunoreactivity.

In conclusion, we believe KLK upregulation in PLGA indicates the involvement of a complex proteolytic cascade, and may involve KLK 1, KLK4, KLK10, KLK12, and KLK15. We suspect this upregulation of KLK activity may be involved in regulating malignant processes in PLGA, and thus implicated in determining its clinical characteristics, including indolent behaviour and infrequent metastatic spread. Furthermore, the results of this study significantly add to the KLK profile of salivary gland neoplasia, at the mRNA and protein level. Importantly, when combining the resultant KLK profile in PLGA with the recently elucidated KLK profile in ACC, the resultant differences may render a diagnostic panel useful in differentiating between the malignancies. 
References:

1. Miloro M, Ghali G, Larsen PE, Waite PD: Peterson's Principles of Oral and Maxillofacial Surgery, 3rd Edition. (ed. 3rd). People's Medical Publishing House USA, 2012

2. Neville B, Damm D, Allen C, Bouquot J: Oral and Maxillofacial Pathology, 3rd Edition. (ed. 3). W.B. Saunders Company, 2008

3. Barnes L: Chapter 5: Tumors of the salivary glands. In Eveson J, Auclair P, Gnepp D, ElNaggar A (eds), (ed., International Agency for Research on Cancer, World Health Orgaizatio, 2005, p 210

4. Tian Z, Li L, Wang L, Hu Y, Li J: Salivary gland neoplasms in oral and maxillofacial regions: a 23-year retrospective study of 6982 cases in an eastern Chinese population. Int J Oral Maxillofac Surg 39:235, 2010

5. Bagheri S, Bell RB, Khan HA: Current Therapy in Oral and Maxillofacial Surgery. Saunders, Elsevier Inc, 2012

6. Castle JT, Thompson LD, Frommelt RA, Wenig BM, Kessler HP: Polymorphous low grade adenocarcinoma: a clinicopathologic study of 164 cases. Cancer 86:207, 1999

7. Schwarz S, Müller M, Ettl T, Stockmann P, Zenk J, Agaimy A: Morphological heterogeneity of oral salivary gland carcinomas: a clinicopathologic study of 41 cases with long term follow-up emphasizing the overlapping spectrum of adenoid cystic carcinoma and polymorphous low-grade adenocarcinoma. Int J Clin Exp Pathol 4:336, 2011

8. Potluri A, Prasad J, Levine S, Bastaki J: Polymorphous low-grade adenocarcinoma: a case report. Dentomaxillofac Radiol 42:14804843, 2013

9. Darling MR, Schneider JW, Phillips VM: Polymorphous low-grade adenocarcinoma and adenoid cystic carcinoma: a review and comparison of immunohistochemical markers. Oral Oncol 38:641, 2002

10. Kimple AJ, Austin GK, Shah RN, Welch CM, Funkhouser WK, Zanation AM, Shockley WW: Polymorphous low-grade adenocarcinoma: a case series and determination of recurrence. Laryngoscope 124:2714, 2014

11. Patel TD, Vazquez A, Marchiano E, Park RC, Baredes S, Eloy JA: Polymorphous low-grade adenocarcinoma of the head and neck: A population-based study of 460 cases. Laryngoscope 125:1644, 2015

12. Takhar AS, Simmons A, Ffolkes L, Hyde N: Not just another paediatric neck lump: metastatic cribriform adenocarcinoma of the palate in an adolescent. J Laryngol Otol 129:194, 2015

13. Fonseca FP, Brierley D, Wright JM, Santos-Silva AR, Almeida OP, Rocha AC, Van Heerden WF, Hunter KD: Polymorphous low-grade adenocarcinoma of the upper lip: 11 cases of an uncommon diagnosis. Oral Surg Oral Med Oral Pathol Oral Radiol 119:566, 2015

14. Rooper L, Sharma R, Bishop JA: Polymorphous low grade adenocarcinoma has a consistent p63+/p40- immunophenotype that helps distinguish it from adenoid cystic carcinoma and cellular pleomorphic adenoma. Head Neck Pathol 9:79, 2015

15. Olusanya AA, Akadiri OA, Akinmoladun VI, Adeyemi BF: Polymorphous low grade adenocarcinoma: literature review and report of lower lip lesion with suspected lung metastasis. J Maxillofac Oral Surg 10:60, 2011 
16. de Araujo VC, Passador-Santos F, Turssi C, Soares AB, de Araujo NS: Polymorphous lowgrade adenocarcinoma: an analysis of epidemiological studies and hints for pathologists. Diagn Pathol 8:6, 2013

17. Fife TA, Smith B, Sullivan CA, Browne JD, Waltonen JD: Polymorphous low-grade adenocarcinoma: a 17 patient case series. Am J Otolaryngol 34:445, 2013

18. Wang XD, Meng $\amalg$, Hou TT, Zheng C, Huang SH: Frequency and distribution pattern of minor salivary gland tumors in a northeastern Chinese population: a retrospective study of 485 patients. J Oral Maxillofac Surg 73:81, 2015

19. Abu El-Naaj I, Leiser Y, Wolff A, Peled M: Polymorphous low grade adenocarcinoma: case series and review of surgical management. J Oral Maxillofac Surg 69:1967, 2011

20. Andreu-Barasoain M, Vicente-Martin J, Gomez de la Fuente E, Salamanca-Santamaria J, Pampin-Franco A, Lopez-Estebaranz JL: Polymorphous low-grade adenocarcinoma in the upper lip: a well-described but infrequently recognized tumor. (ed. Dermatology Online Journal, 2013,

21. Chi AC, Neville BW: Surface Papillary Epithelial Hyperplasia (Rough Mucosa) is a Helpful Clue for Identification of Polymorphous Low-Grade Adenocarcinoma. Head Neck Pathol 9:244, 2015

22. Etıt D, Altinel D, Bayol Ü, Tan A, Türelık Ö, Çukurova I: Polymorphous low-grade adenocarcinoma located in the maxillary sinus. Turk Patoloji Derg 28:274, 2012

23. Sun G, Yang X, Tang E, Wen J, Lu M, Hu Q: The treatment of sublingual gland tumours. Int J Oral Maxillofac Surg 39:863, 2010

24. Lee DH, Yoon TM, Lee JK, Lim SC: Polymorphous low-grade adenocarcinoma of the maxillary sinus. J Craniofac Surg 24:e213, 2013

25. Jafarian AH, Khazaeni K, Rahpeyma A, Khajehahmadi S: Polymorphous low-grade adenocarcinoma of the larynx: a rare case report. Arch Iran Med 16:560, 2013

26. Weinreb I, Zhang L, Tirunagari LM, Sung YS, Chen CL, Perez-Ordonez B, Clarke BA, Skalova A, Chiosea SI, Seethala RR, Waggott D, Boutros PC, How C, Liu FF, Irish JC, Goldstein DP, Gilbert R, Ud Din N, Assaad A, Hornick JL, Thompson LD, Antonescu CR: Novel PRKD gene rearrangements and variant fusions in cribriform adenocarcinoma of salivary gland origin. Genes Chromosomes Cancer 53:845, 2014

27. Weinreb I, Piscuoglio S, Martelotto LG, Waggott D, Ng CK, Perez-Ordonez B, Harding NJ, Alfaro J, Chu KC, Viale A, Fusco N, da Cruz Paula A, Marchio C, Sakr RA, Lim R, Thompson LD, Chiosea SI, Seethala RR, Skalova A, Stelow EB, Fonseca I, Assaad A, How C, Wang J, de Borja R, Chan-Seng-Yue M, Howlett CJ, Nichols AC, Wen YH, Katabi N, Buchner N, Mullen L, Kislinger T, Wouters BG, Liu FF, Norton L, McPherson JD, Rubin BP, Clarke BA, Weigelt B, Boutros PC, ReisFilho JS: Hotspot activating PRKD1 somatic mutations in polymorphous low-grade adenocarcinomas of the salivary glands. Nat Genet 46:1166, 2014

28. PRKD1 mutations characterize salivary gland polymorphous low-grade adenocarcinoma. Cancer Discov 4:1255, 2014

29. Thennavan A, Rao L, Radhakrishnan R: Polymorphous low-grade adenocarcinoma of maxillary alveolus metastasising to the abdomen: the role of immunomarkers in diagnosis. BMJ Case Rep 2013, 2013

30. Verma V, Mendenhall WM, Werning JW: Polymorphous low-grade adenocarcinoma of the head and neck. Am J Clin Oncol 37:624, 2014 
31. Pogodzinski MS, Sabri AN, Lewis JE, Olsen KD: Retrospective study and review of polymorphous low-grade adenocarcinoma. Laryngoscope 116:2145, 2006

32. Dultra FK, Barros AC, Schaer-Barbosa H, Figueiredo AL, Gurgel CA, Ramos EA, da Silva Carvalho AM, dos Santos JN: Immunohistochemical assessment of CD1a-positive Langerhans cells and their relationship with E-cadherin in minor salivary gland tumors. J Oral Pathol Med 41:47, 2012

33. Michal M, Kacerovska D, Kazakov DV: Cribriform adenocarcinoma of the tongue and minor salivary glands: a review. Head Neck Pathol 7 Suppl 1:S3, 2013

34. Persson F, Fehr A, Sundelin K, Schulte B, Löning T, Stenman G: Studies of genomic imbalances and the MYB-NFIB gene fusion in polymorphous low-grade adenocarcinoma of the head and neck. Int J Oncol 40:80, 2012

35. Beltran D, Faquin WC, Gallagher G, August M: Selective immunohistochemical comparison of polymorphous low-grade adenocarcinoma and adenoid cystic carcinoma. J Oral Maxillofac Surg 64:415, 2006

36. Seethala RR, Johnson JT, Barnes EL, Myers EN: Polymorphous low-grade adenocarcinoma: the University of Pittsburgh experience. Arch Otolaryngol Head Neck Surg 136:385, 2010

37. Majewska H, Skálová A, Weinreb I, Stodulski D, Hyrcza M, Stankiewicz C, Biernat W: Giant cribriform adenocarcinoma of the tongue showing PRKD3 rearrangement. Pol J Pathol 67:84, 2016

38. Gailey MP, Bayon R, Robinson RA: Cribriform adenocarcinoma of minor salivary gland: a report of two cases with an emphasis on cytology. Diagn Cytopathol 42:1085, 2014

39. do Prado RF, da Silva Machado AL, Colombo CE, Carvalho YR: Immunohistochemical study of the expression of fatty acid synthase and Ki-67 in salivary gland tumors. J Oral Pathol Med 40:467, 2011

40. Soini Y, Kamel D, Nuorva K, Lane DP, Vähäkangas K, Pääkkö P: Low p53 protein expression in salivary gland tumours compared with lung carcinomas. Virchows Arch A Pathol Anat Histopathol 421:415, 1992

41. Maletzki C, Bodammer P, Breitrück A, Kerkhoff C: S100 proteins as diagnostic and prognostic markers in colorectal and hepatocellular carcinoma. Hepat Mon 12:e7240, 2012

42. Patel KR, Solomon IH, El-Mofty SK, Lewis JS, Chernock RD: Mammaglobin and S-100 immunoreactivity in salivary gland carcinomas other than mammary analogue secretory carcinoma. Hum Pathol 44:2501, 2013

43. Wang Z, Spaulding B, Sienko A, Liang Y, Li H, Nielsen G, Yub Gong G, Ro JY, Jim Zhai Q: Mammaglobin, a valuable diagnostic marker for metastatic breast carcinoma. Int J Clin Exp Pathol 2:384, 2009

44. Treasure J, Lane A, Jones DB, Wright DH: CD43 expression in B cell lymphoma. J Clin Pathol 45:1018, 1992

45. Fok TC, Lapointe $H$, Tuck AB, Chambers AF, Jackson-Boeters L, Daley TD, Darling MR: Expression and localization of osteopontin, homing cell adhesion molecule/CD44, and integrin $\alpha$ v $\beta 3$ in pleomorphic adenoma, polymorphous low-grade adenocarcinoma, and adenoid cystic carcinoma. Oral Surg Oral Med Oral Pathol Oral Radiol 116:743, 2013

46. Frohwitter G, Buerger H, VAN Diest PJ, Korsching E, Kleinheinz J, Fillies T: Cytokeratin and protein expression patterns in squamous cell carcinoma of the oral cavity provide evidence for two distinct pathogenetic pathways. Oncol Lett 12:107, 2016 
47. de Araújo VC, de Sousa SO, Carvalho YR, de Araújo NS: Application of immunohistochemistry to the diagnosis of salivary gland tumors. Appl Immunohistochem Mol Morphol 8:195, 2000

48. Ghazy SE, Helmy IM, Baghdadi HM: Maspin and MCM2 immunoprofiling in salivary gland carcinomas. Diagn Pathol 6:89, 2011

49. Kontos CK, Scorilas A: Kallikrein-related peptidases (KLKs): a gene family of novel cancer biomarkers. Clin Chem Lab Med 50:1877, 2012

50. Obiezu CV, Diamandis EP: Human tissue kallikrein gene family: applications in cancer. Cancer Lett 224:1, 2005

51. Pampalakis G, Sotiropoulou G: Tissue kallikrein proteolytic cascade pathways in normal physiology and cancer. Biochim Biophys Acta 1776:22, 2007

52. Campbell DJ: The kallikrein-kinin system in humans. Clin Exp Pharmacol Physiol 28:1060, 2001

53. Diamandis EP, Yousef GM: Human tissue kallikreins: a family of new cancer biomarkers. Clin Chem 48:1198, 2002

54. Darling MR, Tsai S, Jackson-Boeters L, Daley TD, Diamandis EP: Human kallikrein 8 expression in salivary gland tumors. Head Neck Pathol 2:169, 2008

55. Darling MR, Hashem NN, Zhang I, Mohamed AB, Fung K, Kwan K, Mara TW, Daley TD, Diamandis EP: Kallikrein-related peptidase 10 expression in salivary gland tissues and tumours. Int J Biol Markers 27:e381, 2012

56. Thorek DL, Evans MJ, Carlsson SV, Ulmert D, Lilja H: Prostate-specific kallikrein-related peptidases and their relation to prostate cancer biology and detection. Established relevance and emerging roles. Thromb Haemost 110:484, 2013

57. Pavlopoulou A, Pampalakis G, Michalopoulos I, Sotiropoulou G: Evolutionary history of tissue kallikreins. PLoS One 5:e13781, 2010

58. Kryza T, Silva ML, Loessner D, Heuzé-Vourc'h N, Clements JA: The kallikrein-related peptidase family: Dysregulation and functions during cancer progression. Biochimie 122:283, 2016

59. Schmitt M, Renné T, Scorilas A: The kallikreins: old proteases with new clinical potentials. Thromb Haemost 110:396, 2013

60. Sotiropoulou G, Pampalakis G, Diamandis EP: Functional roles of human kallikrein-related peptidases. J Biol Chem 284:32989, 2009

61. Lundwall A, Band V, Blaber M, Clements JA, Courty Y, Diamandis EP, Fritz H, Lilja H, Malm J, Maltais L, Olsson AY, Petraki C, Scorilas A, Sotiropoulou G, Stenman UH, Stephan C, Talieri M, Yousef GM: A comprehensive nomenclature for serine proteases with homology to tissue kallikreins. Biol Chem 387:637, 2006

62. Kontos CK, Chantzis D, Papadopoulos IN, Scorilas A: Kallikrein-related peptidase 4 (KLK4) mRNA predicts short-term relapse in colorectal adenocarcinoma patients. Cancer Lett 330:106, 2013

63. Alexopoulou DK, Papadopoulos IN, Scorilas A: Clinical significance of kallikrein-related peptidase (KLK10) mRNA expression in colorectal cancer. Clin Biochem 46:1453, 2013

64. Borgoño CA, Diamandis EP: The emerging roles of human tissue kallikreins in cancer. Nat Rev Cancer 4:876, 2004 
65. Prassas I, Eissa A, Poda G, Diamandis EP: Unleashing the therapeutic potential of human kallikrein-related serine proteases. Nat Rev Drug Discov 14:183, 2015

66. Lawrence MG, Lai J, Clements JA: Kallikreins on steroids: structure, function, and hormonal regulation of prostate-specific antigen and the extended kallikrein locus. Endocr Rev $31: 407,2010$

67. Hashem Nea: Kallikrein-related peptidase 7 in salivary gland tumours: Immunohistochemical Expression Profile. (ed. Canadian Journal of Pathology, 2011,

68. Devetzi M, Trangas T, Scorilas A, Xynopoulos D, Talieri M: Parallel overexpression and clinical significance of kallikrein-related peptidases 7 and 14 (KLK7KLK14) in colon cancer. Thromb Haemost 109:716, 2013

69. Borgoño CA, Michael IP, Diamandis EP: Human tissue kallikreins: physiologic roles and applications in cancer. Mol Cancer Res 2:257, 2004

70. Yousef GM: microRNAs: a new frontier in kallikrein research. Biol Chem 389:689, 2008

71. Yousef GM, Diamandis EP: The new human tissue kallikrein gene family: structure, function, and association to disease. Endocr Rev 22:184, 2001

72. Darling MR, Tsai S, Jackson-Boeters L, Daley TD, Diamandis EP: Human kallikrein 3 (prostate specific antigen) and human kallikrein 5 expression in salivary gland tumors. Int J Biol Markers 21:201, 2006

73. Darling MR, Jackson-Boeters L, Daley TD, Diamandis EP: Human kallikrein 6 expression in salivary gland tumors. J Histochem Cytochem 54:337, 2006

74. Sotiropoulou G, Pampalakis G: Targeting the kallikrein-related peptidases for drug development. Trends Pharmacol Sci 33:623, 2012

75. Hashem NN, Mara TW, Mohamed M, Zhang I, Fung K, Kwan KF, Daley TD, Diamandis EP, Darling MR: Human kallikrein 14 (KLK14) expression in salivary gland tumors. Int J Biol Markers 25:32, 2010

76. Darling MR, Jackson-Boeters L, Daley TD, Diamandis EP: Human kallikrein 13 expression in salivary gland tumors. Int J Biol Markers 21:106, 2006

77. Dorn J, Gkazepis A, Kotzsch M, Kremer M, Propping C, Mayer K, Mengele K, Diamandis EP, Kiechle M, Magdolen V, Schmitt M: Clinical value of protein expression of kallikrein-related peptidase 7 (KLK7) in ovarian cancer. Biol Chem 395:95, 2014

78. Strimbu K, Tavel JA: What are biomarkers? Curr Opin HIV AIDS 5:463, 2010

79. Bigbee W HR: Characteristics of the Ideal Tumor Marker. In Kufe DW PR, Weichselbaum RR, et al., editors. (ed) Holland-Frei Cancer Medicine. 6th edition., (ed. Hamilton, ON, BC Decker, 2003,

80. Drucker E, Krapfenbauer K: Pitfalls and limitations in translation from biomarker discovery to clinical utility in predictive and personalised medicine. EPMA J 4:7, 2013

81. Kirby R: The role of PSA in detection and management of prostate cancer. Practitioner 260:17, 2016

82. Carter HB: American Urological Association (AUA) guideline on prostate cancer detection: process and rationale. BJU Int 112:543, 2013

83. Emami N, Diamandis EP: Utility of kallikrein-related peptidases (KLKs) as cancer biomarkers. Clin Chem 54:1600, 2008

84. Kerr Z: Expression of kallikrein-related peptidases (KLKs) in Adenoid Cystic Carcinoma. In Ontario UoW (ed) (ed., 2016, 
85. Rezadoost $\mathrm{MH}$, Kordrostami M, Kumleh $\mathrm{HH}$ : An efficient protocol for isolation of inhibitorfree nucleic acids even from recalcitrant plants. 3 Biotech 6:61, 2016

86. Rao X, Huang X, Zhou Z, Lin X: An improvement of the $2^{\wedge}$ (-delta delta CT) method for quantitative real-time polymerase chain reaction data analysis. Biostat Bioinforma Biomath 3:71, 2013

87. Allred DC, Clark GM, Elledge R, Fuqua SA, Brown RW, Chamness GC, Osborne CK, McGuire WL: Association of $\mathrm{p} 53$ protein expression with tumor cell proliferation rate and clinical outcome in node-negative breast cancer. J Natl Cancer Inst 85:200, 1993

88. Qureshi A, Pervez S: Allred scoring for ER reporting and it's impact in clearly distinguishing ER negative from ER positive breast cancers. J Pak Med Assoc 60:350, 2010

89. Bourne J: Handbook of Immunoperoxidase Staining Methods. (ed., Dako Corporation, 1983,

90. Kokkat TJ, Patel MS, McGarvey D, LiVolsi VA, Baloch ZW: Archived formalin-fixed paraffinembedded (FFPE) blocks: A valuable underexploited resource for extraction of DNA, RNA, and protein. Biopreserv Biobank 11:101, 2013

91. Patel PG, Selvarajah S, Boursalie S, How NE, Ejdelman J, Guerard KP, Bartlett JM, Lapointe J, Park PC, Okello JB, Berman DM: Preparation of Formalin-fixed Paraffin-embedded Tissue Cores for both RNA and DNA Extraction. J Vis Exp, 2016

92. Sant KE, Nahar MS, Dolinoy DC: DNA methylation screening and analysis. Methods Mol Biol 889:385, 2012

93. Kim J, Bretz CL, Lee S: Epigenetic instability of imprinted genes in human cancers. Nucleic Acids Res 43:10689, 2015

94. Hsu CM, Lin PM, Lin HC, Lai CC, Yang CH, Lin SF, Yang MY: Altered Expression of Imprinted Genes in Squamous Cell Carcinoma of the Head and Neck. Anticancer Res 36:2251, 2016

95. Goyal J, Smith KM, Cowan JM, Wazer DE, Lee SW, Band V: The role for NES1 serine protease as a novel tumor suppressor. Cancer Res 58:4782, 1998

96. Hu J, Lei H, Fei X, Liang S, Xu H, Qin D, Wang Y, Wu Y, Li B: NES1/KLK10 gene represses proliferation, enhances apoptosis and down-regulates glucose metabolism of PC3 prostate cancer cells. Sci Rep 5:17426, 2015 


\section{JACQUELINE MARIE COX, BSc DDS MD}

Oral and Maxillofacial Surgery Resident (PGY6), London Health Sciences Centre, London, Ontario

\section{EDUCATION:}

2012-present Oral and Maxillofacial Surgery Residency

London Health Sciences Centre and

Schulich School of Medicine and Dentistry

Western University, London, ON

2012-2017 Masters of Science

Department of Pathology

Western University, London, ON

2013-2017 Doctor of Medicine

Schulich School of Medicine and Dentistry

Western University, London, ON

2010-2011 Clinical Dental Fellowship

Schulich School of Medicine and Dentistry

Western University, London, ON

2006-2010 Doctor of Dental Surgery

Faculty of Dentistry

Dalhousie University, Halifax, Nova Scotia

2002-2006

Bachelor of Science, Microbiology and Immunology

Dalhousie University, Halifax, Nova Scotia

\section{OTHER TRAINING AND SELF-LEARNING}

2016 OMFS Externship (September 26-30, 2016), University of Michigan Health System. Supervisor: Dr. Sean Edwards.

Trauma Elective (June 6 - July 26, 2016), Legacy Emanuel Medical Centre. Supervisor: Dr. Eric Dierks.

2015

Principles of Operative Treatment of Craniomaxillofacial Trauma and Reconstruction

(Continuing Medical Education Activity, AO North America)

North American SORG (Strasbourg Ostheosynthesis Research Group) Modular Training Series 2013: Module 2

Congenital and Developmental Deformities 
Canadian Dental Society of Anesthesiology

Annual Scientific Meeting

"Anesthetic Approaches and When Things Go Bad"

2010

Nobel Biocare Hands On Training

Also trained in: ACLS, ATLS, Principles of Surgery

HONOURS AND AWARDS:

2015

Helen Mildred Blythe Allison Undergraduate Award in Medicine

(Academic Achievement, Medicine)

2014

Best Basic/Clinical Science Collaborative Poster Presentation

Award

(2014 Department of Pathology Annual Research Day)

2012

Dr. A.E. Swanson Award

(First Year Canadian Oral and Maxillofacial Surgery Resident

Award)

2010

Dental Association of Prince Edward Island Prize

(Greatest Proficiency and Interest in Hospital Dentistry)

Quintessence Award for Research Achievement

(Exceptional interest and research abilities over four years of dental study)

2009

Dr. I.K. Lubetsky Scholarship

(Greatest Proficiency in the Practice of Clinical Oral Maxillofacial Surgery)

Pierre Fauchard Academy Annual Scholarship Award

(Outstanding Scholarship and Clinical Research at the Dental Undergraduate Level)

Certificate of Recognition

CDA/DENTSPLY, Student Clinician Research Program

United Dental Learning Centre Table Clinic Award (Best Table Clinic Presentation)

Patterson Dental Table Clinic Prize

(First place Dentistry Table Clinics) 
Dr. Bruce N. Fergusson Prize (Best Table Clinic Presentation)

Halifax County Dental Society

CDA/Dentistry Student Clinician Award (Best Table Clinic Presentation)

Canadian Dental Association

Student Table Clinic $1^{\text {st }}$ Place Prize Recipient

Faculty of Dentistry, Dalhousie University

2007

Charles Bell Memorial Prize

(Second Highest Average, First Year Dentistry)

Dalhousie University

2006

James P. M. McGuigan Scholarship

(Academic Achievement, Dentistry)

Dalhousie University

PUBLICATIONS:

2016

J. Cox, S. Lownie, J. Armstrong. "Needle Fracture During Inferior Alveolar Nerve Block: A Case Report of Management Adjacent the Carotid Sheath". Oral Health. June 2016.

2014

J. Cox, M. Darling, Z. Khan, J. Armstrong. "Expression of human tissue kallikriens (KLKs) in Polymorphous Low Grade Adenocarcinoma (PLGA)". Journal of Oral and Maxillofacial Surgery. 2014; 72: e173

2011

R. Bohay, J. Cox, H.J. Lapointe. "Clinical Decision Making: Cone Beam Computed Tomography for the Extraction of Impacted Third Mandibular Teeth”. Ontario Dentist. 2011; 88, 7: 27-33.

2009

A. Morrison, $\boldsymbol{J}$ Cox. "Incidence of Osteonecrosis of the Jaw (ONJ) in Patients Receiving Intravenous Bisphosphonate Therapy: Data From the First 50 Patients". Journal of Oral and Maxillofacial Surgery. 2009; 67, 9: supplement pages 37-39.

MEMBERSHIPS:

2014-present

Ontario Medical Association

Canadian Medical Association

International Association for Dental Research

2012-present Canadian Association of Oral and Maxillofacial Surgeons

American Association of Oral and Maxillofacial Surgeons 
2010-present Ontario Dental Association

Royal College of Dental Surgeons of Ontario

2003-present Golden Key International Honour Society

2009-2010 The International Association of Student Clinicians - American

Dental Association

\section{LEADERSHIP ROLES:}

2009-2010

Admissions Interviewer, Faculty of Dentistry, Dalhousie University

DDS Student Representative, Dalhousie Student Table Clinics

Committee

$2008-2010$

Executive President, Dalhousie Dentistry Class of 2010

2007-2008

Executive Secretary, Dalhousie Dentistry Class of 2010

Chair, Dalhousie Dentistry Class of 2010 Fundraising: 2007-2008

2005-2006

Secretary \& Executive Member, Dalhousie University Society of Immunology and Microbiology Students

\section{RESEARCH EXPERIENCE:}

2012- 2017

"Expression of human tissue kallikriens (KLKs) in Polymorphous Low Grade Adenocarcinoma (PLGA)"

Candidate for MSc, Pathology

Supervisors: Drs Mark Darling, Zia Khan, and JE Armstrong

University of Western Ontario

Department of Pathology, Schulich School of Medicine and Dentistry

2007- 2010

"Incidence of Osteonecrosis of the Jaw in Patients

Receiving/Having Received Intravenous Bisphosphonate Therapy"

(Prospective Trial at the Nova Scotia Cancer Centre to determine the risk of developing ONJ while on intravenous bisphosphonate therapy). Student Research Investigator under Dr. Archie Morrison Department of Oral \& Maxillofacial Surgery Victoria General Hospital, QEII Health Sciences Centre 
2008-2009

"Incidence of Osteonecrosis of the Jaw in Patients

Receiving/Having Received Intravenous Bisphosphonate Therapy"

Research Investigator/Oral \& Maxillofacial Surgery Elective

Student

Faculty of Dentistry, Dalhousie University

\section{PRESENTATIONS:}

2017

"Primary Intraosseous Squamous Cell Carcinoma (PIOSCC): A Rarely Reported Entity in Paediatrics" (Poster). Presented at the ACOMS/CAOMS Joint Annual Conference and Exhibition.

"Human Tissue Kallikreins (KLKs) in Polymorphous Low Grade Adenocarcinoma (PLGA)" (Poster). Presented at Department of Pathology Annual Research Day.

"Expression of human tissue kallikriens (KLKs) in Polymorphous Low Grade Adenocarcinoma (PLGA)" (Oral Presentation). Presented at the Head and Neck Retreat, London Health Sciences Centre.

"Expression of human tissue kallikriens (KLKs) in Polymorphous Low Grade Adenocarcinoma (PLGA)" (Oral Presentation).

Presented at the CAOMS Annual Conference, Scientific Sessions.

"Expression of human tissue kallikriens (KLKs) in Polymorphous Low Grade Adenocarcinoma (PLGA)" (Poster). Presented at the $93^{\text {rd }}$ General Session \& Exhibition of the International Association for Dental Research.

"Expression of human tissue kallikriens (KLKs) in Polymorphous Low Grade Adenocarcinoma (PLGA)" (Poster). Presented at Department of Pathology Annual Research Day.

"Expression of human tissue kallikriens (KLKs) in Polymorphous Low Grade Adenocarcinoma (PLGA)" (Poster). Presented at the AAOMS $96^{\text {th }}$ Annual Meeting, Scientific Sessions and Exhibition.

"Expression of human tissue kallikriens (KLKs) in Polymorphous Low Grade Adenocarcinoma (PLGA)" (Poster). Presented at Department of Pathology Annual Research Day. 
"Incidence of Osteonecrosis of the Jaw (ONJ) in Patients

Receiving Intravenous Bisphosphonate Therapy: data from the first 50 patients" (Oral Presentation). Presented at the

AAOMS/CAOMS $91^{\text {st }}$ Annual Meeting, Scientific Sessions and Exhibition.

"Incidence of Osteonecrosis of the Jaw in Patients Receiving/Having Received Intravenous Bisphosphonate Therapy" (Poster). Presented at Canadian Dental Association Annual Convention and Pacific Dental Conference.

"Incidence of Osteonecrosis of the Jaw in Patients Receiving/Having Received Intravenous Bisphosphonate Therapy" (Oral Presentation). Presented at Student Table Clinics, Faculty of Dentistry, Dalhousie University

"Incidence of Osteonecrosis of the Jaw in Patients Receiving/Having Received Intravenous Bisphosphonate Therapy" (Poster) Presented at Undergraduate Health Sciences Student Research Day, Faculty of Medicine, Health Professions and Dentistry

"Incidence of Osteonecrosis of the Jaw in Patients Receiving/Having Received Intravenous Bisphosphonate Therapy" (Poster) Presented at Undergraduate Health Sciences Student Research Day, Faculty of Medicine, Health Professions and Dentistry

\section{EMPLOYMENT HISTORY:}

2011-2012

General Dentist

Department of Dentistry, London Health Sciences Centre, London, Ontario

\section{VOLUNTEER AND COMMUNITY:}

2009-2016

2015

2014

2002-2010
Run for the Cure Participant

Do It For Dads Walk Run Participant

Prostate Cancer Canada

Mental Health 10K Run Participant

Dalhousie University, Faculty of Dentistry 
Operation Outreach (Dental clinic for local refugees)

One-on-One Volunteer with Veterans

Volunteer Math Tutor

East Coast Music Awards Volunteer

"Hockey for Everyone Volunteer" 